Aus der Abteilung Klinische Pharmakologie

(Prof. Dr. med. J. Brockmöller)

im Zentrum Pharmakologie und Toxikologie

der Medizinischen Fakultät der Universität Göttingen

\title{
Funktionelle und genetische Variabilität bei der zytotoxischen Wirkung von Nukleosid-Analoga
} Untersuchung in menschlichen Leukozyten und lymphoblastoiden Zelllinien

\section{INAUGURAL-DISSERTATION}

zur Erlangung des Doktorgrades

der Medizinischen Fakultät

der Georg-August-Universität zu Göttingen

vorgelegt von

Christian Kuschel, geb. Oelschläger

aus Hildesheim 
Dekan:

1. Berichterstatter/in:

2. Berichterstatter/in:

Tag der mündlichen Prüfung:
Prof. Dr. med. C. Frömmel

Prof. Dr. med. J. Brockmöller

Prof. Dr. med. G. Wulf

16.05.2012 


\section{Inhaltsverzeichnis}

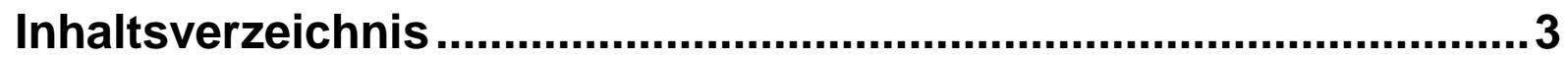

Abkürzungsverzeichnis ............................................................. 5

1. Einleitung ........................................................................ 8

1.1. Klinische Bedeutung von Nukleosid-Analoga ................................... 8

1.2. Nukleosid-Analoga in der Onkologie ..................................................... 9

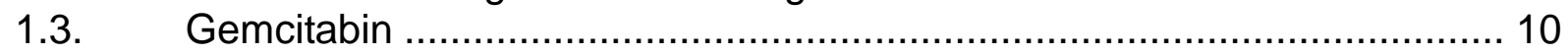

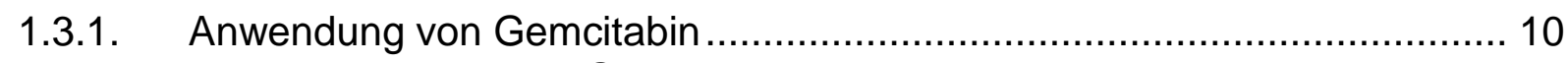

1.3.2. Nebenwirkungen von Gemcitabin .............................................. 11

1.3.3. Pharmakokinetik von Gemcitabin ............................................... 11

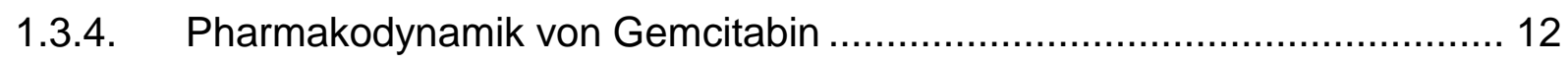

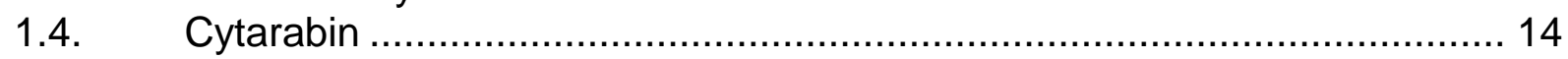

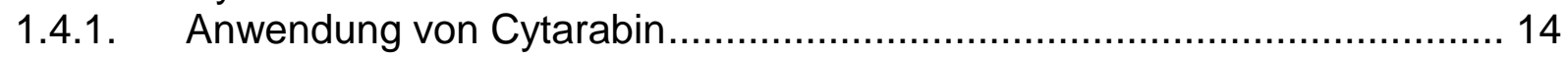

1.4.2. Nebenwirkungen von Cytarabin ................................................... 14

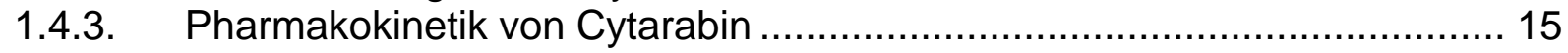

1.4.4. Pharmakodynamik von Cytarabin ........................................................ 16

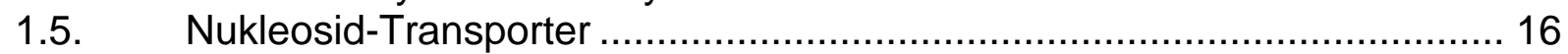

1.5.1. Typen von Nukleosid-Transportern.............................................. 16

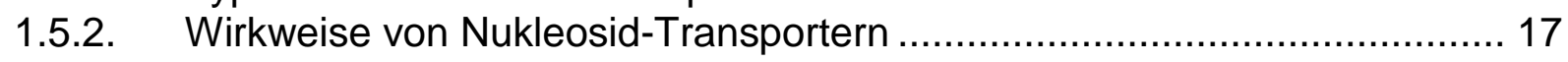

1.5.3. Therapeutische Relevanz der Expressionsstärke

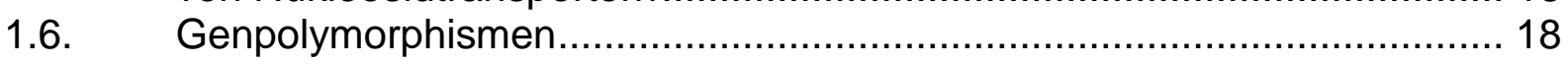

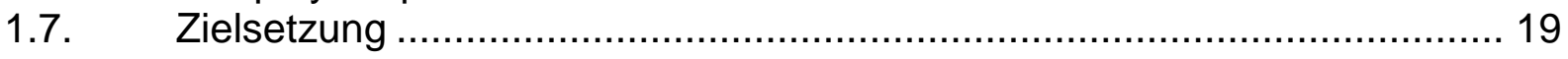

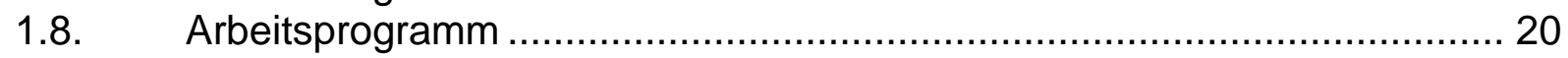

2. Material und Methoden ......................................................22

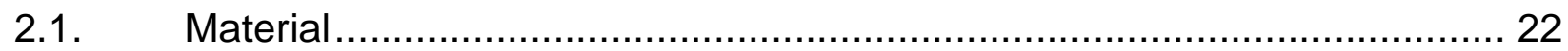

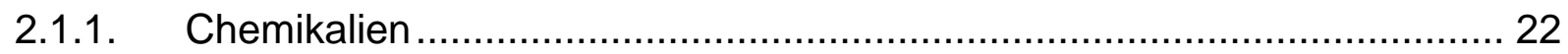

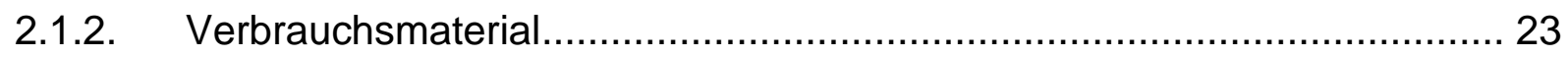

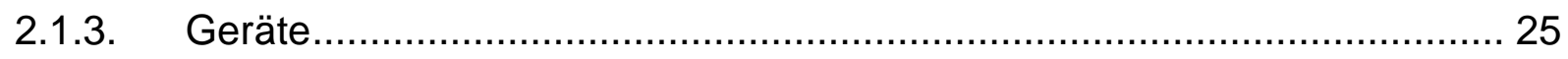

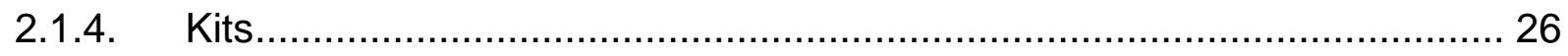

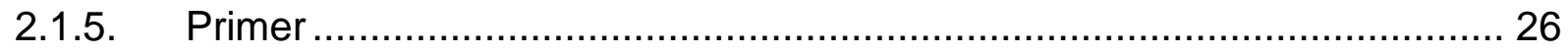

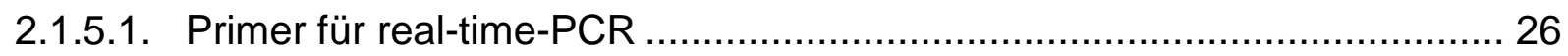

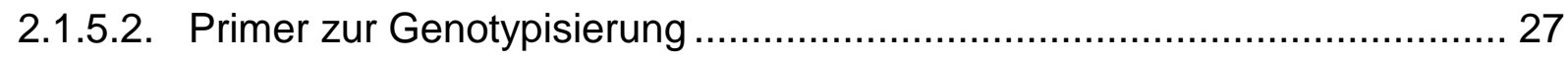

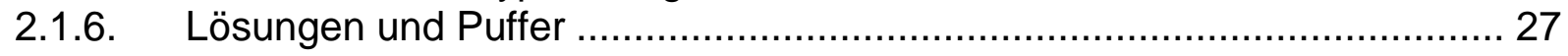

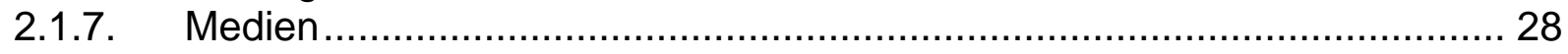

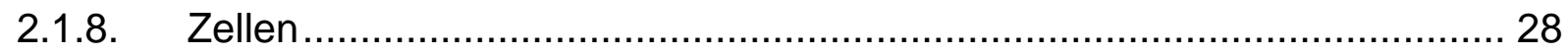

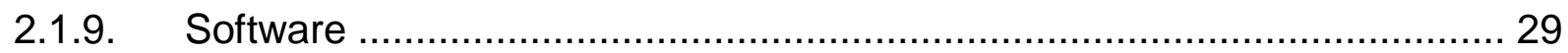

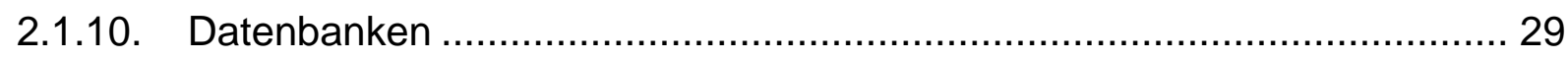

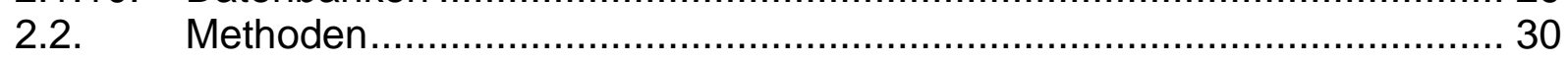

2.2.1. Kultur der lymphoblastoiden Zellen............................................... 30

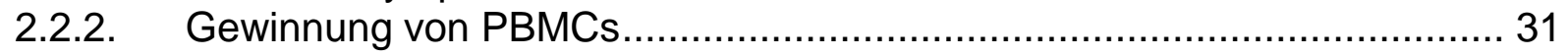

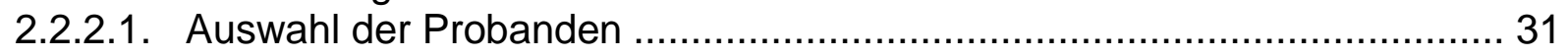

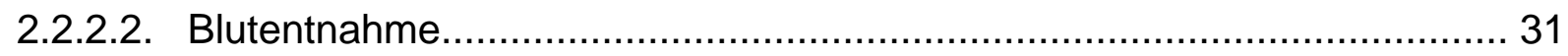

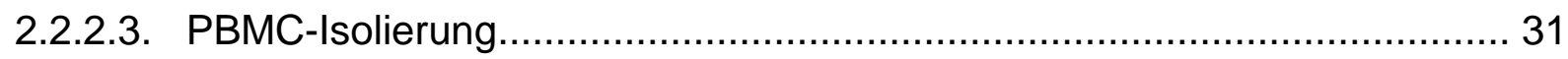

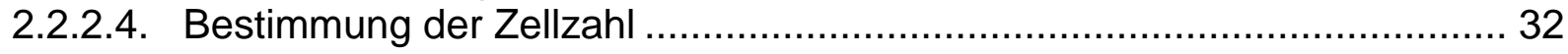


2.2.2.5. Durchflusszytometrie (FACS, Fluorescence-activated cell sorting) .......... 33

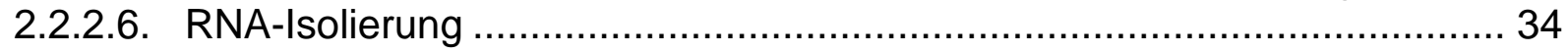

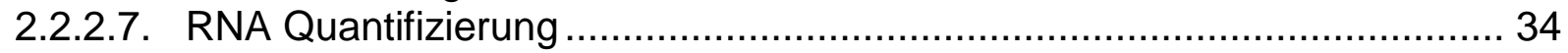

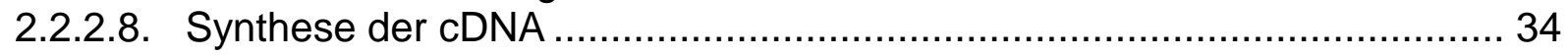

2.2.2.9. Genexpressionsmessung mittels quantitativer Real time-PCR ................ 35

2.2.2.10. Isolierung und Quantifizierung genomischer DNA ................................ 36

2.2.2.11. Polymerase Chain Reaction (PCR) ........................................... 37

2.2.2.12. Agarose Gelelektrophorese ................................................... 38

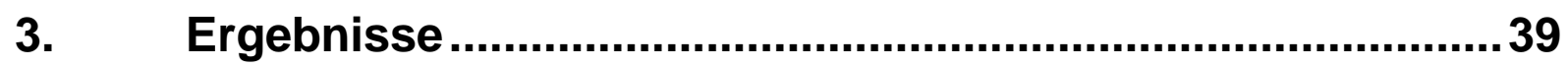

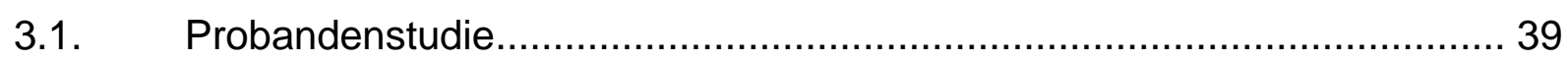

3.1.1. Nukleosid-induzierte Apoptose und Nekrose in PBMCs ......................... 39

3.1.2. Expression des ENT1-Transporters und Zellapoptose ......................... 43

3.1.3. Effekte des ENT1-Inhibitors NBTI auf Nukleosid-induzierte Apoptose ...... 43

3.1.4. Effekte von ENT1-Genpolymorphismen auf die gemessenen

Funktionsparameter...................................................................... 44

3.2. Lymphoblastoide Zelllinien ........................................................... 51

3.2.1. Nukleosid-induzierte Apoptose und Nekrose ...................................... 51

3.2.2. Einfluss von NBTI auf Nukleosid-induzierte Reduktion der Zellvitalität.......55

3.2.3. Einfluss von Genvarianten in Nukleosid-Kandidatengenen auf induzierte Apoptose .............................................................................. 55

4. Diskussion .......................................................................68

4.1. ENT1-Transporter und die Zytotoxizität von Gemcitabin und Cytarabin .... 68

4.1.1. ENT1-Transkription und Apoptose unter Gemcitabin ............................68

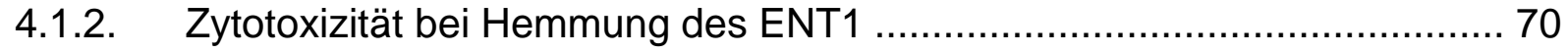

4.1.3. Funktionelle Genvarianten im ENT1 ............................................. 71

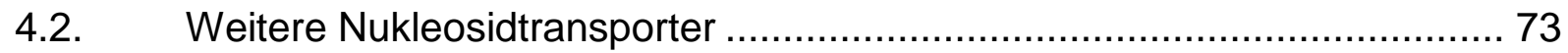

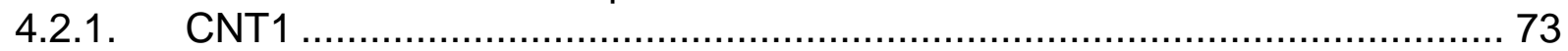

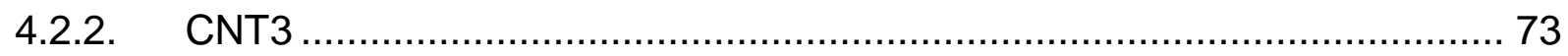

4.3. Enzyme zur Aktivierung von Nukleosid-Analoga ................................... 74

4.4. Enzyme zur Degradierung von Nukleosid-Analoga ............................. 74

4.5. Indirekt mit der Aktivität von Nukleosid-Analoga verbundene Enzyme ...... 76

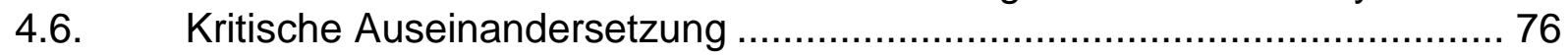

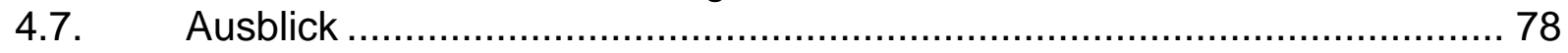

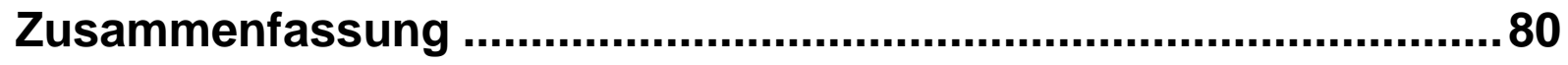

Tabellen- und Abbildungsverzeichnis .......................................... 83

Literaturverzeichnis ........................................................................84 


\section{Abkürzungsverzeichnis}

\begin{tabular}{|c|c|}
\hline$\circ$ & Grad (als Winkelmaß) \\
\hline$A$ & Adenin \\
\hline Abb. & Abbildung \\
\hline ALL & akute lymphatische Leukämie \\
\hline AML & akute myeloische Leukämie \\
\hline AS & Aminosäure \\
\hline $\mathrm{Bp}$ & Basenpaare \\
\hline bzw. & beziehungsweise \\
\hline${ }^{\circ} \mathrm{C}$ & Grad Celsius \\
\hline C & Cytosin \\
\hline ca. & circa \\
\hline CD & Cluster of Differentiation \\
\hline cDNA & komplementäre oder copy DNA \\
\hline $\mathrm{cm}$ & Zentimeter \\
\hline CNTs & Concentrative nucleoside transporters \\
\hline $\mathrm{CO}_{2}$ & Kohlendioxid \\
\hline dbSNP & database SNP (innerhalb NCBI-Datenbank) \\
\hline $\mathrm{ddH}_{2} \mathrm{O}$ & (doppelt destilliertes) Wasser \\
\hline ddNTP & Didesoxynukleosidtriphosphat \\
\hline DNA & Desoxyribonucleic Acid (Desoxyribonukleinsäure) \\
\hline dNTP & Desoxynukleosidtriphosphat \\
\hline dsDNA & doppelsträngige DNA \\
\hline DTT & Dithiothreitol \\
\hline EDTA & Ethylen Diamin Tetraacetic Acid \\
\hline ENTs & Equilibrative nucleoside transporters \\
\hline et al. & et alii (und andere) \\
\hline Exp & expected (erwartete Anzahl) \\
\hline FACS & Fluorescence Activated Cell Sorting \\
\hline FAM & 6-Carboxyfluorescein \\
\hline
\end{tabular}




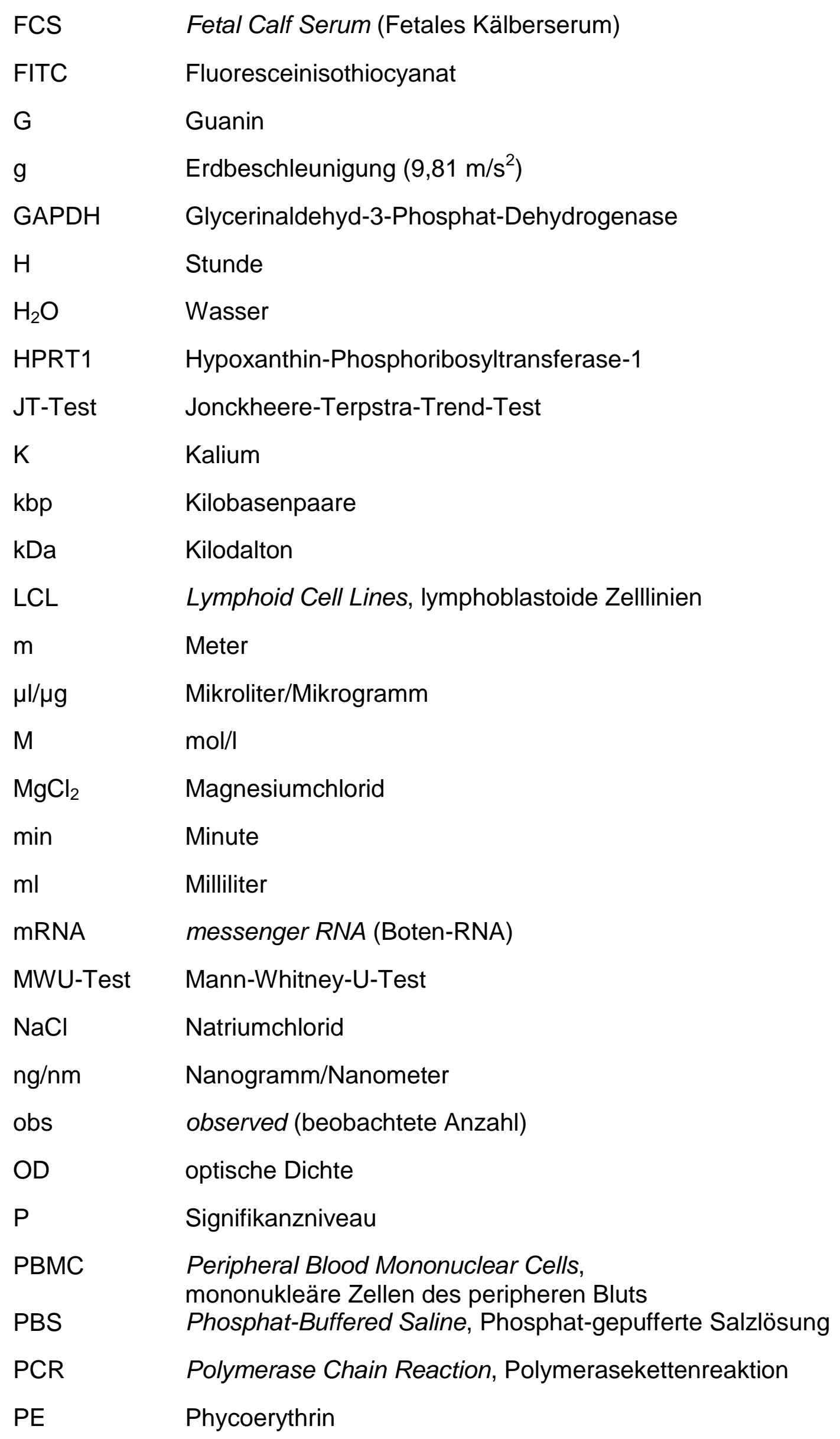




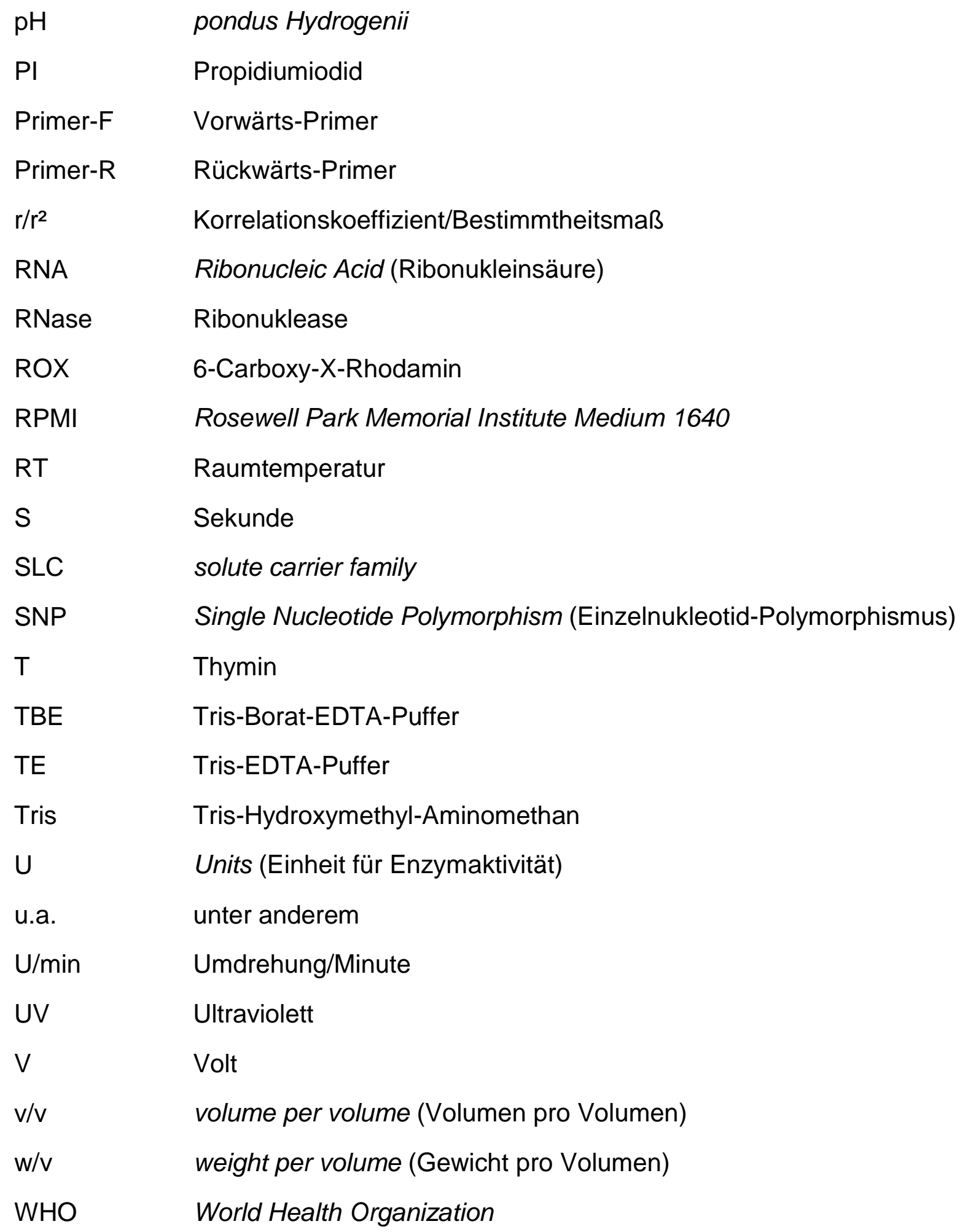




\section{Einleitung}

\subsection{Klinische Bedeutung von Nukleosid-Analoga}

Natürlich vorkommende Nukleoside sind chemische Verbindungen aus einer Nukleobase und einem Zucker, entweder Ribose (bei RNA) oder Desoxyribose (bei DNA). In der Medizin werden zunehmend Nukleosid-Analoga als Antimetabolite eingesetzt. Am bekanntesten ist die Verwendung von Nukleosid-Analoga in der Therapie von viralen Erkrankungen. In der antiretroviralen Therapie bei HIV sind diese typischerweise enthalten. Daneben werden sie in der virustatischen Therapie bei Hepatitis $B$ und $C$ sowie bei Herpesviren eingesetzt. Davon abzugrenzen ist der Einsatz einiger Nukleosid-Analoga als Zytostatika in der Krebstherapie (Tabelle 1).

\section{Tabelle 1}

Übersicht über aktuell in der Medizin verwendete Nukleosid-Analoga

Name analog zu Indikationen

\section{Purin-Analoga}

\begin{tabular}{|c|c|c|}
\hline Cladribin & Adenosin & Haarzell-Leukämie, Multiple Sklerose \\
\hline Didanosin & Adenosin & HIV-1-Infektion \\
\hline Fludarabin & Adenosin & $\begin{array}{l}\text { Chronisch lymphatische Leukämie vom B- } \\
\text { Zell-Typ, niedrig malignes Non-Hodgkin } \\
\text { Lymphom }\end{array}$ \\
\hline Vidarabin & Adenosin & Herpesviren \\
\hline Abacavir & Guanosin & HIV-1-Infektion \\
\hline Entecavir & Guanosin & Hepatitis B \\
\hline \multicolumn{3}{|c|}{ Pyrimidin-Analoga } \\
\hline Apricitabin & Cytidin & HIV-Infektion \\
\hline Capecitabin & Cytidin & $\begin{array}{l}\text { wie bei 5-Fluorouracil: metastasiertes } \\
\text { Dickdarmkarzinom, Pankreaskarzinom }\end{array}$ \\
\hline Cytarabin & Cytidin & 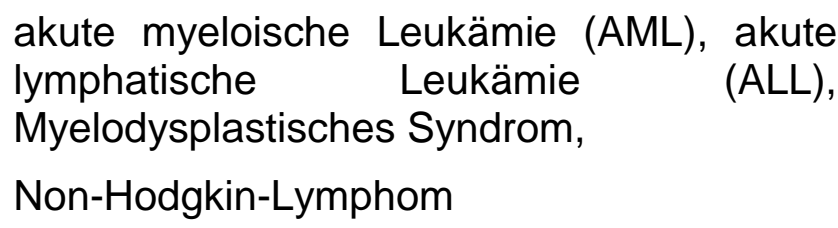 \\
\hline Elvucitabin & Cytidin & HIV-Infektion, Hepatitis-B \\
\hline Emtricitabin & Cytidin & HIV-1+2-Infektion, Hepatitis B \\
\hline
\end{tabular}




\section{Name \\ Pyrimidin-Analoga}

Gemcitabin Cytidin

Lamivudin

Cytidin

Zalcitabin

Cytidin

Brivudin

Thymidin

Clevudin

Stavudin

Zidovudin

Idoxuridin

Trifluridin

\section{Atypische}

Ribavirin

Uridin

Thymidin

Thymidin analog zu

\section{Indikationen}

Adenokarzinom des Pankreas, Nichtkleinzelliges Bronchialkarzinom, Mammakarzinom, Harnblasenkarzinom, Ovarialkarzinom, Non-Hodgkin- und HodgkinLymphome, Gallengangskarzinom

Hepatitis B

HIV-Infektion

Herpes-Simplex-Viren Typ 1+2 (schwach), Herpes-Zoster-Virus, Varicella-Zoster-Virus, in vitro gegen Epstein-Barr-Virus

Hepatitis B

HIV-1-Infektion

HIV-1-Infektion

Herpesviren

superfiziale Herpes-simplex-Keratitis

Hepatitis C, Respiratory Syncytial Virus

(atypische Base und d-Ribose)

\subsection{Nukleosid-Analoga in der Onkologie}

Wie aus Tabelle 1 zu entnehmen, werden die Substanzen Cytarabin und Gemcitabin ausschließlich in onkologischer Indikation verwendet. Für die beiden Purin-Analoga Cladribin und Fludarabin gibt es nur eine sehr begrenzte Verwendung. Cytarabin kommt nur bei hämatologisch-onkologischen Malignitäten zum Einsatz. Capecitabin und Gemcitabin werden bei einer Reihe von soliden Tumoren verwendet. Capecitabin stellt eine oral bioverfügbare Vorstufe des seit langem bewährten 5Fluorouracils dar und wird damit bei ähnlichen Indikationen angewandt. Gemcitabin hat sich seit seiner Markteinführung im Jahre 1998 bei einigen Tumorentitäten erfolgreich bewährt. Dazu zählt in besonderer Weise das Pankreas-Karzinom, aber auch bestimmte Typen von Lungenkrebs, sowie Karzinome der Harn- und der Gallenblase einschließlich der Gallenwege. Weiterhin wird es manchmal auch bei 
Brustkrebs und bei einigen Ovarialkarzinomen eingesetzt. In dieser Arbeit wurden die beiden Pyrimidin-Analoga Gemcitabin und Cytarabin untersucht.
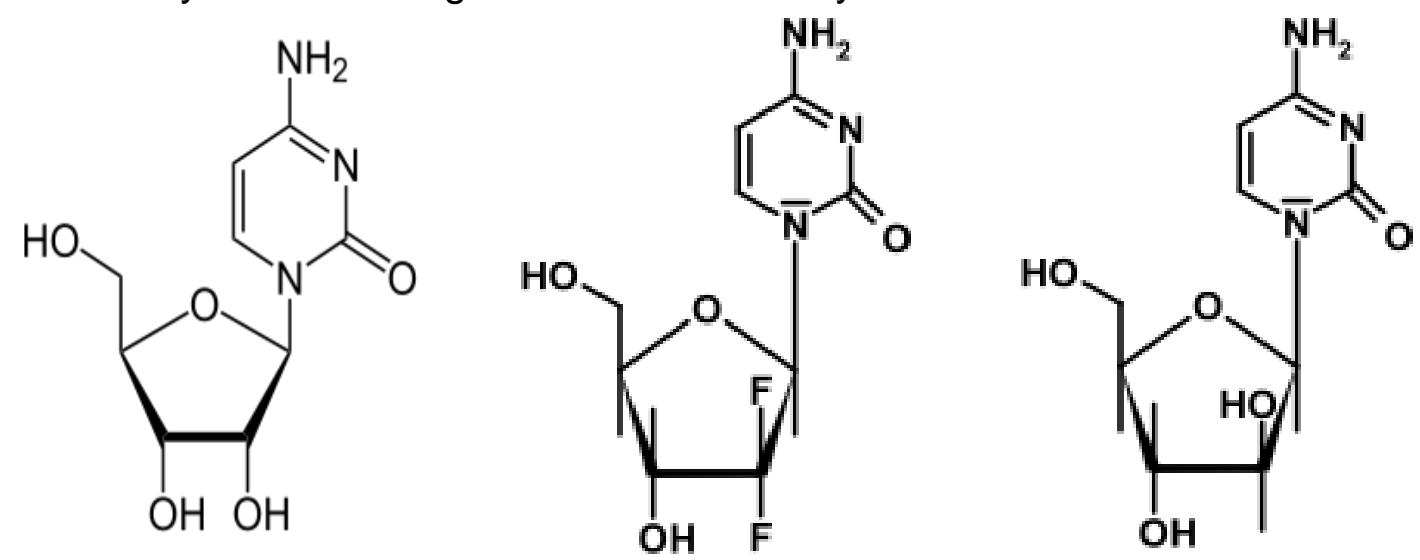

\section{Abbildung 1}

Strukturformeln von Cytidin (links), Gemcitabin (Mitte) und Cytarabin (rechts). Die Bilder wurden erstellt mit ISIS Draw Version 2.1.4 (MDL Information Systems Inc., USA). Bei beiden handelt es sich um Analoga des physiologischen Cytidin. Hier ist zu erkennen, dass im Unterschied zum physiologischen Cytidin (Cytosin und Ribose) die Pyrimidinbase Cytosin beim Cytarabin mit Arabinose verknüpft ist (B-D-Arabinosylcytosin) und beim Gemcitabin Cytosin ebenfalls an einen modifizierten Zucker gekoppelt ist. Hierbei handelt es sich um Deoxy-Ribose, welche zwei Fluor-Atome am C2Atom trägt (2',2'-Difluorodeoxycytidin).

\subsection{Gemcitabin}

\subsubsection{Anwendung von Gemcitabin}

Ursprünglich wurde Gemcitabin (Molekulargewicht $263 \mathrm{~g} / \mathrm{mol}$ ) für die virustatische Therapie konzipiert (Lopez et al. 1980). Hierbei wies es jedoch entgegen den Erwartungen eine wenig selektive und zu toxische Wirkung auf und war somit nicht für die Therapie von Virusinfektionen geeignet. Stattdessen wird es seit ca. 10 Jahren erfolgreich bei diversen soliden Tumoren verabreicht.

In der Monotherapie wird es bei lokal fortgeschrittenem Pankreas-Adenokarzinom als Mittel der Wahl verwendet (Burris et al. 1997) - mit zumeist nur palliativer Intention. Bei komplett im Gesunden resezierten Fällen (R0-Status) wird aktuell die Kombination von Gemcitabin mit neuen Tyrosinkinase-Inhibitoren geprüft. Bei fortgeschrittenen Malignomen der Blase (von der Maase et al. 2000), des Ovars (Lund et al. 1994) sowie beim nicht-kleinzelligen Bronchial-Ca (Sandler et al. 2000) dient es als First-line-Medikament in Kombination mit anderen Zytostatika. Weitere Indikationen als Second-line-Medikament bestehen z.B. bei einem metastasierten Mamma-Ca (Heinemann 2003). Im Falle des Mamma-Ca werden Kombinationspartner wie Paclitaxel oder Platinverbindungen verwendet. Insgesamt lässt sich - nach der zunächst meist palliativen Verabreichung von Gemcitabin - eine 
zunehmend adjuvante Anwendung in Kombination mit anderen Substanzen beobachten (Oettle et al. 2007). Standard bei Gemcitabin ist die wöchentliche Gabe mit einer Dosierung von $1000-1250 \mathrm{mg} / \mathrm{m}^{2}$ Körperoberfläche, intravenös injiziert über 30 min (Abbruzzese et al. 1991). Die beiden häufigsten Therapiezyklen sehen nach drei bzw. 4 Wochen eine einwöchige Pause in der Verabreichung vor. Üblicherweise wird eine Gabe von Gemcitabin über 6 Monate angestrebt, wobei im Einzelfall oder aktuell in Studien auch eine längere Anwendung praktiziert wird. Vor jeder Applikation hat eine Blutbildkontrolle zu erfolgen. Bei pathologischen Werten wird die Dosis reduziert, eine zusätzliche Pause eingelegt oder aber die Therapie beendet.

\subsubsection{Nebenwirkungen von Gemcitabin}

Dosis-limitierend ist die Myelosuppression, wobei es zu einem beträchtlichen Absinken der Zellzahlen aller drei Blutzellreihen kommen kann. Weitere Nebenwirkungen sind häufig Übelkeit, Erbrechen, Erhöhung der Leberenzyme, Dyspnoe, Hämaturie, Proteinurie sowie Ödeme und allergische Hautausschläge (nach Fachinformation Firma Lilly, Gießen). Es liegt nahe, dass das Ausmaß der Nebenwirkung zum Teil mit den therapeutischen Wirkungen korreliert.

\subsubsection{Pharmakokinetik von Gemcitabin}

Pharmakokinetisch besteht für die Plasmaspiegel-Konzentration im Steady-state eine Linearität über einen breiten Dosisbereich von $53-1000 \mathrm{mg} / \mathrm{m}^{2}$. Bevor die Substanz an der Zielzelle ankommt, wird ein erheblicher Anteil des Gemcitabins als Nukleosid inaktiviert. Dafür verantwortlich ist die CDA, die aus Gemcitabin den inaktiven Metaboliten 2',2'-Difluorodeoxyuridin bildet. Vor allem in der Leber und Niere, aber auch im kleinen Maße im Plasma erfolgt die Inaktivierung entsprechend der Höhe der CDA-Expression (Storniolo et al. 1997). Hierdurch entsteht ein starker First-passEffekt, weshalb die Verabreichung parenteral erfolgen muss. Die terminale HWZ von Gemcitabin ist recht kurz und liegt zwischen 8 und 25 min (Abbruzzese et al. 1991). Weniger als 10\% der applizierten Dosis erscheinen unverändert im Urin. Betrachtet man die verabreichte Menge an Gemcitabin und den inaktiven Metabolit dFdU im Urin, so ergab sich eine Wiederfindungsrate von $30 \%$ bis annähernd $100 \%$ (Abbruzzese et al. 1991). Intrazellulär gebildete Gemcitabin-Phosphate können die Zelle nicht verlassen und erscheinen daher nicht in Plasma und Urin. Eine 
Dephosphorylierung ist jedoch durch Pyrimidin-Nukleotidasen möglich (Amici et al. 1997).

\subsubsection{Pharmakodynamik von Gemcitabin}

Pharmakodynamisch ist die Wirkweise von Gemcitabin zwar in den Grundzügen verstanden, die Ursachen für die große inter-individuelle Variabilität für das therapeutische Ansprechen wie auch für die Nebenwirkungen sind jedoch noch unklar. Präklinisch konnte ein ungewöhnlich breites Aktivitätsspektrum gegen humane Tumore, die Nagetieren verpflanzt wurden (Braakhuis et al. 1991), sowie gegen murine Tumoren (Hertel et al. 1990) nachgewiesen werden. Hierdurch wurde die Erforschung des Wirkmechanismus neben einer großen Anzahl von Studien vorangetrieben, wodurch man erkannte, dass Gemcitabin ein hervorragendes Substrat für die Deoxy-Cytidin-Kinase (dCK) war.

Voraussetzung für die zytostatische Wirksamkeit von Gemcitabin ist dessen zelluläre Aufnahme über spezifische Transporter (Abbildung 2). In der Zelle erfolgen dann multiple Phosphorylierungen am 5'-Ende des Gemcitabins durch die dCK, wodurch letztlich Gemcitabin-Triphosphat entsteht (Plunkett et al. 1989). Die Phosphorylierung von Gemcitabin zum Monophosphat durch die Deoxycytidin-Kinase (dCK), wird als die Geschwindigkeit limitierender Schritt angesehen (Shewach et al. 1992). Die Applikationsweise bestimmt die Aufnahmerate und diese wiederum die intrazellulären Konzentrationen an phosphorylierter Substanz (Tempero et al. 2003). Gemcitabin besitzt eine selbstpotenzierende Wirkung mit Verstärkung der eigenen Aktivierung und Hemmung des Abbaus, wie es in Abbildung 2 dargestellt ist. Die Ribonukleotidreduktase wird durch das Diphosphat dFdCDP gehemmt, wodurch die Cytidin-Triphosphat-Konzentration (CTP) sinkt und vermehrt GemcitabinTriphosphate in die DNA eingebaut werden (Heinemann et al. 1990). Durch die verminderte CTP-Konzentration schwächt sich auch deren Hemmeffekt auf die dCK ab. Dies führt zu einer verstärkten Aktivierung von Gemcitabin durch die dCK.

Auf Grund der reduzierten Konzentration an Cytidin-Triphosphaten reduziert sich auch deren stimulierende Wirkung auf die Deoxycytidylat-Deaminase (DCTD), was zur Folge hat, dass weniger Gemcitabin-Monophosphat (dFdCMP) abgebaut wird (grüner Pfeil links in Abbildung 2). Zusätzlich wird die DCTD direkt durch das Gemcitabin-Triphosphat dFdCTP gehemmt (Heinemann et al. 1992, roter Pfeil rechts in Abbildung 2). Diese Mechanismen bewirken in der Zelle eine Akkumulation von 
Nukleotidformen von Gemcitabin gegenüber denen von Cytidin (Plunkett et al. 1996). Das Gemcitabin-Triphosphat dFdCTP wird als Substrat von der DNA-Polymerase- $\alpha$ in die DNA eingebaut. Zudem fungiert dFdCTP als kompetitiver Inhibitor dieser Polymerasen, wodurch auch die Zellproliferation gehemmt wird. Anders als bei in die DNA eingebautem Cytarabin-Monophosphat kann die Exonukleaseaktivität der Polymerase in den DNA-Strang integriertes dFdCMP nicht entfernen (Huang et al. 1991).

Die hier beschriebenen Mechanismen gelten prinzipiell für alle Nukleosid-Analoga (z.B. auch für Cytarabin), jedoch sind im Detail Unterschiede zwischen den einzelnen Substanzen zu erkennen.

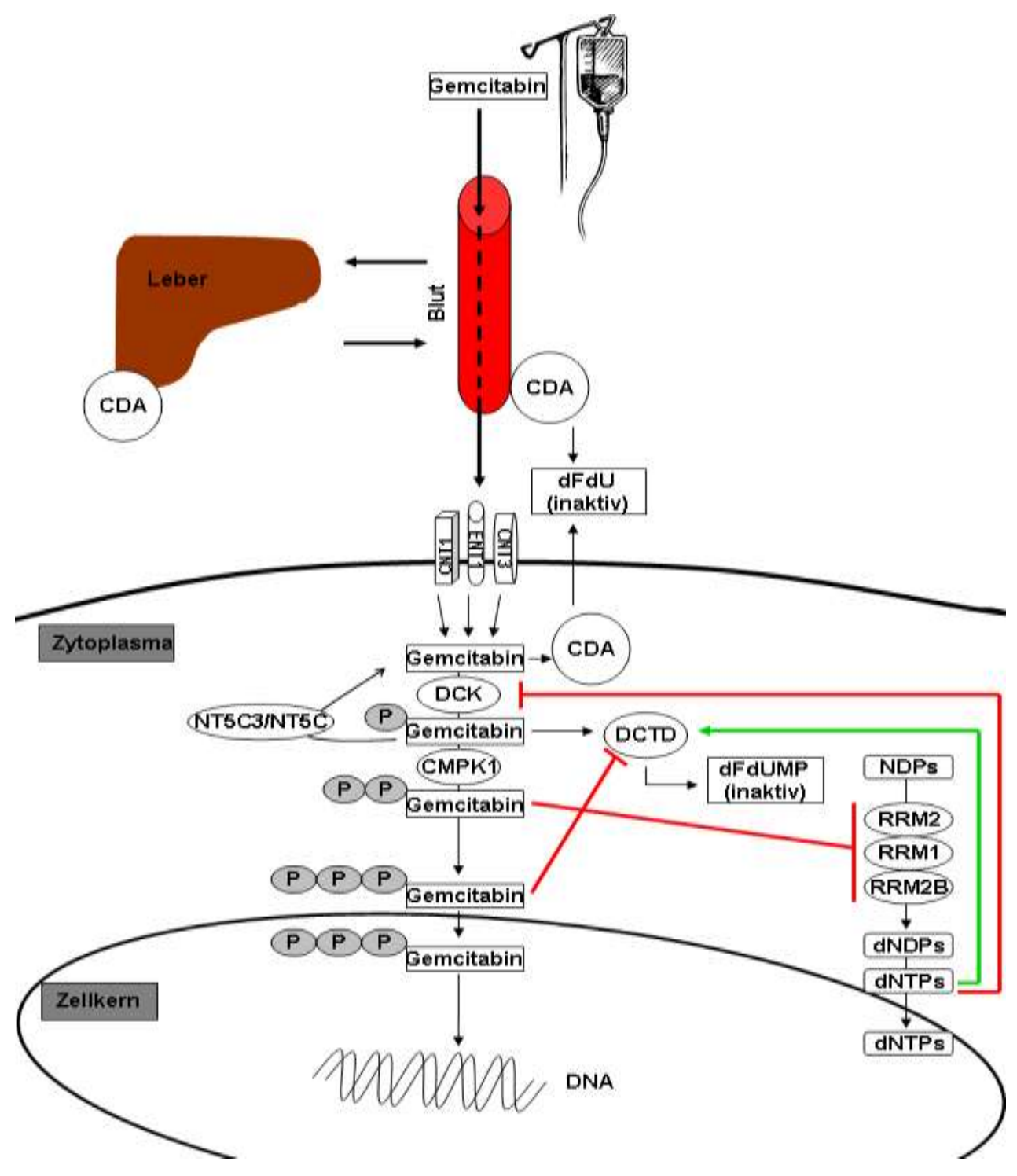

\section{Abbildung 2}

Metabolismus und Wirkung von Gemcitabin 


\subsection{Cytarabin}

\subsubsection{Anwendung von Cytarabin}

Seit etwa 40 Jahren findet Cytarabin (Molekulargewicht: $243 \mathrm{~g} / \mathrm{mol}$ ) erfolgreich in der Behandlung von Leukämien und Lymphomen von Kindern und Erwachsenen Anwendung (Creutzig et al. 2001; Ellison et al. 1968). Hierzu zählen die akute lymphatische Leukämie und die akute myeloische Leukämie, Leukämien mit besonderem Risiko, Rezidive der akuten Leukämie, sekundäre Leukämien nach vorangegangener Radio- oder Chemotherapie sowie Morbus Hodgkin und NonHodgkin-Lymphome. Die Verwendung bezieht sich auf alle drei Phasen der Chemotherapie: Induktion, Konsolidierung, Erhaltung. Typischerweise kommt dabei Cytarabin in Kombination mit einer Reihe weiterer Zytostatika zum Einsatz. In den vergangenen Jahren hat sich - bei Vorliegen geeigneter Voraussetzungen zunehmend eine Hochdosistherapie mit Cytarabin etabliert, die beachtliche Erfolge erbrachte (Plunkett et al. 1985; Velasquez et al. 1988). Dabei wird eine CytarabinDosis von 1-3 g/m² Körperoberfläche verteilt über 4-6 Tage intravenös verabreicht. Das Prinzip der Hochdosistherapie beruht auf der Eradikation möglichst aller Tumorzellen. Chemotherapeutika werden dabei 3-10 fach höher dosiert als sonst üblich. Dabei wird das Knochenmark weitgehend zerstört, weshalb für diese Therapie eine autologe Stammzelltransplantation erforderlich ist.

\subsubsection{Nebenwirkungen von Cytarabin}

Besonders bei der Hochdosistherapie werden verstärkt Nebenwirkungen von Cytarabin beobachtet. Die hohe Knochenmarktoxizität gehört mitunter zu den beabsichtigten Wirkungen, die mit der Stammzelltransplantation umgangen werden. In diesem Fall ist nicht - wie sonst bei vielen Zytostatika - die Knochenmarktoxizität Dosis-limitierend, sondern der Patient wird durch andere Toxizitäten der hohen Cytarabin-Dosis gefährdet. Dazu gehören schwere Schleimhautentzündungen mit Ulzerationen einschließlich Darmnekrosen mit der Gefahr von lleus und Peritonitis. Weitere sehr häufige Nebenwirkungen bei der Hochdosis-Therapie betreffen das Zentralnervensystem (hier z.B. Kopfschmerzen, Verwirrtheitszustände, Dysarthrien), Entzündungen am Auge (Keratitis, Konjunktivitis) sowie Leberschäden. Bekannt ist das Cytarabin-Syndrom, welches durch Fieber, Myalgien, Knochenschmerzen, 
makulopapulöse Ausschläge, Konjunktivitis und Unwohlsein gekennzeichnet ist. Diese Nebenwirkungen können prinzipiell auch bei niedrigeren Cytarabin-Dosen auftreten, sind dann aber meist deutlich milder ausgeprägt. Dann steht typischerweise die Myelotoxizität im Vordergrund. Bei konventionellen Dosen liegt der Tiefpunkt der Leukozyten (Nadir) zwischen dem 12. und 24. Tag nach Gabe des Cytarabins.

\subsubsection{Pharmakokinetik von Cytarabin}

Es besteht ein linearer Zusammenhang mit biphasischer Kinetik zwischen der Dosis und der Plasmakonzentration bei intravenöser Bolusgabe von Cytarabin (Slevin et al. 1982). Hierbei handelt es sich um eine schnelle initiale Umverteilung mit einer HWZ von 15 min und eine terminale Elimination mit einer HWZ von 1,5 h. Vor allem die schnelle Elimination beruht zum größten Teil auf der weitgehend vollständigen Deaminierung zum pharmakologisch inaktiven Metaboliten Arabinosyluracil (Camiener und Smith 1965). Dies geschieht wie bei Gemcitabin durch die CytidinDeaminase. Unter der Hochdosis-Therapie werden Plasmaspiegel von 5-40 $\mu \mathrm{mol} / \mathrm{l}$ erreicht. Außer der intravenösen-Applikation (kurz $3 \mathrm{~h}$, lang über $24 \mathrm{~h}$ ) besteht die Möglichkeit der intrathekalen und subkutanen Gabe. Die Eliminationshalbwertszeit aus dem Intrathekalraum (2-11 h) liegt weitaus höher als aus dem Plasma (1,47,5 min). In Tabelle 2 sind einige wichtige Therapieschemata aufgeführt.

\section{Tabelle 2}

Gebräuchliche Therapie-Schemata mit Cytarabin.

\section{Schema enthaltene Substanzen}

AML SG 07-04 Cytarabin (Hochdosis)

BEAM

BCNU (Carmustin), Etoposid, Cytarabin, Melphalan

Dexa-BEAM

Dexamethason (Dexa), BCNU, Etoposid, Cytarabin, Melphalan

DHAP

Dexamethason, Cytarabin (Hochdosis), Cisplatin

GMALL 07/2003

Cytarabin, Methotrexat, Dexamethason, Vindesin, Etoposid, G-CSF

ICE Idarubicin, Cytarabin, Etoposid 


\subsubsection{Pharmakodynamik von Cytarabin}

Um in die Zelle zu gelangen, muss auch Cytarabin über spezifische Transporter aufgenommen werden (Cass et al. 1998). Wie oben für Gemcitabin dargelegt, wird auch Cytarabin analog zu den physiologischen Nukleosiden zu CytarabinTriphosphat (araCTP) aktiviert. Das araCTP wird während der Reparatur von DNASchäden oder bei der Replikation von DNA bzw. RNA eingebaut. Wie beim phosphorylierten Gemcitabin können auch die entsprechenden Cytarabin-Metabolite die Zelle im phosphorylierten Zustand nicht verlassen.

Der erste Aktivierungsschritt zum Cytarabin-Monophosphat wird wie bei Gemcitabin durch die dCK bewerkstelligt. Die weiteren Phosphorylierungen erfolgen dann durch die (Deoxy)cytidylat-Kinase (UMP-CMPK) zu Diphosphat bzw. durch die NukleotidDiphosphat-Kinasen (NDPKs) zu araCTP (Stam et al. 2003). Im Gegensatz zur selbst potenzierenden Aktivierung bei Gemcitabin liegt bei Cytarabin ein negativer Feedback-Mechanismus vor, indem die dCK durch hohe araCTP-Konzentrationen gehemmt werden. Bei Cytarabin hat nur die Triphosphatform (das araCTP) eine pharmakologische Wirkung (Matsuda und Sasaki 2004), die über die DNAPolymerase- $\alpha$ als falsches Substrat in den DNA-Strang eingebaut wird und als potenter Apoptose-Trigger fungiert. Zusätzlich werden durch araCTP Bindetaschen der Polymerase für das physiologische Substrat CTP blockiert. Das araCTP hat eine vergleichsweise kurze Halbwertszeit. Cytarabin bzw. Cytarabin-Monophosphat sind darüber hinaus gute Substrate für die katabolisierenden Enzyme Cytidin-Deaminase (CDA, Abbau des Cytarabins, Neff und Blau 1996) bzw. Deoxycytidylat-Deaminase (DCTD, Inaktivierung des Cytarabin-Monophosphats, Schroder et al. 1998).

\subsection{Nukleosid-Transporter}

\subsubsection{Typen von Nukleosid-Transportern}

Für die Aufnahme in die Zelle können die hydrophilen Moleküle der Nukleoside nur über spezifische Nukleosidtransporter (NTs), die in der Zellmembran integriert sind, aufgenommen werden. Bislang wurden sieben unterschiedliche NTs entdeckt (Baldwin et al. 2004; Griffiths et al. 1997; Ritzel et al. 2001a; Ritzel et al. 2001b; Ritzel et al. 1997; Ritzel et al. 1998). Vier von innen zählen zu den äquilibrierenden (ENT 1-4) (Damaraju et al. 2003), drei zählen zu den konzentrativen NTs (CNT 1-3, Gray et al. 2004b). 


\subsubsection{Wirkweise von Nukleosid-Transportern}

Die ENTs sorgen für einen Konzentrationsausgleich, transportieren bidirektional und natriumunabhängig (Baldwin et al. 2004; Mackey et al. 1998). Die CNTs sind in der Lage, die Aufnahme von Stoffen von extra- nach intrazellulär auch gegen ein Konzentrationsgefälle zu ermöglichen und transportieren dabei natrium-abhängig (Belt et al. 1993; Crawford et al. 1990). Während die ENTs in praktisch allen Geweben und Zelltypen vorkommen (Baldwin et al. 2004), scheint das Vorkommen der CNTs auf spezifische Zellen wie Epithelien der Nieren, Leber und des Gastrointestinaltraktes limitiert zu sein (Mackey et al. 1998; Pennycooke et al. 2001). Alle ENTs besitzen 11 Transmembrandomänen (Sundaram et al. 2001a; Sundaram et al. 2001b; Yao et al. 1997). In Säugetiergewebe befindet sich der ENT1 ubiquitär und somit auch in Blutzellen (Griffiths et al. 1997), in polaren Zellen zu einem Großteil basolateral (Chandrasena et al. 1997; Mangravite et al. 2001). Das für den ENT1 kodierende SLC29A1-Gen erstreckt sich über $15 \mathrm{kbp}$, enthält 13 Exone und liegt auf Chromosom 6.

Die pharmakologische Wirkung von Nukleosidanaloga ist abhängig vom NTvermittelten Eintritt in die Zelle (Cass et al. 1998; Mackey et al. 1998). Die unterschiedliche Kapazität der Transporter und deren Affinität zum jeweiligen Substrat ist ein entscheidender Faktor für die pharmakologische Wirkung (Clarke et al. 2006). Die Aufnahme von Gemcitabin erfolgt überwiegend durch ENT1, aber auch durch CNT1 und CNT3, was in-vitro-Studien mit Zelllinien aus menschlichem Pankreasgewebe zeigten (Garcia-Manteiga et al. 2003; Mackey et al. 1998; Mackey et al. 1999; Ritzel et al. 2001a). Soll die Wirkung von Gemcitabin in Blutzellen als Modellsystem demonstriert werden, kommt hier auf Grund des Expressionsniveaus im Wesentlichen nur der ENT1 in Betracht (Griffiths et al. 1997). Neben Gemcitabin transportiert der ENT1 in effizientem Maß unter anderem auch Cytarabin. Der Transport von Cytarabin durch CNT1 spielt aufgrund der geringen Affinität lediglich eine untergeordnete Rolle (Smith et al. 2004). Es gibt Hinweise, dass ein Mangel an NT-Aktivität für Resistenzen gegenüber Nukleosidanaloga wie Cytarabin und Gemcitabin in vivo und in vitro verantwortlich ist (Mackey et al. 1998; White et al. 1987). 


\subsubsection{Therapeutische Relevanz der Expressionsstärke von Nukleosidtransportern}

Auf Grund der zuvor dargelegten Bedeutung der Nukleosidtransporter für die Wirkung von Gemcitabin und Cytarabin könnte deren Expressionsstärke im Tumorgewebe von großer Bedeutung für den Therapieerfolg sein. In einer ersten Pilotstudie mit einem Patientenkollektiv von 21 Personen wurde in Pankreasgewebe immunhistochemisch der ENT1 bestimmt und dessen Expression mit dem Outcome einer Gemcitabin-Therapie verglichen. Hierbei zeigte sich, dass Patienten, bei denen der ENT1 nicht nachweisbar war, erheblich schlechter auf Gemcitabin ansprachen: 13 Monate medianes Überleben, wenn der ENT1 exprimiert war, und nur vier Monate, wenn dieser nicht nachweisbar war (Spratlin et al. 2004). Ein vergleichbarer Zusammenhang wurde beim nicht-kleinzelligen Bronchialkarzinom beschrieben, welches eine ebenfalls häufige Indikation für Gemcitabin darstellt (Oguri et al. 2007). Eine weitere Bestätigung lieferte eine Studie, in welcher die ENT1-Expression auf mRNA-Ebene in mikrodisseziierten Pankreastumorzellen untersucht wurde: Auch hier zeigte sich eine hoch signifikant positive Beziehung zum Gesamtüberleben unter einer Gemcitabin-Therapie (Giovannetti et al. 2006).

In ähnlicher Weise wie für Gemcitabin ist das Vorhandensein des ENT1 auch für die Wirkung von Cytarabin bei der Behandlung von akut myeloischen Leukämien (AML) bedeutsam (Galmarini et al. 2002).

\subsection{Genpolymorphismen}

Es wird vermutet, dass zur variablen Expression des ENT1 auch genetische Polymorphismen in der Keimbahn des Menschen beitragen. Als solche werden natürlicherweise vorkommende genetische Varianten mit mindestens $1 \%$ Allelfrequenz bezeichnet. Diese finden sich im Normalgewebe und auch in den daraus hervorgegangenen Tumorzellen, welche zusätzlich noch über spezifische Mutationen verfügen. Somit könnten die Keimbahn-Polymorphismen nicht nur für die Toxizität, sondern auch für das Ansprechen einer Therapie relevant sein (Damaraju et al. 2003). Es ist von vielen Chemotherapien bekannt, dass Patienten mit starken Nebenwirkungen häufig diejenigen sind, die besser auf die Therapie ansprechen. Demzufolge wäre die Kenntnis solcher klinisch bedeutsamen Genvarianten hilfreich, um einerseits Toxizitäten zu begrenzen und Therapieerfolge verbessern zu können. 
Eine so auf die jeweilige Person abgestimmte Therapie bezeichnet man „personalized medicine“. Sie ist heutzutage bereits Realität in Bezug auf die Vielfältigkeit der Subentitäten eines Tumortyps. Ein Beispiel hierfür ist die Therapie bei einer Untergruppe von Brustkrebs mit Trastuzumab, wobei ein bestimmter Antikörper mit einem speziellen Expressionsmuster zum Einsatz kommt.

Die Variabilität auf der Wirtsseite wird derzeit noch zu wenig berücksichtigt, gelangt aber zunehmend in den Fokus des wissenschaftlichen und medizinischen Interesses (Fukunaga et al. 2004; Maring et al. 2005). Im Visier sind genetische Polymorphismen der CDA, welche Nukleoside und deren Analoga abbauen (Sugiyama et al. 2007; Yue et al. 2003), aktivierende Enzyme wie der dCK (Shi et al. 2004) und Nukleosid-Transporter. Die genetische Variabilität in den kodierenden Bereichen des ENT1 sind sehr gering (Leabman et al. 2003) und von keiner relevanten Bedeutung (Osato et al. 2003) im Gegensatz zu Polymorphismen im Promotorbereich dieses Gens, wo eine funktionelle Bedeutung vermutet wird (Myers et al. 2006; Preuß 2009).

\subsection{Zielsetzung}

Basis dieser Arbeit waren Literaturberichte und Vorbefunde in der Abteilung Klinische Pharmakologie der Universität Göttingen, in denen ein relevanter Zusammenhang zwischen der Wirksamkeit der Nukleosid-Analoga Gemcitabin und Cytarabin mit der Expression des Nukleosid-Transporters ENT1 besteht. Weiterhin wird angenommen, dass diese auch durch genetische Polymorphismen beeinflusst werden. Bei der Auswahl eines geeigneten Modellsystems zur Erfassung der genetischen Variabilität muss neben der Verfügbarkeit größerer Stichprobenzahlen auch eine nennenswerte Expression des zu untersuchenden ENT1-Transporters vorhanden sein. Diese Voraussetzungen waren für Leukozyten des peripheren Bluts und auch für lymphoblastoide Zelllinien (LCLs), die durch Immortalisierung von B-Lymphozyten hergestellt werden, gegeben. Für diese Arbeit waren etwa 50 LCLs mit umfassender genetischer Charakterisierung (aus dem HapMap-Projekt) verfügbar. Für die Untersuchungen mit den Blutzellen wurde eine Fallzahl von 80 gesunden Spendern angestrebt. An diesen Untersuchungsmaterialen waren folgende Fragestellungen als Hypothesen zu prüfen: 
1. Lässt sich die in einer Pilotstudie der Abteilung Klinische Pharmakologie (Preuß 2009) aufgezeigte Korrelation zwischen der Expression des ENT1 in PBMCs (periphere mononukleäre Blutzellen) und der zytotoxischen Wirkung von Gemcitabin auf diese Zellen bestätigen? Und verhält sich dies vergleichend bei Cytarabin?

2. Im Promotor- bzw. Intron-1-Bereich des ENT1 werden zwei häufig vorkommende Genpolymorphismen als möglicherweise funktionell angesehen. Welche Bedeutung haben diese und gegebenenfalls weitere Polymorphismen auf die Expression des ENT1 und die zytotoxische Wirkung von Gemcitabin und Cytarabin? Dies sollte an den PBMCs und den LCLs dargestellt werden.

3. Eine Hemmung des ENT1 durch einen spezifischen Inhibitor (hier NBTI) sollte die ENT1-vermittelten Effekte des ENT1 reduzieren. Dies sollte anhand der zytotoxischen Wirkung von Gemcitabin und Cytarabin sowohl in den PBMCs als auch in den LCLs überprüft werden. Zudem wurde auch hier gefragt, ob die Genpolymorphismen im ENT1 darauf einen Einfluss haben.

4. Durch die Verwendung der umfassend genetisch charakterisierten LCLs sollte explorativ getestet werden, welchen Einfluss weitere Genpolymorphismen im ENT1 und in anderen Genen (CDA, DCK, RRM1) haben, die mit der Wirkung von Gemcitabin und Cytarabin in Verbindung gebracht werden.

\subsection{Arbeitsprogramm}

Wie in der Zielsetzung dargelegt, dienten für diese Arbeit als Untersuchungsmaterial PBMCs gesunder Spender sowie LCLs (immortalisierte B-Lymphozyten), in beiden Fällen kaukasischen Ursprungs und ohne Verwandtschaft der Spender.

Im Einzelnen ergaben sich folgende Arbeitsschritte:

1. Durchführung einer ex-vivo-Studie mit PBMCs 80 gesunder Spender/-Innen:
a. Rekrutierung, Aufklärung und Blutentnahmen
b. Isolierung von PBMCs (peripheral blood mononuclear cells)
c. Behandlung der Zellen mit den Nukleosid-Analoga Gemcitabin und Cytarabin und Kultur bis $48 \mathrm{~h}$


d. Entfernung der Zytostatika bei einem Teil der Proben nach $6 \mathrm{~h}$ zur Evaluierung des Auswärtstransportes über den ENT1

e. RNA-Asservierung nach $6 \mathrm{~h}$ und nach $48 \mathrm{~h}$ bei den Zytostatikabefreiten Proben

f. Messung der Zelltodparameter Apoptose und Nekrose mittels FACSAnalysen, dies auch in Verbindung mit dem ENT1-Inhibitor NBTI

g. RNA-Isolierung, Quantifizierung, reverse Transkription und Genspezifische RT-PCR

h. DNA-Isolierung, Quantifizierung und Bestimmung der Genpolymorphismen.

2. Studie mit etwa 50 lymphoblastoiden Zelllinien:

a. Kultivierung von LCLs, bis ausreichende Zellzahl erreicht (bei einigen Linien nicht möglich)

b. Für Versuchsreihe Einstellung auf 1 Million/ml und analoge Behandlung wie bei den PBMCs

c. Vorgehensweise und Methoden wie unter 1. beschrieben und zusätzlich hier noch ein weiterer Zellvitalitätsassay (MTT).

3. Statistische Auswertung (deskriptiv und analytisch):

a. ENT1-Genexpression in Zusammenhang mit zytotoxischer Wirkung von Gemcitabin und Cytarabin

b. Effekte der analysierten ENT1-SNPs auf Genexpression und Zytotoxizität

c. Evaluierung der Hemmwirkung des ENT1-Inhibitors NBTI

d. Assoziationsanalysen aus genomweiten Genotypisierungsdaten der LCLs für spezifische Gene

e. Grafische Darstellung der Ergebnisse. 


\section{Material und Methoden}

\subsection{Material}

\subsubsection{Chemikalien}

\section{Tabelle 3}

In den Versuchen verwendeten Chemikalien

\section{Chemikalie}

Annexin, FITC-markiert

CIAP

Cytarabin $10 \mathrm{mg} / \mathrm{ml}$

di-Natriumhydrogen-phosphat

dNTP-Set

Ethanol

Exonuklease I

FACS Flow / Rinse

FCS (Fetales Kälberserum)

Ficoll-Plaque Plus

GeneScan $^{\mathrm{TM}} \mathrm{LIZ}^{\circledR} 120$ Size Standard

Gemcitabin $10 \mathrm{mg} / \mathrm{ml}$

Hepes

HiDi-Lösung (enthält Formamid)

Kaliumchlorid

Kaliumdihydrogenphosphat

Kalziumchlorid

6- $\beta$-Mercaptoethanol

MTT-Reagenz (1-(4,5-Dimethylthiazol-2-yl)3,5-diphenylformazan)

Natriumchlorid

Penicillin/Streptomycin-Lösung

PicoGreen ${ }^{\circledast}$

\section{Firma}

Becton Dickinson, Franklin Lakes, USA

Fermentas, St. Leon-Rot

Klinikapotheke, Göttingen

Merck, Darmstadt

ABgene, Epsom

J. T. Baker, Phillipsburg, USA

USB, Staufen

Becton Dickinson, Franklin Lakes, USA

Gibco/Invitrogen, Karlsruhe

GE Healthcare, Uppsala, Schweden

Applied Biosystems, Darmstadt

Klinikapotheke, Göttingen

Applied Biosystems, Darmstadt

Applied Biosystems, Darmstadt

Riedel-De Haën AG, Seelze

Merck, Darmstadt

Merck, Darmstadt

Sigma, St.Louis, USA

Sigma, St.Louis, USA

J. T. Baker, Phillipsburg, USA

Invitrogen $\mathrm{GmbH}$, Karlsruhe

Applied Biosystems, Darmstadt 
Primer (Design nach gewünschter Sequenz, MWG-Biotech, Ebersberg siehe Anhang)

Propidiumiodid

Random Primer dN6

Ribonuklease-Inhibitor (RNA guard)

RNase Zap

RPMI Medium 1640

Shrimp Alkalische Phosphatase (SAP)

Taq-DNA-Polymerase

Tris

Türck'sche Lösung
Becton Dickinson, Franklin Lakes, USA

Roche, Mannheim

Amersham, Freiburg

Ambion, Austin, USA

Gibco/Invitrogen, Karlsruhe

USB, Staufen

Qiagen

Roth, Karlsruhe

Merck, Darmstadt

\subsubsection{Verbrauchsmaterial}

\section{Tabelle 4}

Verwendetes Verbrauchsmaterial

\section{Verbrauchsmaterial}

Alkoholisches Haut-Desinfektionsspray $\left(\right.$ Kodan $^{\circledR}$ )

Blutentnahme-Material (Butterfly, Micro-Flo ${ }^{\mathrm{TM}}$ )

Combitip plus $0,1,0,2,0,5,1,0,2,5 \mathrm{ml}$

Einweg-Pasteurpipetten

Einweg-Pasteurpipetten, Glas, 230 mm

Einweg-Pasteurpipetten, Kunststoff, $3 \mathrm{ml}$

Kalium-EDTA-Monovetten $(2,7 \mathrm{ml})$

Kulturflaschen $25 \mathrm{~cm}^{2}$

Lithium-Heparin-Monovetten $(5,5 \mathrm{ml}, 9 \mathrm{ml})$

Mehrkanal Pipette (8er) 0,5 - $10 \mu \mathrm{l}$

Mikroschraubröhrchen (2 ml)

Multiadapter für Blutentnahme-Monovetten

$\mathrm{NaCl}$-Lösung, isoton $0,9 \%$

\section{Firma}

Schülke \& Mayr, Norderstedt

LDKS Oversan, Gemonio, Italien

Eppendorf, Hamburg

Roth, Karlsruhe

Brand, Wertheim

Roth, Karlsruhe

Sarstedt, Nümbrecht

Sarstedt, Nümbrecht

Sarstedt, Nümbrecht

Eppendorf, Hamburg

Sarstedt, Nümbrecht

Sarstedt, Nümbrecht

Braun, Melsungen 
PAXgene ${ }^{\mathrm{TM}}$ Blood RNA Tube

PCR Softtubes Flachdeckel, RNase- und

DNase-frei $(0,2 \mathrm{ml})$

PCR-Folien (Adhesive PCR Foil Seals)

Pipettenspitzen $(10 \mu \mathrm{l}, 100 \mu \mathrm{l}, 1000 \mu \mathrm{l})$

Pipettenspitzen RNase-, DNase-frei $(10 \mu \mathrm{l}$, $100 \mu \mathrm{l}, 1000 \mu \mathrm{l})$

Platten, Nunclon Surface steril für Zellkultur (6- Nunc, Roskilde, Dänemark und 24-Well)

Platten, transparent für MTT-Assay (96-Well) Sarstedt, Nümbrecht

Platten, Thermo fast 384-Well

Platten, Thermo fast 96-Well

Rahmen und Septen für Sequenzierer

Reaktionsgefäße (1,5 ml, $2 \mathrm{ml})$

Röhrchen $15 \mathrm{ml}$

Röhrchen $5 \mathrm{ml}$ für FACS

Röhrchen $50 \mathrm{ml}$

Seraplas Filter V15

Sequenzierplatte
Abgene, Epsom

Sarstedt, Nümbrecht

Kisker, Steinfurt
Abgene, Epsom

Abgene, Epsom

Applied Biosystems, Darmstadt

Sarstedt, Nümbrecht

Sarstedt, Nümbrecht

Becton Dickinson, Franklin Lakes, USA

Sarstedt, Nümbrecht

Sarstedt, Nümbrecht

Applied Biosystems, Darmstadt
PreAnalytiX, vertrieben von Becton Dickinson, Heidelberg

Biozym, Hessisch Oldendorf

Spitzen für Multipipette plus (Combitip plus 0,1, Eppendorf, Hamburg $0,2,0,5,1,0,2,5 \mathrm{ml})$

Spritzen, BD Discardit ${ }^{\mathrm{TM}}(5 \mathrm{ml})$

Sarstedt, Nümbrecht

Sterile Pipetten $(5 \mathrm{ml}, 10 \mathrm{ml}, 25 \mathrm{ml})$

Sarstedt, Nümbrecht

Streifen, Flat cap strips (8er) für PCR-Platten

Softasept, Desinfektionsmittel

Abgene, Epsom

TaqMan Adhesive Optical Covers

Braun, Melsungen

Applied Biosystems, Darmstadt

Vacutainer BD Adaptersystem 


\subsubsection{Geräte}

\section{Tabelle 5}

Verwendete Geräte

\section{Geräte}

Accu-jet $^{\circledR}$

Autoklav

Biofuge fresco

Biofuge pico

BioRobot $^{\circledR} E Z 1$

FACScan

Feinwaage BL 610

Hämatocytometer (Neubauer-Zählkammer Improved)

Inkubator Function line

Kühlschrank VIP Series $-86^{\circ} \mathrm{C}$

Magnetrührer (IKAMAG RET)

Mastercycler 384 gradient

Mikroliter-Küvette für Photometer (LabelGuard ${ }^{\mathrm{TM}}$ )

Mikroplatten-Reader (96-Well, Tecan ULTRA)

Mikroskop Axiovert $40 \mathrm{CFL}$

Multipipette plus

PCR-Gradienten-Cycler (384-Well), Typ

Master-Cycler

PCR-Gradienten-Cycler (96-Well),

Typ PTC-200 Peltier

PH-Meter CG822

Photometer (Biophotometer 6313)

Pipetten (0,5-10 $\mu \mathrm{l}, 10-100 \mu \mathrm{l}, 100-1000 \mu \mathrm{l})$, Typen Research and Reference

PTC-200 Peltier Thermal Gradient Cycler

Sequenzierer 3100 Genetic Analyser

Stauschlauch zur Blutentnahme

\section{Firma}

Brand, Wertheim

Tecnorama, Fernwald

Heraeus, Hanau

Heraeus, Hanau

Qiagen, Hilden

Becton Dickinson, Franklin Lakes, USA

Sartorius, Göttingen

Brand, Wertheim

Heraeus, Hanau

Sanyo Electric Co Ltd., Japan

IKA, Staufen

Eppendorf

Implen, München

Tecan, Crailsheim

Zeiss, Jena

Eppendorf, Hamburg

Eppendorf, Hamburg

MJ Research/BioRad, Hercules, USA

Schott Geräte

Eppendorf, Hamburg

Eppendorf, Hamburg

MJ Research/BioRad, Hercules, USA Applied Biosystems, Darmstadt Prämeta, Troisdorf 
Sterilbank-Clean Air type DFL/REC4 KL 2A

TaqMan $7900 \mathrm{HT}$

Thermomixer 5436

Vortexer (MS 2 Minishaker)

Wärmeschrank

Wasserbad GFL 1083

Zentrifuge 5810R
Mahl, Trendelburg

Applied Biosystems, Darmstadt

Eppendorf, Hamburg

IKA, Staufen

Binder, Tuttlingen

Schütt, Göttingen

Eppendorf, Hamburg

\subsubsection{Kits}

Tabelle 6

Verwendete Geräte

\section{Kits}

Firma

EZ1 DNA Blood Kit

Qiagen, Hilden

Real-time-PCR-Mastermix mit $\mathrm{SYBR}^{(}$green

USB, Staufen

RNeasy Mini Kit

Qiagen, Hilden

SNaPshot ${ }^{\mathrm{TM}}$ Multiplex Kit

Applied Biosystems, Darmstadt

Super Script II Reverse Transcriptase Invitrogen, Karlsruhe

Taq DNA Polymerase

Qiagen, Hilden

\subsubsection{Primer}

\subsubsection{Primer für real-time-PCR}

\section{Tabelle 7}

Verwendete Primer für die real-time-PCR

\section{Primer}

ENT1-for (human)

ENT1-rev (human)

HPRT1-for (human)

HPRT1-rev (human)

TBP-for (human)

TBP-rev (human)

\section{Sequenz}

5'-TGTTTCCAGCCGTGACT-3'

5'-CAGGCCACATGAATACAG-3'

5'-TGACACTGGCAAAACAATGCA-3'

5'-GGTCCTTTTCACCAGCAAGCT-3'

5'-GAACCACGGCACTGATTTTC-3'

5'-CCCCACCATGTTCTGAATCT-3' 
TUBB-for (human)

TUBB-rev (human)
5'-CTTCGGCCAGATCTTCAGAC-3'

5'-AGAGAGTGGGTCAGCTGGAA-3'

\subsubsection{Primer zur Genotypisierung}

\section{Tabelle 8}

Verwendete Primer zur Genotypisierung

\section{Primer}

\section{Sequenz}

PCR-Primer:

SLC29A1_rs747199_for:

5'-AGGCCCCTCTCTGCAAGTCTGGTCT-3'

SLC29A1_rs747199_rev: 5'-TCTTGGAAAACCGGCCAGCAACTAG-3'

SLC29A1_rs1057985_for: 5'-CCAGTGCTTAACTGAGGGACAAGTG-3'

SLC29A1_rs1057985_rev: 5'-TGCCAGGCCAGGTTAAACTGTT-3'

SNaPshot ${ }^{\mathrm{TM}}$-Primer:

rs1057985

5'-(ACTG) ${ }_{5}$ CAGGTCTGCCTCCATA-3'

rs747199

5'-(ACTG) 4 ACTTGGCTGGAAAGAAAGGTTAAG-3'

\subsubsection{Lösungen und Puffer}

\section{Tabelle 9}

Verwendete Lösungen und Puffer

\section{Lösungen und Puffer}

Abkürzung

Masse

Annexin-Puffer, $\mathrm{pH}$ 7,4

eingestellt mit $\mathrm{NaOH}$

PBS-Puffer, pH 7,4
hergestellt als $10 x-K o n z e n t r a t$,
1 -Verdünnen mit $\mathrm{NaOH}$
eingestellt

eingestellt

Restriktionsenzym-Puffer

TE-Puffer, pH 7,5

eingestellt mit $\mathrm{HCl}$
HEPES

$\mathrm{NaCl}$

$\mathrm{CaCl}_{2}$

$\mathrm{NaCl}$

$\mathrm{KCl}$

$\mathrm{Na}_{2} \mathrm{HPO}_{4}$

$\mathrm{KH}_{2} \mathrm{PO}_{4}$

Tris

$\mathrm{MgCl}_{2}$

Tris

EDTA
$10 \mathrm{mM}$

$140 \mathrm{mM}$

$5 \mathrm{mM}$

$136 \mathrm{mM}$

2,68 mM

$8,2 \mathrm{mM}$

$1,47 \mathrm{mM}$

$200 \mathrm{mM}$

$100 \mathrm{mM}$

$10 \mathrm{mM}$

$1 \mathrm{mM}$ 


\subsubsection{Medien}

Tabelle 10

Verwendete sonstige Produkte und Materialien

\section{Medien Bezeichnung Konzentration}

$\begin{array}{lll}\text { Lymphozyten-Medium-10\% } & \text { RPMI-Medium } & 89 \%(\mathrm{v} / \mathrm{v}) \\ (\text { LM-10\%) } & \text { FCS } & 10 \%(\mathrm{v} / \mathrm{v}) \\ & \text { Penicillin-/ } & 1 \%(\mathrm{v} / \mathrm{v}) \\ & \text { Streptomycin-Lösung } & \\ \text { Lymphozyten-Medium-15\% } & \text { RPMI-Medium } & 84 \%(\mathrm{v} / \mathrm{v}) \\ \text { (LM-15\%) } & \text { FCS } & 15 \%(\mathrm{v} / \mathrm{v}) \\ & \text { Penicillin-/ } & 1 \%(\mathrm{v} / \mathrm{v}) \\ & \text { Streptomycin-Lösung } & \end{array}$

\subsubsection{Zellen}

PBMCs (peripheral blood mononuclear cells): von freiwilligen Spendern europäischer Abstammung.

LCLs (Iymphoblastoid cell lines), aus B-Lymphozyten mit Eppstein-Barr-Virus transformiert und immortalisiert. Spender kaukasischen Ursprungs (NIGMS Human Genetic Mutant Cell Repository Collection, Corriell Institute for Medical Research, Camden, New Jersey, USA). Nachfolgend sind die zugehörigen ID-Nummern des Corriell-Instituts aufgelistet:

GM07000, GM11839, GM11840, GM11993, GM12003, GM12005, GM12056, GM12154, GM12750, GM12760, GM12762, GM12763, GM12812, GM12814, GM12873, GM12875, GM06985, GM06993, GM06994, GM07022, GM07034, GM07055, GM07056, GM07345, GM07357, GM11830, GM11831, GM11832, GM11881, GM11882, GM11992, GM11994, GM11995, GM12004, GM12006, GM12043, GM12044, GM12057, GM12144, GM12145, GM12146, GM12155, GM12156, GM12234, GM12239, GM12248, GM12249, GM12717, GM12813, GM12815, GM12872, GM12874, GM12891 GM12892. 


\subsubsection{Software}

Adobe Photoshop: Bildbearbeitung

ISIS Draw Version 2.1.4 (MDL Information Systems Inc., San Leandro, USA 1999): Bildbearbeitung von chemischen Strukturformeln

Cell-QuestVersion1.1.2 ${ }^{\mathrm{TM}}$ : Software zur Durchführung und Visualisierung der durchflusszytometrischen Messungen für das FACS-Scan Gerät von BD

3100 Data Collection Software Version 1.0 (Applied Biosystems): Erhebung von Daten mit dem 3100 Genetic Analyser Sequenzierer

HaploView-Software (http://www.broad.mit.edu/mpg/haploview): Software zur grafischen Aufbereitung von Daten aus den Genotyp-Datenbanken

MS Office: Programme für Textverarbeitung, Präsentationen und Tabellenkalkulation

\section{PHASE-Software,Version2.1,}

(http://www.stat.washington.edu/stephens/software.html): Programm zur HaplotypBerechnung

SDS 2.1 (Applied Biosystems): Auswertung von Expressionsmessungen, die mit dem TaqMan 9100 HT gemacht wurden

SPSS Version 12.0: Grafische Darstellung von Messdaten und Testung auf mögliche Assoziationen

XFluor4 (Tecan): Programm zur Auswertung von Daten, die mit dem TecanMikroplattengerät gemessen wurden

\subsubsection{Datenbanken}

NCBI (http://www.nih.gov/) 
Zur Information über genomische DNA enthält NCBI eine Reihe von Datenbanken und Datensammlungen sowie über Proteine, mRNA, Genstrukturen (GenBank: http://www.ncbi.nlm.nih.gov/entrez) und vieles mehr (z.B. die Standard-LiteraturDatenbank PubMed). Von besonderem Interesse waren für diese Arbeit die Informationen $\mathrm{zu}$ genetischen Polymorphismen (Sub-Datenbank dbSNP, http://www.ncbi.nlm.gov/SNP).

HapMap-Projekt (http://hapmap.org/index.html.en)

HaploView (http://www.broad.mit.edu/mpg/haploview)

Das HapMap-Projekt wurde so konzipiert, dass man so genannte Haplotyp-Karten des gesamten menschlichen Genoms durch Bestimmung einer großen Zahl von genetischen Polymorphismen an denselben Individuen erstellen kann. Es gibt zur Zeit etwa 4 Millionen Einträge für Varianten der Keimbahn des Menschen (alles Kaukasier), welche an 90 Personen (davon 30 Familien mit jeweils drei Mitgliedern bestehend aus Vater, Mutter und einem Kind) erhoben wurden.

\subsection{Methoden}

Die Anreicherung von Gemcitabin und Cytarabin, sowie die Messungen der zytotoxischen Wirkung, wurden in den Zellen mit Hilfe von funktionellen Untersuchungen an lymphoblastoiden (LCLs) und primären mononuklearen Zellen des peripheren Blutes (PBMCs, peripheral blood mononuclear cells) nachgewiesen.

\subsubsection{Kultur der lymphoblastoiden Zellen}

In der Studie wurden so genannte lymphoblastoide B-Lymphozyten von Kaukasiern verwendet, die mittels des Epstein-Barr-Virus immortalisiert wurden. Inkubiert wurden die Zellen in RPMI-Medium bei $37^{\circ} \mathrm{C}$ und $5 \% \mathrm{CO}_{2}$ und alle 3-4 Tage mikroskopiert, um die Zelldichte zu bestimmen. Je nach Abhängigkeit des Zustands und der Dichte der Zellen wurden sie mit zusätzlichem Medium versorgt oder passagiert. Stieg die Zahl auf zwölf Millionen an, konnten sie für die bevorstehenden Versuchsreihen verwendet werden. 


\subsubsection{Gewinnung von PBMCs}

\subsubsection{Auswahl der Probanden}

Zur Auswahl zur Gewinnung von PBMCs standen freiwillige Probanden im Alter von 21 bis 55 Jahren (Median 26,0), die zum Zeitpunkt der Blutentnahme weder akut noch chronisch erkrankt waren. Zum Nachweis wurde von jedem Probanden ein Differentialblutbild angefertigt. An der Studie nahmen 72 Personen kaukasischer Abstammung in der dritten Generation teil, die weder miteinander verwandt noch gegenwärtige Raucher waren.

\subsubsection{Blutentnahme}

Den freiwilligen Probanden wurden jeweils $6 \times 9 \mathrm{ml}$ Blut in Heparin-Röhrchen und $4 \mathrm{x}$ 2,7 ml in EDTA-Röhrchen abgenommen. Das Blut in den EDTA-Röhrchen war für die DNA-Isolierung bestimmt und wurde bei $-20^{\circ} \mathrm{C}$ eingefroren. Die Weiterverarbeitung des Heparinblutes erfolgte in einem Zeitrahmen von $2 \mathrm{~h}$ nach Abnahme.

\subsubsection{PBMC-Isolierung}

PBMCs setzen sich aus 90-95\% Lymphozyten und 5-10\% Monozyten zusammen, wobei andere zelluläre Bestandteile wie Granulozyten, Thrombozyten und Erythrozyten als Verunreinigung bei der PBMC-Gewinnung auftreten können. Isoliert wurden sie unter der Sterilbank aus $45 \mathrm{ml}$ Heparinblut und der Verwendung von Ficoll, einem neutralen, hydrophilen, stark verzweigten Sucrose-Polymer mit einer Dichte von $1,077 \mathrm{~g} / \mathrm{cm}^{3}$. Die Dichte von Ficoll ermöglicht es, die Zellen voneinander zu trennen, da sie höher ist als von Lymphozyten und Monozyten, jedoch geringer als die von Granulozyten und Erythrozyten. Nach der Zentrifugation entstand ein Ring aus PBMCs zwischen Ficoll und einem Überstand aus Plasma und Thrombozyten, die Granulozyten und Erythrozyten befanden sich hingegen am Boden im Pellet.

Um nun die Ausbeute zu erhöhen, wurden 7,5 ml Blut aus den Heparin-Röhrchen mit 7,5 ml RPMI-Medium in einem 50-ml-Röhrchen verdünnt. Zusätzlich wurden weitere 50 -ml-Röhrchen mit $15 \mathrm{ml}$ Ficoll vorgelegt und mit $15 \mathrm{ml}$ verdünntem Blut jeweils sehr langsam überschichtet, um eine Durchmischung zu verhindern. Nach diesem 
Schritt folgte die Zentrifugation für $30 \mathrm{~min}$ bei $400 \mathrm{~g}$ und einer Temperatur von $18^{\circ} \mathrm{C}$, bei abgeschalteter Bremse und geringer Beschleunigung.

Nach der Zentrifuge wurden die PBMCs in je drei 50-ml-Röhrchen mit Hilfe einer 3ml-Pasteurpipette überführt. Zur Entfernung des noch im Röhrchen befindlichen Ficolls folgten zwei Waschvorgänge mit RPMI. Der erste bestand darin, die 50-mlRöhrchen mit RPMl aufzufüllen und sie dann für 10 min bei $18^{\circ} \mathrm{C}$ mit $500 \mathrm{~g}$, geringer Bremse und Beschleunigung zu zentrifugieren. Im Anschluss wurden die Röhrchen vorsichtig aus der Zentrifuge entnommen und der Überstand unter der Sterilbank abgesaugt. Die übrig gebliebenen Zellpellets wurden mit ca. $5 \mathrm{ml}$ RPMI resuspendiert und in ein 50-ml-Röhrchen zusammengeführt.

Nun folgte der zweite Waschvorgang, wobei die Röhrchen erneut mit RPMI aufgefüllt und für 10 min bei $18^{\circ} \mathrm{C}$ mit $500 \mathrm{~g}$, geringer Bremse und Beschleunigung zentrifugiert wurden. Der restliche Überstand wurde abgesaugt und das vorhandene Zellpellet diesmal anstelle von RPMI mit 5 ml Lymphozytenmedium resuspendiert.

\subsubsection{Bestimmung der Zellzahl}

Zur Zellzahlbestimmung wurden $200 \mu \mathrm{l}$ Türkscher Lösung mit $20 \mu \mathrm{l}$ der Zellsuspension in einem $1,5 \mathrm{ml}$ Plastik-Gefäß mit einer Pipette sorgfältig durchmischt. Anschließend wurden $10 \mu \mathrm{l}$ in eine Neubauer-Zählkammer pipettiert, wobei eine Kammertiefe von 0,1 mm durch das Vorhandensein von Newtonschen Ringen gewährleistet wurde. Unter dem Mikroskop waren vier Großquadrate zu sehen. Diese wurden einzeln ausgezählt und der Mittelwert aus diesen vier Quadraten gebildet. Dieser wurde mit dem Faktor 10 (pro Großquadratvolumen 0,1 $\mu l)$ und dem Verdünnungsfaktor 11 multipliziert, wodurch man die Zelldichte pro $\mathrm{ml}$ erlangte. Nach Beendigung des Auszählens wurde die Zellsuspension zusammen mit Lymphozytenmedium auf $2 \times 10^{6}$ Zellen/ml eingestellt.

Bei den LCLs wurde anstelle der Türckschen Lösung Trypanblau mit einer Verdünnung im Verhältnis 1:2 verwendet, wobei die Einstellung $2 \times 10^{6}$ Zellen/ml erhalten blieb. Der Vorteil von Trypanblau liegt darin, dass man tote Zellen nachweisen kann, welche bei der Zellzahlbestimmung außer Acht geblieben sind. 


\subsubsection{Durchflusszytometrie (FACS, Fluorescence-activated cell sorting)}

Anhand von FACS-Analysen können über Fluoreszenz sowohl allgemeine zelluläre (Granularität, Größe) als auch spezifische Eigenschaften erfasst werden. Mit unserem FACS-Gerät erfolgte die Anregung bei $488 \mathrm{~nm}$. Das Emissionslicht von Phycoerythrin wurde bei $575 \mathrm{~nm}$, das von FITC bei $515 \mathrm{~nm}$ und das von Propiumjodid, welches zum Nachweis nekrotischer Zellen verwendet wurde, bei 670 $\mathrm{nm}$ detektiert.

Der CD3-Antikörper markiert speziell T-Lymphozyten und ermöglicht so eine Abgrenzung von den übrigen Zellen. Phosphatidylserin, welches sich bei Apoptose von der zytoplasmatischen Seite auf die Außenseite der Zellmembran verlagert, wird spezifisch von Annexin gebunden, das durch einen fluoreszierenden Farbstoff (FITC) gekoppelt ist. Durch Anregung mittels des Laserstrahls bei einer Wellenlänge von $488 \mathrm{~nm}$ strahlt FITC Licht bei $515 \mathrm{~nm}$ ab. Somit stellt das Signal einen Indikator für apoptotische Zellen dar.

Zur Apoptosemessung und zur Bestimmung des intrazellulären Cytarabin- bzw. Gemcitabingehaltes in den PBMCs wurde nach 48-stündiger Inkubation im Brutschrank eine FACS-Analyse durchgeführt.

Die Zellansätze, die mit Cytarabin und Gemcitabin beimpft wurden, befanden sich in 5-ml-FACS-Röhrchen. Nun erfolgte die Waschung. Hierfür wurde jede Probe mit PBS-Puffer aufgefüllt und für 5 min bei geringer Bremse und Beschleunigung zentrifugiert und der Überstand anschließend abgesaugt. Nun wurde jeder Probe der PBMCs $100 \mu$ l einer Lösung, bestehend aus Annexin-Puffer, Annexin V (markiert mit FITC) und einem monoklonalem CD3-Antikörper (gekoppelt an Phycoerythrin) dazugegeben. Die Behandlung der LCLs erfolgte auf die gleiche Weise, jedoch wurde auf die Zugabe des monoklonalen Antikörpers verzichtet. Die Proben wurden bei $1400 \mathrm{U} / \mathrm{min}$ für ca. $3 \mathrm{~s}$ gevortext, danach im Dunkeln für 10 min inkubiert. Nach Ablauf der Zeit wurde auf jede Probe $400 \mu$ Annexin-Puffer mit einer Pipette gegeben und die Durchflusszytometriemessung (mit FACScan der Firma Dickinson) begonnen. 


\subsubsection{RNA-Isolierung}

Die Isolierung der RNA wurde mit dem BasicRna-Kit von OLS nach vorhandenem Protokoll durchgeführt. Da RNA sehr empfindlich ist, wurden an separaten Bereichen gearbeitet und RNase-freies Eigenmaterial bzw. mit RNase-Zap gereinigte Gebrauchsgegenstände verwendet. Zur Weiterverarbeitung wurden die auf $-80^{\circ} \mathrm{C}$ eingefrorenen Lysate auf Eis langsam aufgetaut. Durch eine vorgeschaltete Säule wurde in einem der ersten Schritte die DNA entfernt. Daraufhin erfolgten zwei Waschschritte und eine Trockenzentrifugation.

Die RNA wurde anhand von $40 \mu \mathrm{l}$ RNase-freiem Wasser eluiert. Das gewonnene Eluat wurde vorerst auf Eis gelagert und anschließend bei $-80^{\circ} \mathrm{C}$ eingefroren.

\subsubsection{RNA Quantifizierung}

Die RNA-Konzentration der Proben wurde durch die Messung der optischen Dichte mit einem Photometer bestimmt. Das Absorptionsmaximum von Nukleinsäuren liegt bei einer Wellenlänge von $260 \mathrm{~nm}$, das von Proteinen bei $280 \mathrm{~nm}$. Somit ist die Reinheit der Nukleinsäuren durch das Verhältnis von OD260/OD280 bestimmbar. Ab einem Quotient von 1,8 liegt ein hoher Reinheitsgrad der RNA vor.

\subsubsection{Synthese der cDNA}

Eine Expressionsmessung von RNA mittels PCR-basierten Verfahren durchzuführen, erfordert das Vorhandensein von DNA. Aus diesem Grund wurde die RNA mit Hilfe der Reversen Transkriptase in cDNA (complementary DNA) umgeschrieben. Eingesetzt wurden hierfür je $1 \mu \mathrm{g}$ RNA. Durch Hinzufügen von 0,1 unit dN6 RandomPrimer, welche aus allen möglichen Variationen von sechs Basen $\left(4^{6}\right)$ bestehen, wurde die Anlagerung ermöglicht und der Ansatz mit $\mathrm{H}_{2} \mathrm{O}$ auf ein Gesamtvolumen von 18,5 $\mu \mathrm{l}$ ergänzt. Somit war es möglich, den kompletten RNA-Pool umzuschreiben. Der Ansatz wurde für 10 min bei $72^{\circ} \mathrm{C}$ inkubiert, um die RNA zu denaturieren. Anschließend wurde diese zur Anlagerung der Primer auf Raumtemperatur abgekühlt. Nun wurde der cDNA-Reaktions-Mastermix (Tabelle 11) dem Ansatz hinzugefügt, welcher für $1 \mathrm{~h}$ bei $42^{\circ} \mathrm{C}$ im PCR-Gerät inkubierte, um die gesamte RNA umzuschreiben. Zuletzt wurde die gewonnene cDNA auf $10 \mathrm{ng} / \mu \mathrm{lmit}$ $\mathrm{ddH}_{2} \mathrm{O}$ eingestellt und bei $-80^{\circ} \mathrm{C}$ eingelagert. Voraussetzung hierfür war eine 100\%ige Effizienz. 


\section{Tabelle 11}

Reaktions-Mastermix für cDNA-Synthese.

\begin{tabular}{lc}
\hline Mastermix für cDNA-Synthese & Menge \\
\hline Reverse Transkriptase $(200 \mathrm{U} / \mu \mathrm{l})$ & $0,25 \mu \mathrm{l}$ \\
Rnase-Inhibitor $(30 \mathrm{U} / \mu \mathrm{l})$ & $1,00 \mu \mathrm{l}$ \\
$10 \mathrm{mM}$ dNTPs & $1,00 \mu \mathrm{l}$ \\
$0,1 \mathrm{M}$ DTT & $3,50 \mu \mathrm{l}$ \\
5 x RT Puffer & $6,00 \mu \mathrm{l}$ \\
\hline Gesamt & $11,75 \mu \mathrm{l}$ \\
\hline
\end{tabular}

\subsubsection{Genexpressionsmessung mittels quantitativer Real time- PCR}

Wie bei herkömmlicher PCR werden bei der quantitativen Real time-PCR spezifische Sequenzbereiche, so genannte Matrizen, vervielfältigt. Zudem erfolgt während der Amplifikationszyklen eine direkte fluoreszenzbasierte Quantifizierung. Zur Detektion gibt es zwei Möglichkeiten, erstens mit Farbstoffen, die sich in die dsDNA einlagern, zweitens mit spezifischen Sonden. Hier wurde als Nachweisreagenz SYBR ${ }^{\circledR}$ Green der Firma USB als Mastermix verwendet. Bei komplikationslosem Ablauf hat sich am Ende eines einzelnen PCR-Zyklus der zu amplifizierende DNA-Bereich verdoppelt. Folglich konnte ein stärkeres SYBR® Green-Signal detektiert werden. Gemessen wurde anhand der Zyklenzahl, wobei das Fluoreszenz-Signal eine bestimmte Stärke erreicht hat.

Genannt wird diese Zyklenzahl als Ct-Wert oder „cycle number at which the given threshold is reached." Das bedeutet, dass die Anzahl der Zyklen um so höher ist, je mehr Zyklen zum Erreichen der Signalstärke nötig sind. Anders herum kann man sagen, dass ursprünglich weniger RNA-Kopien in der Probe vorkamen.

So ist es möglich die Genexpression zwischen unterschiedlichen Proben zu vergleichen.

Es muss sichergestellt werden, dass nur ein PCR-Produkt gebildet wird, da das SYBR $^{\circledR}$ Green nicht sequenzspezifisch ist. Dies erfolgt mittels Schmelzkurvenanalyse durch ansteigende Temperaturen. In Abhängigkeit von seiner Länge und der Nukleotidzusammensetzung zerfällt jeder DNA-Doppelstrang bei seiner charakteristischen Schmelztemperatur (TM), wobei man in diesem Bereich in der 
Schmelzkurve die stärksten Abweichungen in der Signalabnahme sehen kann, was sich in der ersten Ableitung anhand eines Peaks zeigt. Ist nur ein Produkt entstanden, sollte man annehmen, dass auch nur ein Peak zu sehen ist.

Mittels der CDNA aus den LCL-Zellen erfolgte die Genexpressionsmessung.

Für die Real-time-PCR wurden dem Mastermix der Firma USB die jeweils spezifischen Primer zugefügt und auf einer 384-Well-Platte je $5 \mu$ l verteilt.

Zum Reaktionsmix wurden noch zusätzlich $5 \mu \mathrm{l}$ cDNA gegeben. Hierbei wurde jede Probe doppelbestimmt. Anschließend wurde die Platte mit einer optischen, laserlichtdurchlässigen Folie abgeklebt und ein PCR-Programm in einem 7900HTMessgerät der Firma Applied Biosystems gestartet und mit der Software SS 2.1 ausgewertet. Das PCR-Programm ist in Tabelle 12 aufgeführt.

\section{Tabelle 12}

Real-time-PCR-Programm.

\section{PCR-Programm}

\begin{tabular}{ll}
\hline Denaturierung & $95^{\circ} \mathrm{C} 15 \mathrm{~s}$ \\
Annealing & $60^{\circ} \mathrm{C} 20 \mathrm{~s}$ \\
Elongation & $72^{\circ} \mathrm{C} 40 \mathrm{~s}$ \\
Aktivierung der Taq- & $95^{\circ} \mathrm{C} 2 \mathrm{~min}$ \\
Polymerase & \\
\hline Schmelzkurve & $95^{\circ} \mathrm{C} 15 \mathrm{~s}$ \\
& $60^{\circ} \mathrm{C} 15 \mathrm{~s}$ \\
& $95^{\circ} \mathrm{C} 15 \mathrm{~s}$ \\
\hline
\end{tabular}

\subsubsection{Isolierung und Quantifizierung genomischer DNA}

Das den Probanden zusätzlich abgenommene Blut wurde in 2,7ml EDTA-Monovetten bei $20^{\circ} \mathrm{C}$ eingefroren. Anhand des Bio Robots EZ1 unter Verwendung des EZ1 DNA Blood Kit von Qiagen aus je $350 \mu \mathrm{l}$ Gesamtblut erfolgte die Isolierung der genomischen DNA.

Zur DNA-Quantifizierung verwendeten wir PicoGreen®, das nach Einlagerung in die dsDNA fluoreszierte. Die Exzitation erfolgte bei 485 nm, die Emission bei 535 nm. 
In jedes Well wurden $200 \mu \mathrm{l}$ PicoGreen® in TE-Puffer verdünnt (1:400) vorgelegt. Nun wurden unterschiedlich große Mengen bekannter DNA Konzentration pipettiert. Hierbei erhielt man eine Standardreihe. Auf die Platte wurden Aliqouts der zu bestimmenden DNA-Proben nach einer Vorverdünnung von 1:10 in $\mathrm{dd}_{2} \mathrm{O}$ gegeben. Infolge der hohen Lichtempfindlichkeit von PicoGreen®, wurde Alufolie auf die Platte geklebt. Anschließend wurde die Platte gevortext, zentrifugiert und bei Raumtemperatur 30 min inkubiert. Im Folgenden wurde die Fluoreszensmessung in einem Mikroplattengerät (Tecan Ultra) durchgeführt. Die Auswertung erfolgte mittels der XFluor4-Software von Tecan.

\subsubsection{Polymerase Chain Reaction (PCR)}

Mit Hilfe der PCR ist es möglich, beliebige in-vitro-DNA-Abschnitte von vielen Zehnerpotenzen (> 10 Milliarden) zu vervielfältigen. Die Reaktionsansätze bestehen aus Puffer, optionalen Zusätzen (z.B. Q-Solution von Qiagen), den vier Desoxynukleotiden (dNTPs), einem sequenzspezifischen Primerpaar, dem zu amplifizierenden DNA-Template und einer hitzestabilen Polymerase. Beim Menschen lassen sich mit der gewöhnlichen Polymerase Sequenzbereiche bis zu 2000 bp amplifizieren. Es wiederholen sich die Schritte Denaturierung, Annealing (Primeranlagerung) und Elongation (Kettenverlängerung). Bei idealen Bedingungen kann so pro Zyklus der gewünschte DNA-Abschnitt verdoppelt werden.

Anfangs müssen die DNA-Stränge des gesamten Moleküls in einer längeren (ca. 2-5 min) Denaturierungsphase getrennt werden. Nach dem letzten Zyklus werden während einer 10-minütigen Elongation inkomplette Fragmente vervollständigt. Um mit der PCR nur gewünschte DNA-Abschnitte zu amplifizieren, müssen sequenzspezifische Primerpaare ausgewählt werden (20-30 Nukleotide).

Das Primerpaar besteht aus einem Vorwärtsprimer für den Sense-Strang und einem Rückwärtsprimer für den Antisense-Strang. Zunächst muss die optimale AnnealingTemperatur mit einer Gradienten-PCR bestimmt werden. Hierbei ist das Ziel, eine sehr spezifische Amplifikation ohne störende Nebenprodukte zu bekommen. Sind mit Hilfe einer Test-DNA die optimalen Bedingungen gefunden, kann die PCR für die gesamte DNA-Serie benutzt werden. 


\subsubsection{Agarose Gelelektrophorese}

Mit Hilfe der Agarose-Gelelektrophorese können unterschiedlich lange DNAFragmente aufgespalten werden. Hierbei wandern die negativ geladenen Nukleinsäuren zum positiv geladenen Pol, wobei die Geschwindigkeit den unterschiedlichen Größen entspricht. Größere Fragmente wandern langsamer, da sie in der Bewegung stärker durch die Agarose gebremst werden, kleinere Fragmente dementsprechend schnell. 


\section{Ergebnisse}

\subsection{Probandenstudie}

\subsubsection{Nukleosid-induzierte Apoptose und Nekrose in PBMCs}

In der Probandenstudie wurden mononukleäre Zellen des peripheren Blutes (PBMCs) von 72 gesunden Spendern kaukasischer Abstammung isoliert, mit Cytarabin und Gemcitabin für 6 und $48 \mathrm{~h}$ bei $37^{\circ} \mathrm{C}$ behandelt und als funktioneller Endpunkt Apoptose und Nekrose mittels FACS-Messungen ermittelt. Zunächst wurde untersucht, inwieweit induzierte Apoptose und Nekrose miteinander korrelierten. Es zeigte sich eine deutliche Korrelation der beiden Messparameter nach $48 \mathrm{~h}$ Zytostatikainkubation, etwas ausgeprägter noch bei Cytarabin (Abbildung 3). Die entsprechenden Korrelationen waren bei den T-Lymphozyten noch etwas deutlicher ausgeprägt. Hier konnte jedoch keine Normalverteilung angenommen werden und die Korrelationsstärke zwischen Apoptose und Nekrose wurde mit dem SpearmanRangsummen-Koeffizienten rho ermittelt. Dieser betrug bei Gemcitabin 0,85 und bei Cytarabin 0,88 . Wurden die Zellen nur $6 \mathrm{~h}$ gegenüber Zytostatikum exponiert und anschließend gewaschen, fanden sich $48 \mathrm{~h}$ nach Behandlungsbeginn etwas geringere Korrelationen zwischen Apoptose und Nekrose. Zusammenfassend lässt sich sagen, dass bei den isolierten Leukozyten zwar eine deutliche Korrelation zwischen Apoptose und Nekrose besteht, jedoch ein substanzieller Anteil der Variabilität des einen Parameters nicht durch den des anderen erklärt wird. Daher wurden für die statistischen Tests mit den Zellen aus der Probandenstudie beide Funktionsparameter separat analysiert. 

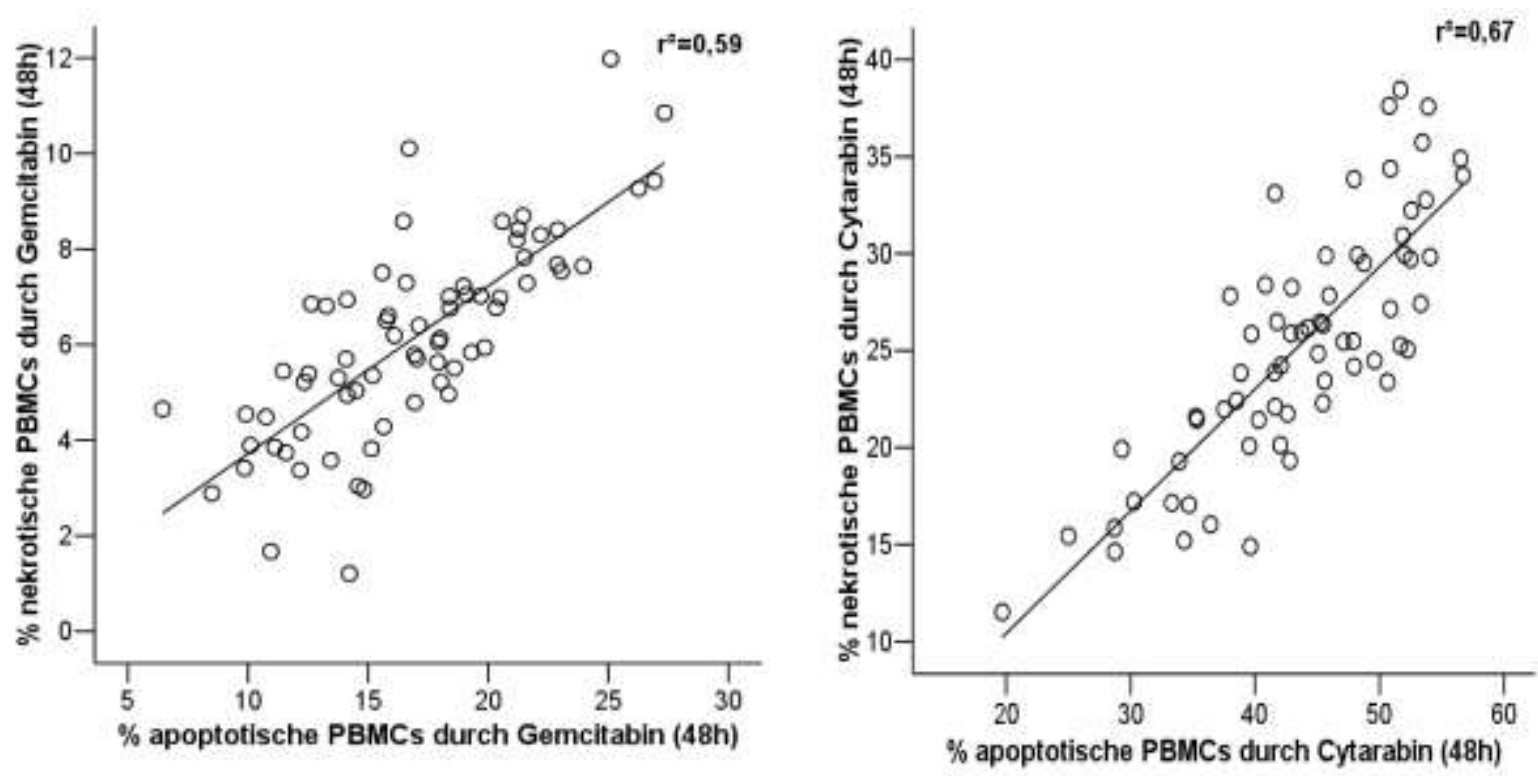

\section{Abbildung 3}

Korrelation zwischen induzierter PBMC-Apoptose und -Nekrose. Die Zellen wurden entweder mit $10 \mu \mathrm{g} / \mathrm{ml}$ Gemcitabin (links) oder Cytarabin (rechts) bei $37^{\circ} \mathrm{C}$ für $48 \mathrm{~h}$ inkubiert. Der statistische Zusammenhang ist mit dem Bestimmtheitsmaß $\mathrm{r}^{2}$ angegeben. 
In Abbildung 4 ist die apoptotische Wirkung von Gemcitabin und Cytarabin auf TLymphozyten nach einer Behandlungszeit von 6 und $48 \mathrm{~h}$ veranschaulicht. Zum Vergleich ist links die Kontrolle ohne Zytostatikum dargestellt. Nach $6 \mathrm{~h}$ war bei beiden Behandlungen kaum eine Erhöhung der Apoptoserate zu beobachten (obere Reihe rechts in Abbildung 4). Nach $48 \mathrm{~h}$ zeigte sich bei den mit Cytarabinbehandelten Zellen eine starke Zunahme des Anteils apoptotischer T-Lymphozyten, bei Gemcitabin erfolgte diese nur geringfügig (untere Reihe rechts).

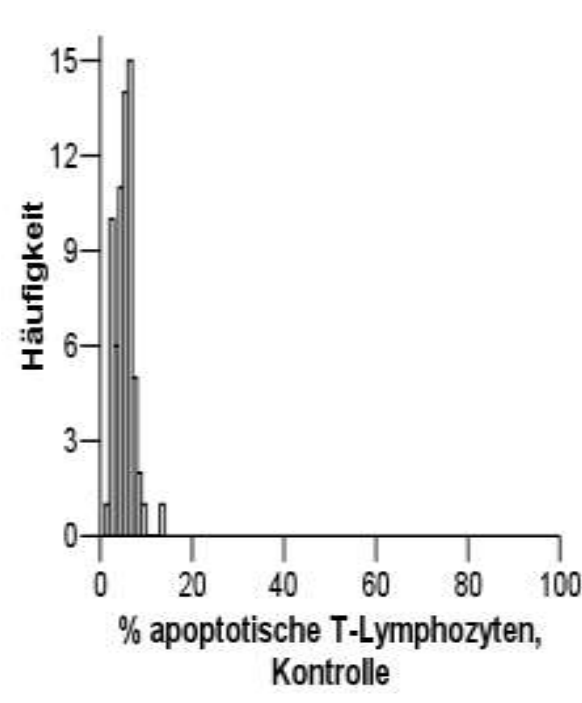

\section{Abbildung 4}

Histogramme für den Anteil apoptotischer T-Lymphozyten. Links ist die Verteilung auf Kontrollniveau gezeigt. Rechts daneben finden sich oben die entsprechenden Verteilungen nach $6 \mathrm{~h}$, unten diejenigen nach $48 \mathrm{~h}$ Inkubation mit $10 \mu \mathrm{g} / \mathrm{ml}$ Gemcitabin bzw. Cytarabin.

Es sollte untersucht werden, inwieweit für Cytarabin bzw. Gemcitabin die Apoptoseinduktion in T-Lymphozyten zwischen den beiden Inkubationszeiten 6 und $48 \mathrm{~h}$ korreliert. Insgesamt war der Zusammenhang eher geringgradig, etwas mehr bei Gemcitabin (Abbildung 5) als bei Cytarabin (Abbildung 5). Die Messparameter nach 6-stündiger Inkubation waren für die 48-stündige Inkubation somit nicht repräsentativ. Ähnliches galt für die Induktion der Nekrose (Abbildung 6). 

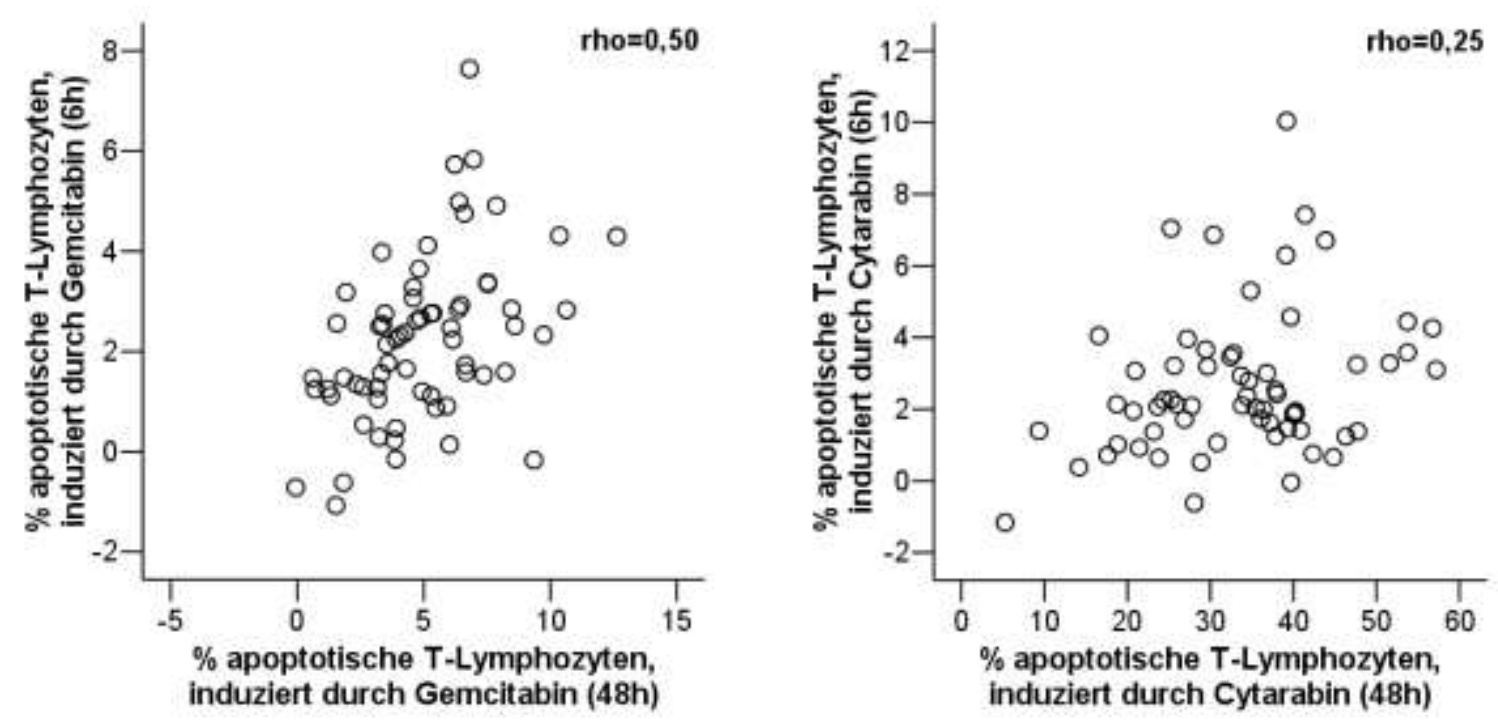

\section{Abbildung 5}

Korrelation der T-Zell-Apoptose zwischen 6 und $48 \mathrm{~h}$ Zytostatika-Exposition. Die Zellen wurden für diese Zeitintervalle mit $10 \mu \mathrm{g} / \mathrm{ml}$ Gemcitabin (links) bzw. $10 \mu \mathrm{g} / \mathrm{ml}$ Cytarabin (rechts) bei $37^{\circ} \mathrm{C}$ inkubiert. Dargestellt sind jeweils die durch die Behandlung gegenüber der Kontrolle hervorgerufenen Veränderungen. Für diese konnte keine Normalverteilung angenommen werden und daher wurde der nicht-parametrische Spearman-Rangsummen-Korrelationskoeffizient rho verwendet.
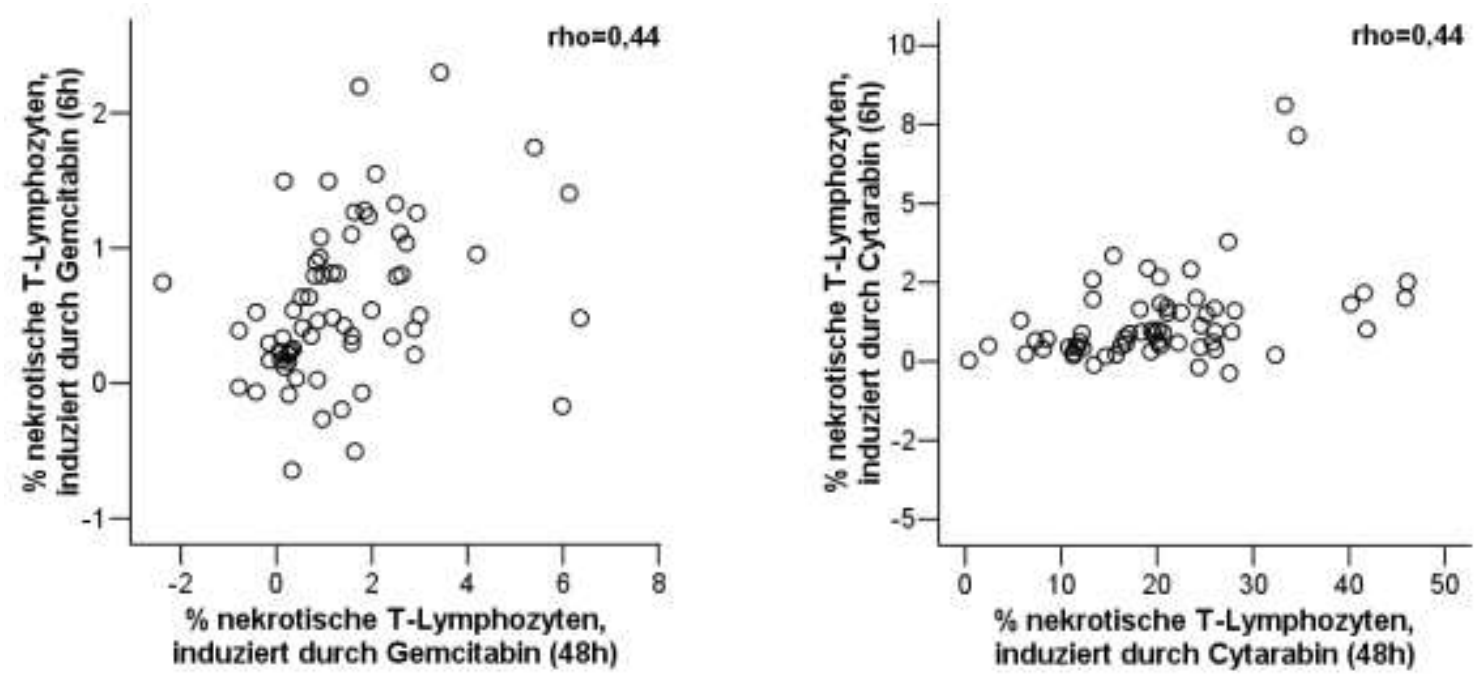

\section{Abbildung 6}

Korrelation der T-Zell-Nekrose zwischen 6 und 48 h Zytostatika-Exposition. Hier sind die Verhältnisse für die Nekrose gezeigt, ansonsten ist die Darstellung analog zu Abbildung 5.

Eine wichtige Frage meiner Arbeit war, inwieweit die apoptotische Wirkung von Gemcitabin und Cytarabin - wie in anderen Kontexten in der Literatur beschrieben über den ENT1-Transporter vermittelt wird. Zur Beantwortung dieser Frage wurden erstens die basale mRNA-Expression des ENT1 mit der apoptotischen Wirkung der beiden Zytostatika verglichen, zweitens ein spezifischer Inhibitor (NBTI) des ENT1 verwendet und drittens genetische Polymorphismen im Genbereich des ENT1 mit 
den Funktionsmessungen in Beziehung gesetzt. Diese drei Aspekte sind nachfolgend dargestellt.

\subsubsection{Expression des ENT1-Transporters und Zellapoptose}

Zunächst sollte die Hypothese geprüft werden, ob eine höhere ENT1-Expression mit einer erhöhten Apoptoserate durch verstärkte Zytostatika-Aufnahme verbunden ist. Dazu wurde die Transkriptionsstärke des ENT1 auf Basalniveau verwendet, wodurch Zytostatika-induzierte Veränderungen ausgeschlossen wurden. Dabei war bereits auf dem Kontrollniveau (also ohne Zytostatika) eine geringgradig positive Korrelation zu sehen. Für die unter Gemcitabin gemessene Apoptoserate war dieser Zusammenhang noch etwas stärker ausgeprägt, bei Cytarabin dagegen schwächer als bei der Kontrolle (Abbildung 7).
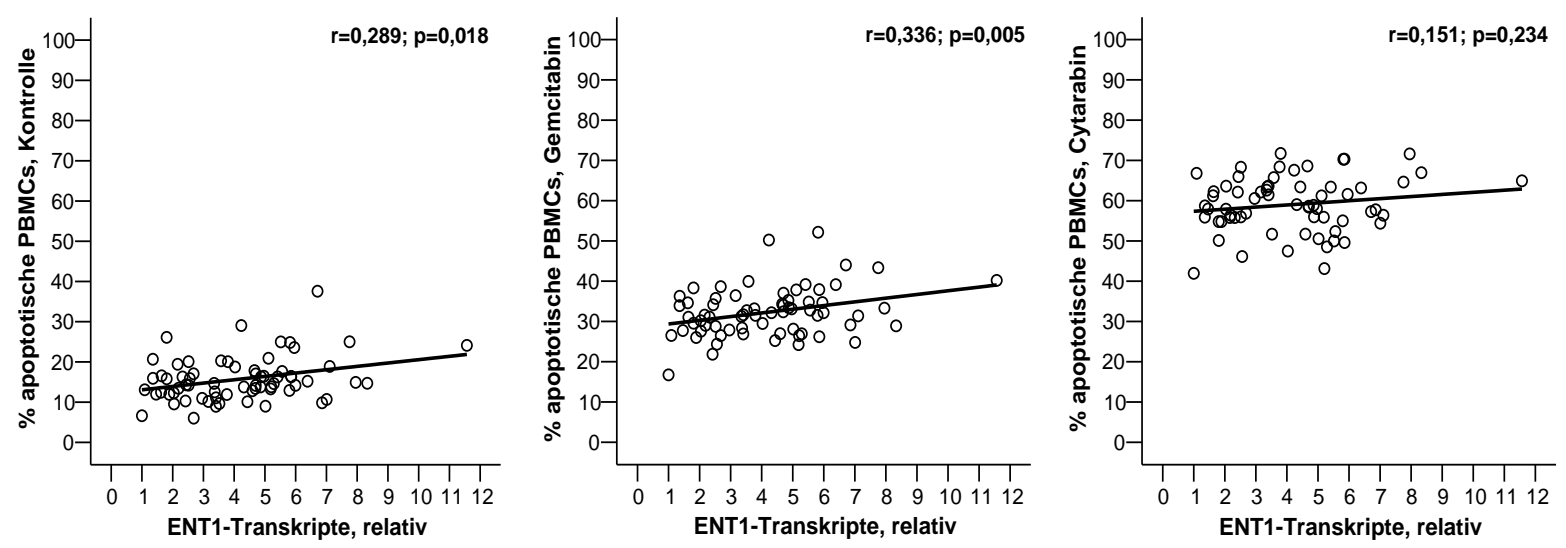

\section{Abbildung 7}

Korrelation zwischen ENT1-Transkripten und PBMC-Apoptose basal und nach Behandlung. Die Rohdaten der ENT1-mRNA-Expression wurden auf das gewichtete Mittel der beiden Referenzgene GAPDH und HPRT1 normiert und sind relativ zum niedrigsten Wert dieser Serie dargestellt. Die beiden Zytostatika Gemcitabin und Cytarabin wurden jeweils mit $10 \mu \mathrm{g} / \mathrm{ml}$ eingesetzt und die Inkubation erfolgte für $48 \mathrm{~h}$ bei $37^{\circ} \mathrm{C}$. Zur Berechnung des Pearson-Korrelationskoeffizienten wurden jeweils die zur Basis 10 logarithmierten Transkript- und Apoptose-Werte verwendet, welche mit einer Normalverteilung vereinbar waren.

\subsubsection{Effekte des ENT1-Inhibitors NBTI auf Nukleosid-induzierte Apoptose}

Weiterhin sollte die Bedeutung des ENT1 für die zytotoxische Wirkung von Nukleosid-Analoga durch Hemmung dieses Transporters durch NBTI demonstriert werden. Diese Experimentenreihe wurde mit demselben Biomaterial wie zuvor durchgeführt, jedoch fokussiert auf Cytarabin als Zytostatikum, da dieses in äquimolaren Konzentrationen wesentlich toxischer auf Leukozyten wirkt. Sehr 
deutlich ist zu erkennen, dass die Cytarabin-vermittelte Apoptoserate durch Zugabe von NBTI stark abgeschwächt war. Das war sowohl für PBMCs (Abbildung 8, links) als auch für T-Lymphozyten zu beobachten (Abbildung 8, rechts).
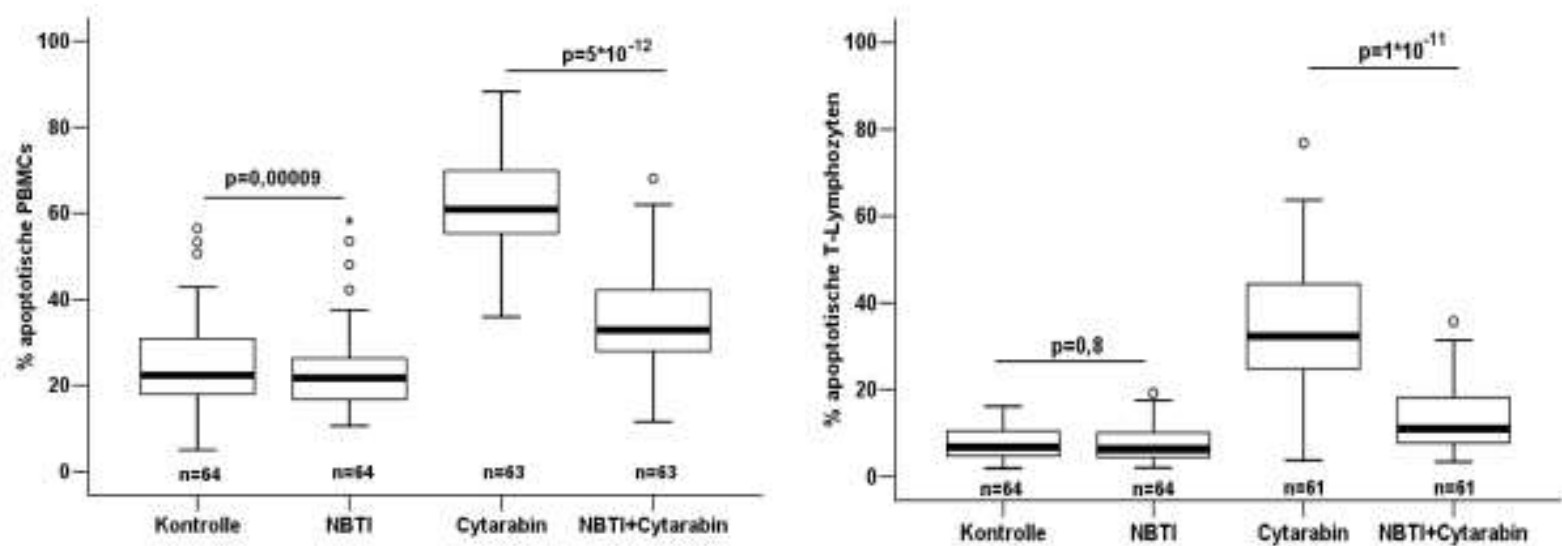

\section{Abbildung 8}

NBTI-Effekte auf die Cytarabin-induzierte Apoptose in PBMCs (links) und T-Zellen (rechts). Alle Ansätze wurden bei $37^{\circ} \mathrm{C}$ für $48 \mathrm{~h}$ inkubiert. Cytarabin wurde dabei in einer Konzentration von $10 \mu \mathrm{g} / \mathrm{ml}$, der ENT1-Inhibitor Nitrobenzylthioinosin (NBTI) mit $100 \mathrm{nM}$ eingesetzt. Die $\mathrm{p}$-Werte geben die statistische Signifikanz an. Sie wurden mit dem gepaarten Wilcoxon-Rangsummentest berechnet. Bei den PBMCs wurde in 47 Zelllinien nach NBTI-Behandlung eine geringere Apoptoserate als in der Kontrolle beobachtet, bei den T-Lymphozyten war hier kein Unterschied festzustellen. NBTI verringerte in allen Proben die Cytarabin-induzierte Apoptose. Die Anzahl $n$ der jeweiligen Zelllinien ist für jede Behandlungsbedingung angegeben.

\subsubsection{Effekte von ENT1-Genpolymorphismen auf die gemessenen Funktionsparameter}

Auf Grund der Bedeutung des ENT1-Transporters für die zelluläre Aufnahme der hier untersuchten Zytostatika sollte untersucht werden, ob Genpolymorphismen in der ENT1-Region mit den gemessenen Funktionsparametern Apoptose/Nekrose und ENT1-Expression assoziieren. Dazu wurden insgesamt 18 Varianten, die die genetische Variabilität in der ENT1-Region umfassend abbilden, analysiert (Tabelle 13). Als ein Gütekriterium für die Genotypisierung wurde das Hardy-WeinbergGleichgewicht (engl. Hardy-Weinberg Equilibrium) angewandt, das in allen Fällen erfüllt war. Die Architektur des ENT1 und das genetische Kopplungsungleichgewicht (engl. linkage disequilibrium) dieser 18 Genpolymorphismen sind in Abbildung 9 veranschaulicht. 


\section{Tabelle 13}

Untersuchte Polymorphismen im Genbereich von ENT1. Für jeden Polymorphismus ist die rs-Nummer aus der Datenbank dbSNP (http://www.ncbi.nlm.nih.gov/sites/entrez) mit der zugehörigen Position auf Chromosom 6 und die Zuordnung zum Genelement des ENT1 angegeben. In der Spalte "BA" stehen die beiden Allele jedes Polymorphismus mit dem selteneren Allel rechts des ">"-Zeichen. Die genannten Häufigkeiten beziehen sich auf die 72 Probanden der Probandenstudie. WT = Wildtyp, d.h. Homozygotie für das häufigere Allel, Het $=$ Heterozygotie für beide Allele, Var $=$ Homozygotie für das seltenere Allel. MAF $=$ Häufigkeit des selteneren Allels (minor allele frequency). HWE $=$ Hardy Weinberg Equilibrium. UTR = untranslated region

\section{Polymor- Position
phismus auf Chr 6 Genelement}

BA $\begin{gathered}\text { WT, } \\ \text { beob- } \\ \text { achtet }\end{gathered} \begin{gathered}\text { Het, } \\ \text { beob- } \\ \text { achtet }\end{gathered} \begin{gathered}\text { Var, } \\ \text { beob- } \\ \text { achtet }\end{gathered}$

MAF, Chiachtet achtet achtet achtet (HWE)

\begin{tabular}{|c|c|c|c|c|c|c|c|c|}
\hline rs9357436 & 44182720 & 5'-Promotorregion & $\mathrm{G}>\mathrm{A}$ & 47 & 21 & 2 & 0.18 & 0.98 \\
\hline rs2297393 & 44184719 & 5'-Promotorregion & $C>T$ & 23 & 32 & 15 & 0.44 & 0.83 \\
\hline rs3734701 & 44185254 & 5'-Promotorregion & $C>T$ & 48 & 19 & 3 & 0.18 & 0.82 \\
\hline rs1057985 & 44185901 & 5'-Promotorregion & $C>T$ & 29 & 33 & 10 & 0.37 & 0.99 \\
\hline $\begin{array}{l}\text { rs6687234 } \\
7\end{array}$ & 44187386 & 5' UTR & $C>T$ & 57 & 13 & 0 & 0.09 & 0.69 \\
\hline $\begin{array}{l}\text { rs6705773 } \\
2\end{array}$ & 44187402 & 5' UTR & del>T & 66 & 4 & 0 & 0.03 & 0.97 \\
\hline rs6914414 & 44188277 & Intron 1 & $C>T$ & 59 & 11 & 0 & 0.08 & 0.78 \\
\hline rs9462977 & 44188701 & Intron 1 & $\mathrm{~T}>\mathrm{C}$ & 19 & 39 & 12 & 0.45 & 0.58 \\
\hline $\begin{array}{l}\text { rs1127422 } \\
0\end{array}$ & 44191783 & Intron 1 & del>ins & 49 & 18 & 3 & 0.17 & 0.73 \\
\hline rs693955 & 44191920 & Intron 1 & $\mathrm{C}>\mathrm{A}$ & 49 & 18 & 3 & 0.17 & 0.73 \\
\hline rs1886884 & 44192158 & Intron 1 & $\mathrm{~T}>\mathrm{C}$ & 19 & 41 & 10 & 0.44 & 0.28 \\
\hline rs747199 & 44194345 & Intron 1 & $\mathrm{G}>\mathrm{C}$ & 43 & 26 & 2 & 0.21 & 0.71 \\
\hline rs9394992 & 44195992 & Intron 1 & $C>T$ & 34 & 30 & 6 & 0.30 & 0.99 \\
\hline rs324148 & 44196578 & Intron 1 & $\mathrm{G}>\mathrm{A}$ & 41 & 24 & 5 & 0.24 & 0.85 \\
\hline rs324149 & 44196995 & Intron 1 & $C>T$ & 36 & 32 & 2 & 0.26 & 0.26 \\
\hline $\begin{array}{l}\text { rs4557393 } \\
6\end{array}$ & 44198362 & Exon 9 & $\mathrm{~T}>\mathrm{C}$ & 67 & 3 & 0 & 0.02 & 0.98 \\
\hline rs1128930 & 44200325 & Intron 13 & $A>C$ & 20 & 37 & 13 & 0.45 & 0.85 \\
\hline rs760370 & 44200953 & Intron 14 & $A>G$ & 17 & 39 & 14 & 0.48 & 0.62 \\
\hline
\end{tabular}




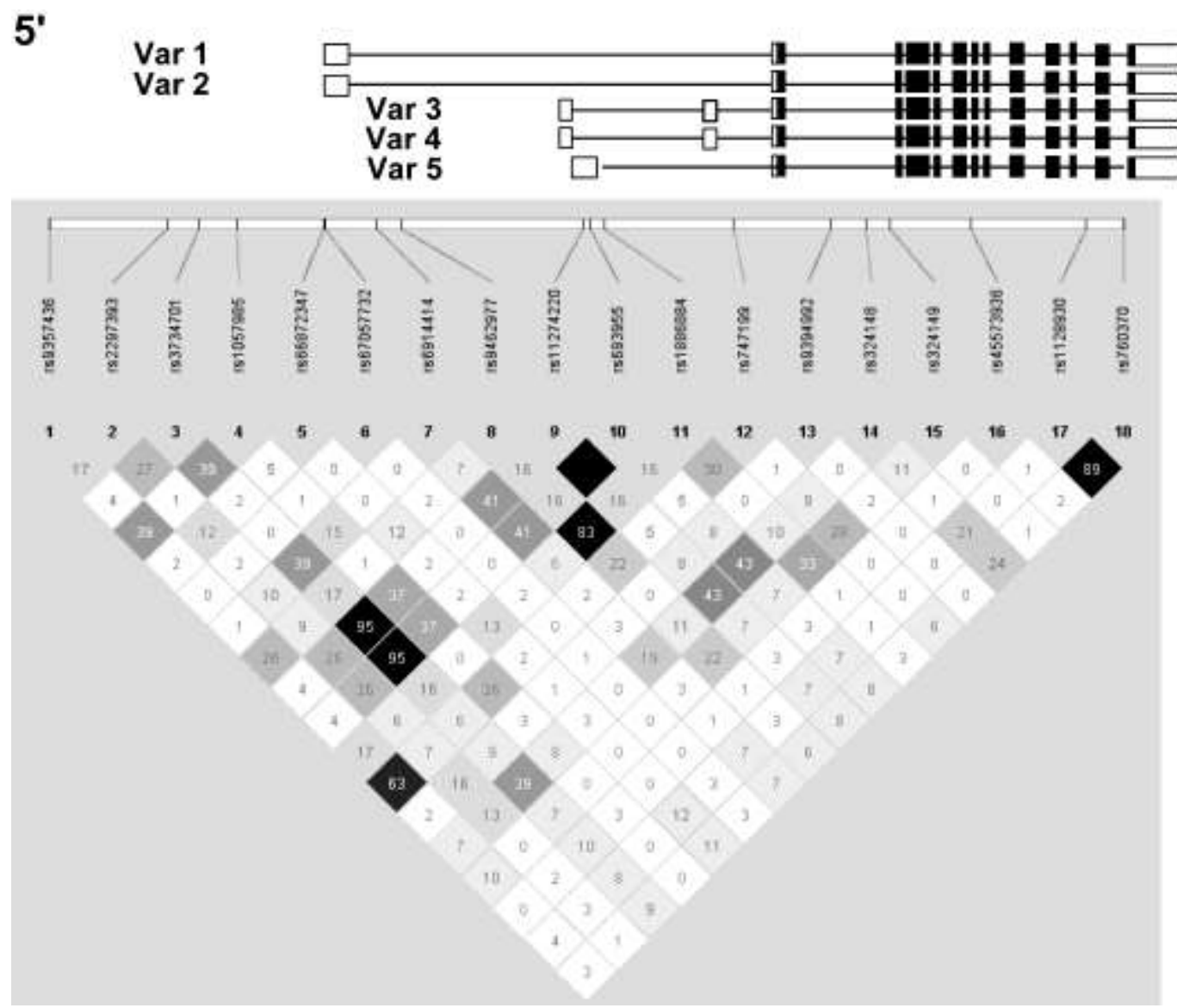

\section{Abbildung 9}

Genetische Architektur des ENT1 und Kopplung der analysierten 18 Polymorphismen. Illustriert sind die fünf Transkriptvarianten des ENT1 in Relation zu den Genpolymorphismen, deren paarweises Kopplungsungleichgewicht (linkage disequilibrium, $L D$ ) als Plot dargestellt ist. Die Zahlen und Farbkodierung in den Rauten geben die Stärke des $L D$ an: Je höher der Zahlenwert und je dunkler die Farbe, desto stärker ist das LD, d.h. umso stärker ist die genetische Kopplung und umso häufiger werden die betreffenden Allele gemeinsam vererbt. Ein dunkel-schwarzes Feld ohne Zahl steht für ein $L D$ von $100 \%$.

Nachfolgend sind Assoziationen mit einem statistischen Signifikanzniveau von 5\% zwischen ENT1-Genpolymorphismen einerseits und der ENT1-Basalexpression oder den Zytostatika-induzierten Effekten auf die Zellvitalität dargestellt. Im Sinne dieser Definition konnten in meiner Stichprobe von 72 Probanden für drei Genpolymorphismen signifikante Assoziationen gefunden werden.

Ein SNP in Intron 1 des ENT1 zeigte eine erhöhte Empfindlichkeit auf Gemcitabininduzierte Zytotoxizität in PBMCs, jedoch nicht in der Subgruppe der T-Lymphozyten (Abbildung 10). Diese Variante wurde auch an Proben einer vorangegangenen Studie (Preuß 2009) nachträglich bestimmt. Dabei war kein signifikanter Einfluss zu erkennen. Auch zeigte sich keine Abhängigkeit der ENT1-Expression von diesem SNP. 

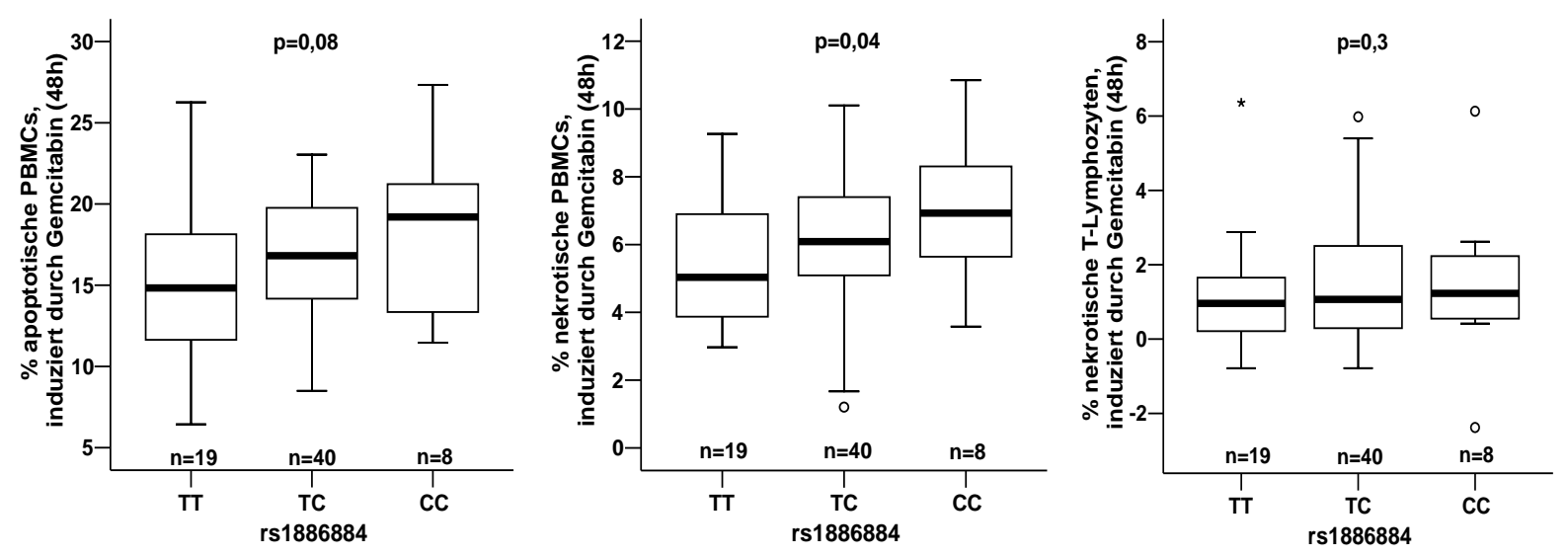

\section{Abbildung 10}

Einfluss des Intron-1-SNPs rs1886884 auf zytotoxische Effekte von Gemcitabin. Die Zellen wurden mit $10 \mu \mathrm{g} / \mathrm{ml}$ Gemcitabin für $48 \mathrm{~h}$ bei $37^{\circ} \mathrm{C}$ inkubiert. Links sind die Verhältnisse für Apoptose von PBMCs, in der Mitte für Nekrose von PBMCs und rechts für Nekrose von T-Lymphozyten dargestellt. Zur Testung einer statistischen Signifikanz wurde der Jonckheere-Terpstra-Trend-Test verwendet und die entsprechenden $p$-Werte sind angegeben.

Interessante Assoziationen zeigten sich für einen SNP in Exon 9 des ENT1, der zu einem Aminosäureaustausch von Isoleucin (lle) nach Threonin (Thr) an Position 216 führt. Wegen der Seltenheit des Variantenallels (Thr216) gab es in meiner Studienpopulation nur drei heterozygote Personen und niemanden mit Homozygotie für Thr216. Nach 48-stündiger Exposition gegenüber Cytarabin zeigte sich eine geringere Apoptoseinduktion für PBMCs für Thr216 (Abbildung 11, links). Auch diese Variante wurde nachträglich an den Proben des früheren Kollektivs (Preuß 2009) bestimmt. Hier war nur eine Person heterozygot für Thr216. Die Kombination mit meinen Daten ergab einen noch etwas stärkere Assoziation hinsichtlich Cytarabininduzierter Apoptose in PBMCs (Abbildung 11, rechts). Auch die von mir durchgeführte Subgruppenanalyse an T-Lymphozyten zeigte einen ähnlichen Effekt von Thr216 (Abbildung 12, links), wenngleich hier eine heterozygote Probe nicht auswertbar war.

Es stellt sich die Frage, ob dieser Aminosäureaustausch nicht nur die Aufnahme von Gemcitabin bzw. Cytarabin beeinflussen könnte, sondern eventuell auch die Bindung des ENT1-Inhibitors NBTI. Tatsächlich traten bei Verwendung von NBTI entgegengesetzte Effekte dieser Variante auf. Beim Ile216-Wildtyp wurde die Cytarabin-verursachte Apoptose durch NBTI im Mittel um etwa 20\% reduziert. In Gegenwart eines Thr216-Allels hatte NBTI praktisch keinen Effekt (Abbildung 12, rechts). Ähnliche Assoziationen des lle216Thr-Polymorphismus zeigten sich auch für Gemcitabin, allerdings nur für die 6-stündige Exposition (Abbildung 13). Nach $48 \mathrm{~h}$ 
Dauerinkubation bestand dieser Zusammenhang nicht. Eine Beziehung dieser Genvariante zur ENT1-Transkription konnte nicht festgestellt werden.
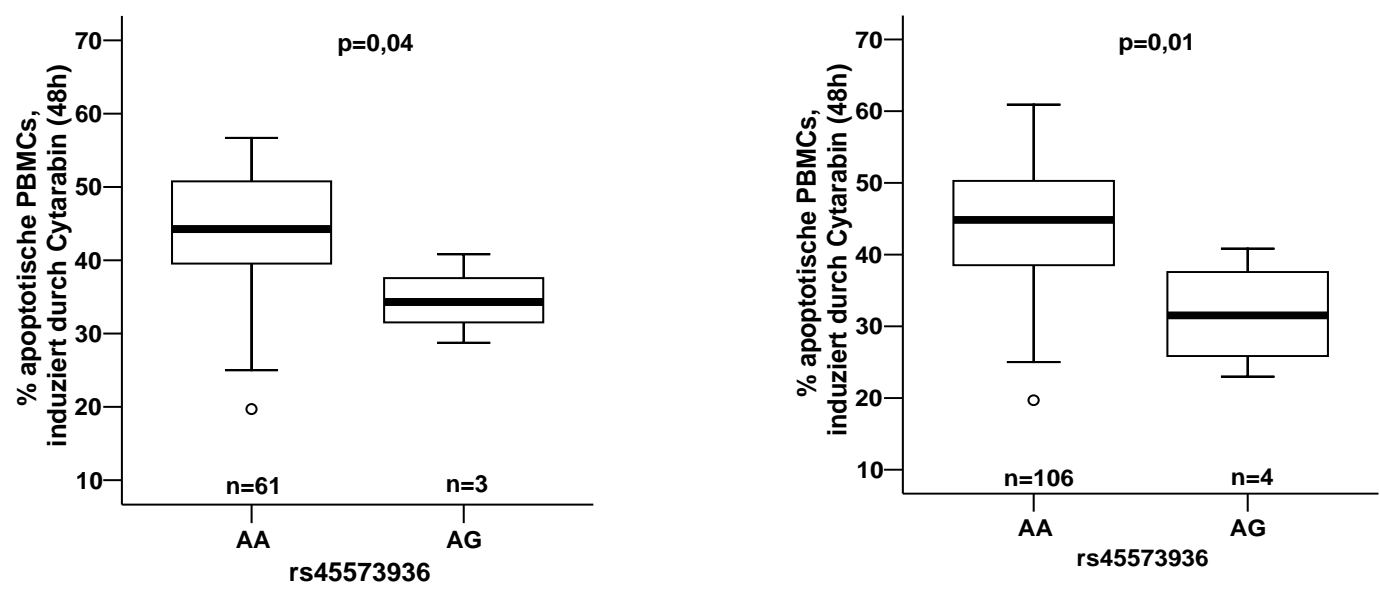

\section{Abbildung 11}

Von SNP rs45573936 (lle216Thr) abhängige Cytarabin-Toxizität in PBMCs. Links sind die Daten meiner Studie, rechts kombiniert mit einer früher in gleicher Weise durchgeführten Studie (Preuß 2009) dargestellt. Die Endkonzentration an Cytarabin betrug jeweils $10 \mu \mathrm{g} / \mathrm{ml}$. Ein Unterschied zwischen den beiden Genotyp-Gruppen wurde jeweils mit dem Mann-Whitney-U-Test geprüft und die entsprechenden $p$-Werte sind eingetragen.
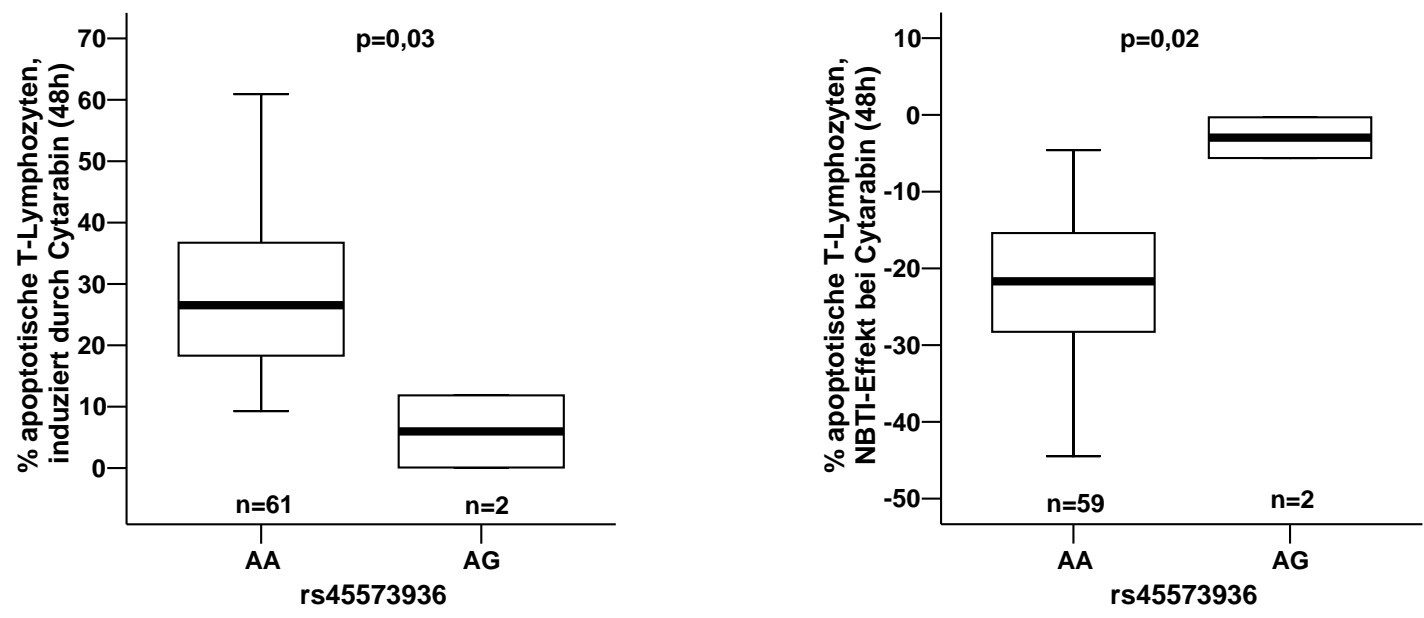

\section{Abbildung 12}

Von SNP rs45573936 (Ile216Thr) abhängige Cytarabin-Toxizität in T-Lymphozyten. Links sind die Cytarabin-Effekte $(10 \mu \mathrm{g} / \mathrm{ml})$ gegenüber der Kontrolle, rechts die Kombinationsbehandlung aus Cytarabin $(10 \mu \mathrm{g} / \mathrm{ml})$ mit dem ENT1-Inhibitor Nitrobenzylthioinosin (NBTI, $100 \mathrm{nM})$. Die statistische Signifikanzprüfung erfolgte mit dem Mann-Whitney-U-Test. 

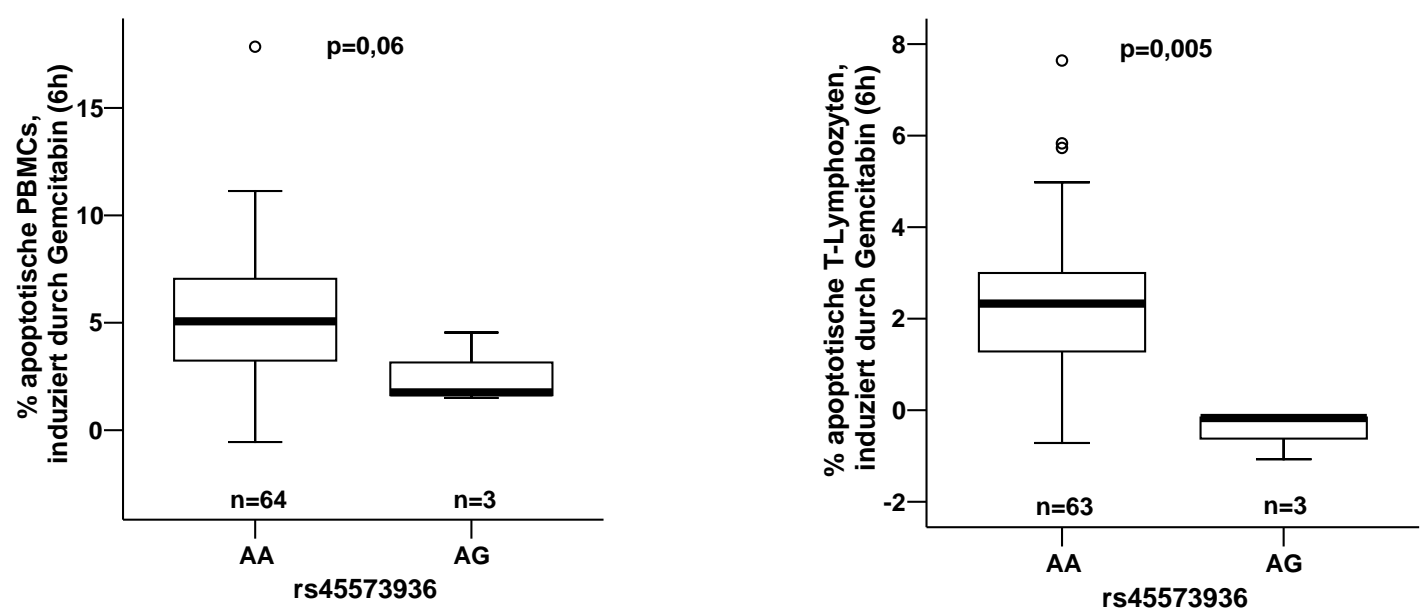

\section{Abbildung 13}

Von SNP rs45573936 (lle216Thr) abhängige Gemcitabin-Toxizität. Die Inkubationszeit war hier 6 h, links für PBMCs, rechts für T-Lymphozyten. Darstellung und Auswertung ansonsten wie in Abbildung 12

Ein dritter Polymorphismus, rs9394992, welcher im Intron 1 von ENT1 lokalisiert ist, zeigte in meiner Studie zwei interessante Assoziationen. Zum einen ging das TVariantenallel mit einer geringeren ENT1-Expression einher (Abbildung 14, links), zum anderen mit einer erhöhten Sensibilität gegenüber der zytotoxischen Wirkung von Cytarabin (Abbildung 15, links). Diese beiden Assoziationen wirkten sehr plausibel, daher wurde eine Nachanalyse der Proben aus der früheren Pilotstudie (Preuß 2009) in Bezug auf diesen Polymorphismus durchgeführt. Hinsichtlich der ENT1-Expression zeigte sich dabei kein Zusammenhang (Abbildung 14, rechts), bezüglich der Cytarabin-Empfindlichkeit ein entgegengesetzter Effekt. 

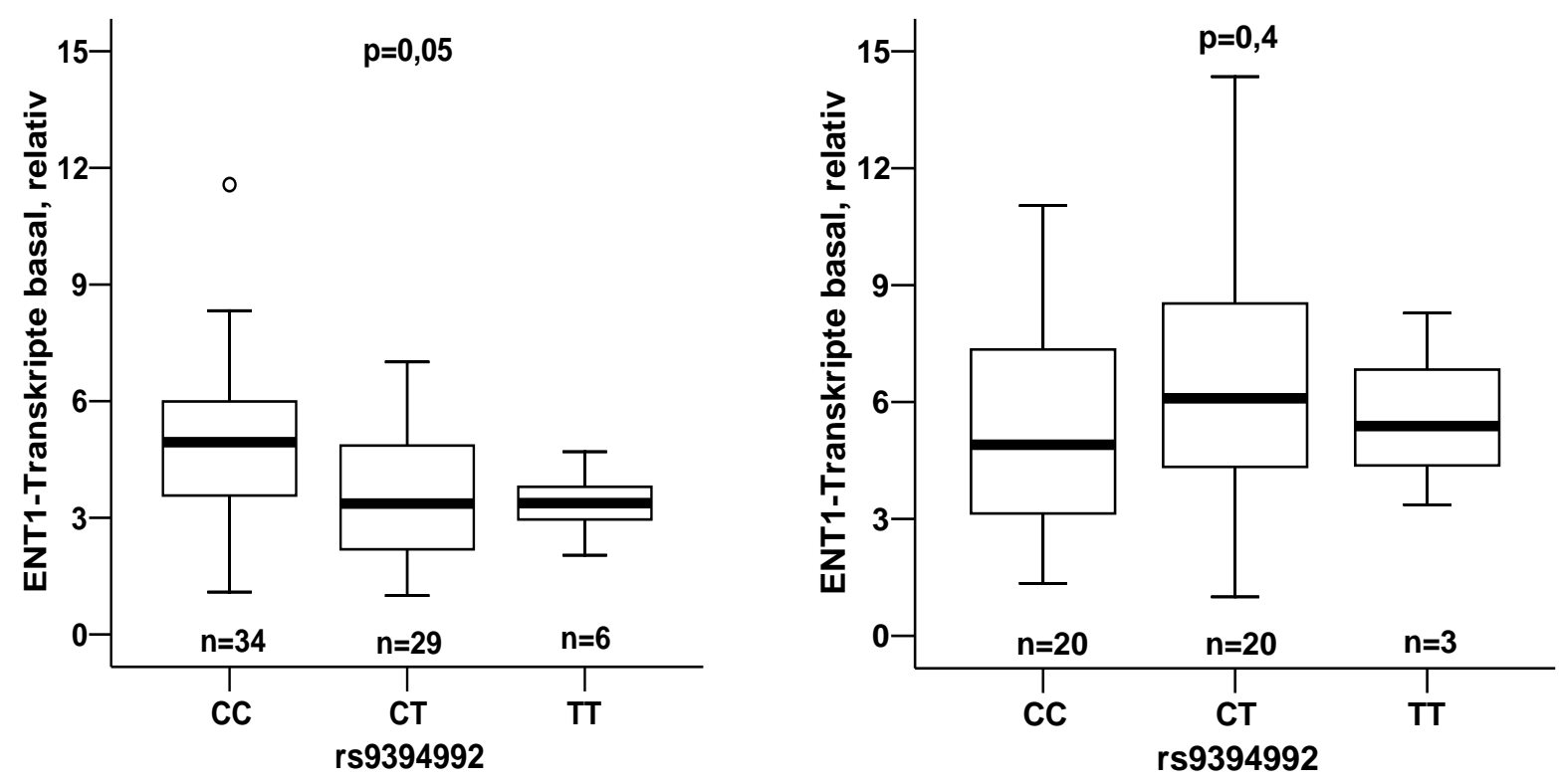

\section{Abbildung 14}

Einfluss des Intron-1-SNPs rs9394992 auf die basale ENT1-Transkription. Links sind die Daten aus meiner Studie, rechts zum Vergleich die aus einer früheren Studie (Preuß 2009) dargestellt. Aus PBMCs wurde nach $24 \mathrm{~h}$ Inkubation ex vivo bei $37^{\circ}$ RNA isoliert und revers transkribiert. Die gemessenen Rohdaten der ENT1-mRNA-Expression wurden zunächst auf die Referenzgene GAPDH und HPRT1 normiert und dann in Bezug zum niedrigsten Wert der jeweiligen Messserie bezogen. Die angegebenen $p$-Werte wurden mit dem Jonckheere-Terpstra-Trend-Test ermittelt.
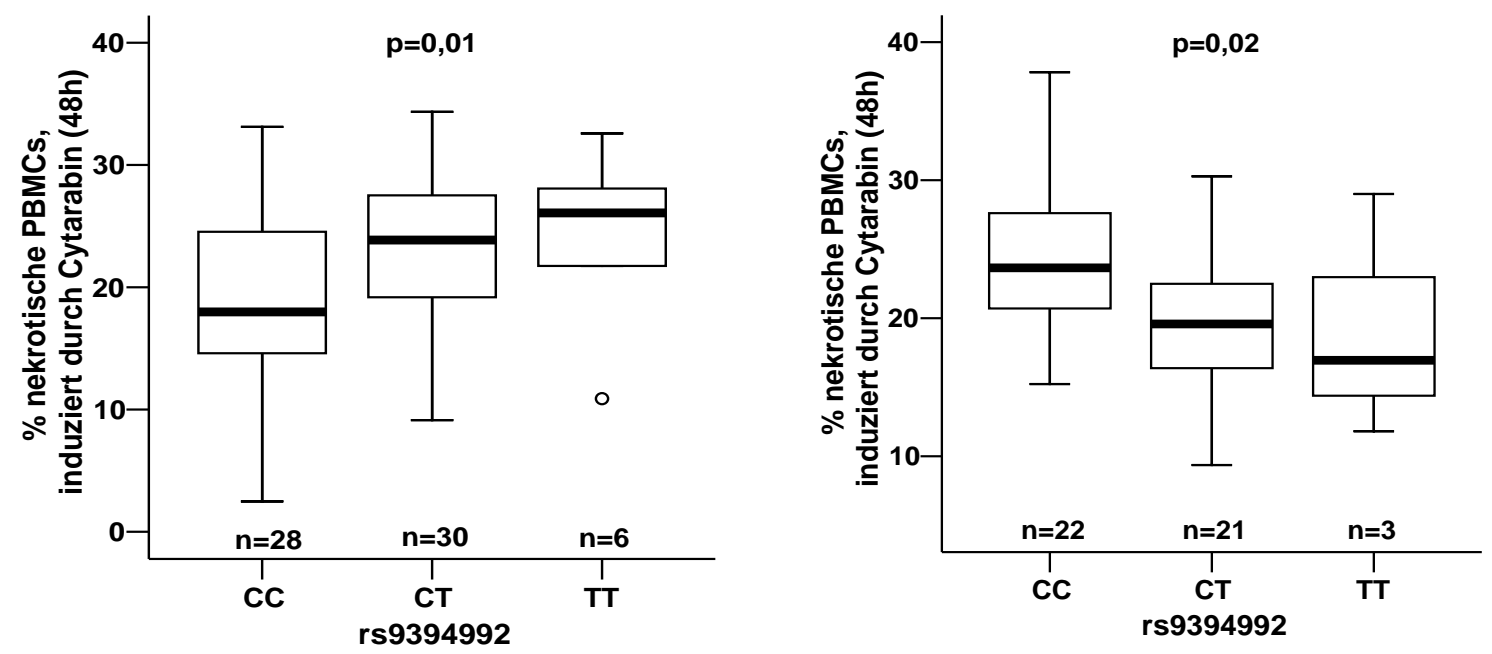

\section{Abbildung 15}

Einfluss des Intron-1-SNPs rs9394992 auf die Cytarabin-vermittelte Nekrose von PBMCs. Die Zellen wurden $48 \mathrm{~h}$ ex vivo bei $37^{\circ} \mathrm{C}$ mit $10 \mu \mathrm{g} / \mathrm{ml}$ Cytarabin behandelt. Der gegenüber einer Kontrolle ohne Cytarabin induzierte Anteil apoptotischer Zellen ist in Abhängigkeit der Genotypen von rs9394992 aufgetragen, links die Daten aus meiner Studie, rechts von Preuß 2009 mit p-Werten entsprechend des Test nach Jonckheere-Terpstra. 


\subsection{Lymphoblastoide Zelllinien}

\subsubsection{Nukleosid-induzierte Apoptose und Nekrose}

Zunächst sollte die funktionelle Variabilität der Apoptose- bzw. Nekroserate von LCLs nach $48 \mathrm{~h}$ Inkubation mit Cytarabin und Gemcitabin untersucht werden. Wie in Abbildung 16 ersichtlich, zeigte sich bei beiden Substanzen eine nahezu vollständige Korrelation. Daher wurde im Weiteren nur noch die durch Annexin gemessene Apoptoserate betrachtet. Auffallend war, dass bei den LCLs die Zytotoxizität von Gemcitabin - im Gegensatz zu den PBMCs - deutlich stärker war als bei Cytarabin.
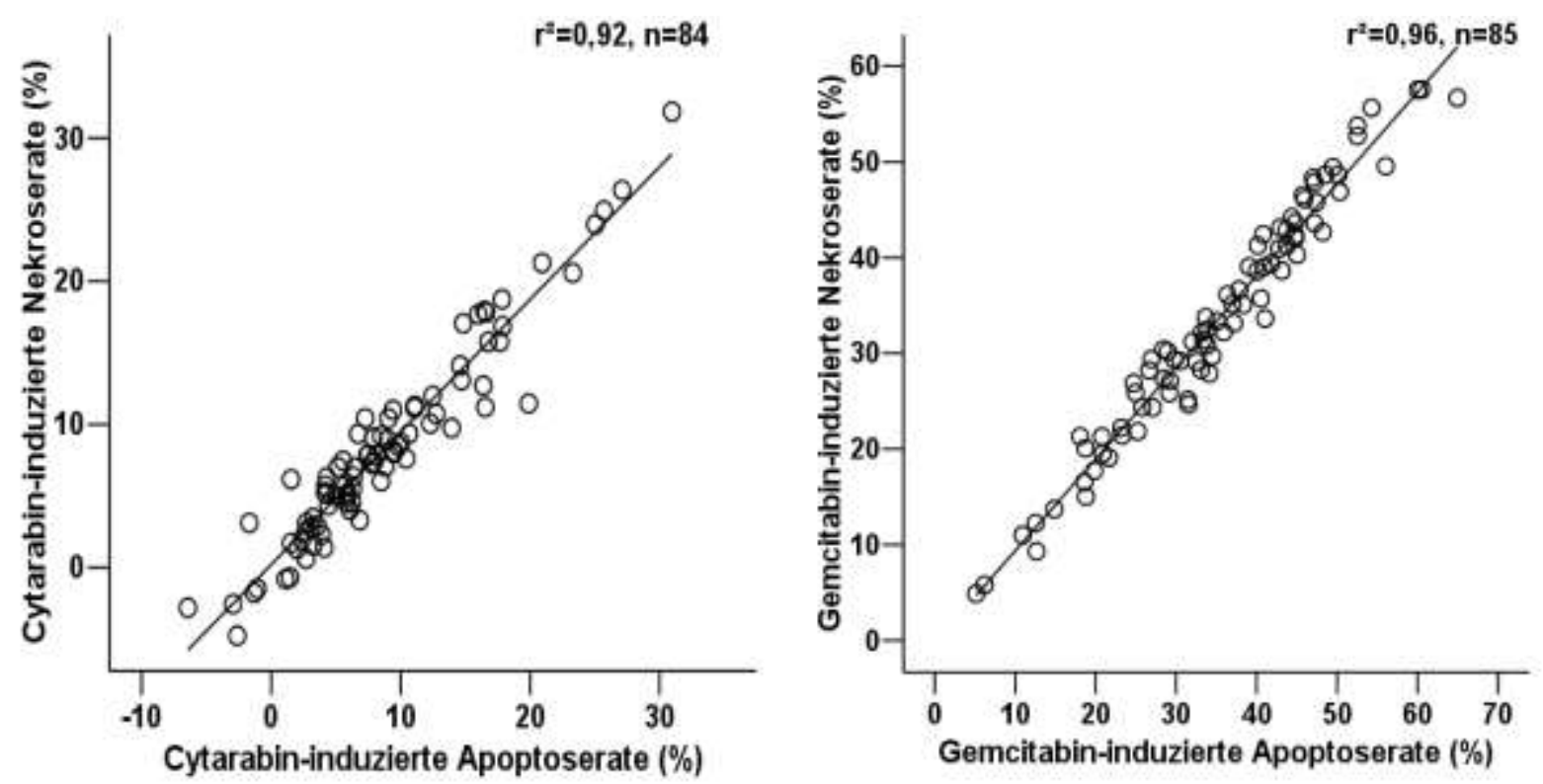

\section{Abbildung 16}

Korrelation zwischen Apoptose und Nekrose bei LCLs. Die Zellen wurden mit Cytarabin und Gemcitabin in einer Konzentration von $10 \mu \mathrm{g} / \mathrm{ml}$ für $48 \mathrm{~h}$ bei $37^{\circ} \mathrm{C}$ inkubiert. Im Abstand von mindestens einer Woche wurde das Experiment wiederholt. Dieser Grafik liegen die Daten aus beiden Messungen pro Zelllinie zu Grunde. Angegeben ist das Bestimmtheitsmaß $\mathrm{r}^{2}$ als Ausdruck der Korrelation der beiden Messparameter Apoptose und Nekrose, welche jeweils in Bezug zu einer Zytostatika-freien Kontrolle gesetzt wurden.

Weiterhin sollte die Verteilung der Nukleosid induzierten Apoptoserate in LCLs dargestellt werden, um gegebenenfalls auch parametrische Tests anwenden zu können. Hierfür konnte bei beiden Medikamenten an beiden Messtagen eine Normalverteilung angenommen werden (Abbildung 17; $\mathrm{p}$-Werte nach Shapiro-WilkTest alle $>0,1$ ). 

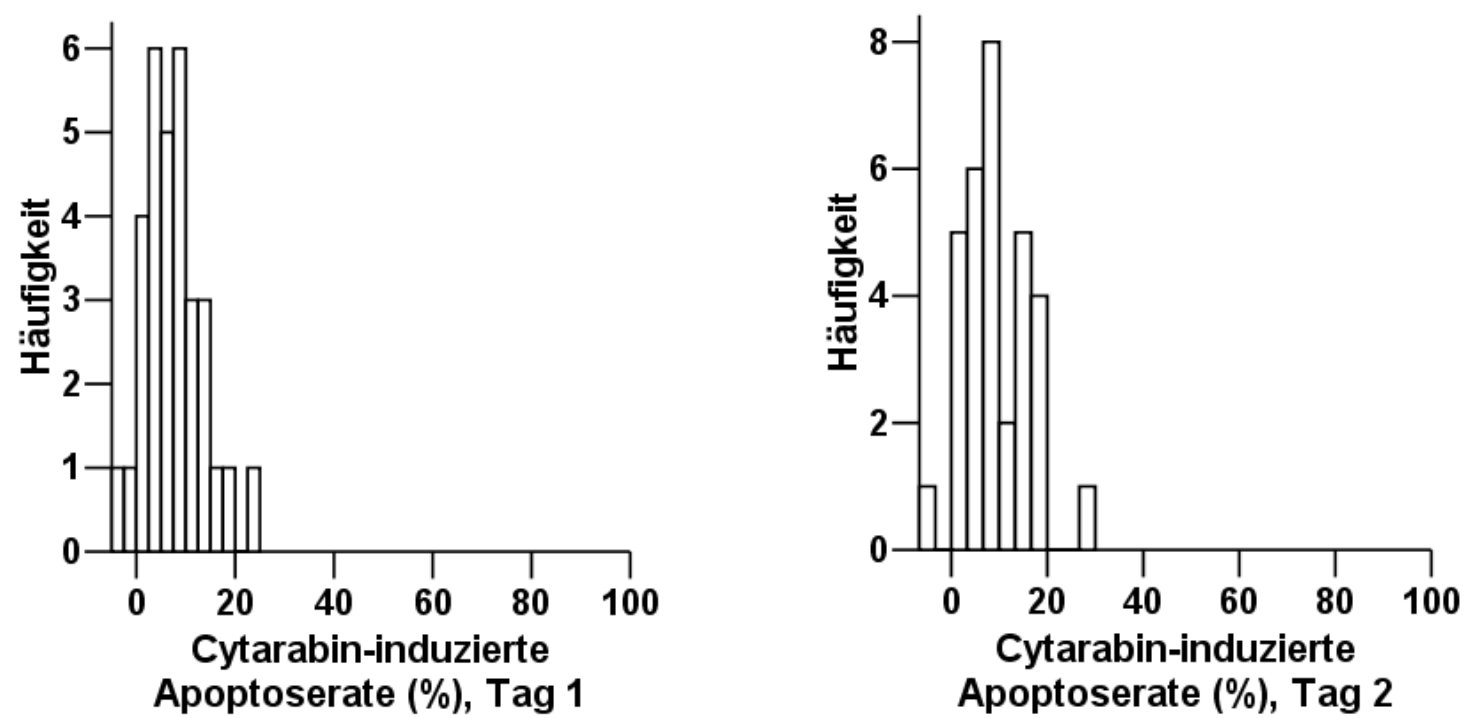

Apoptoserate (\%), Tag 2
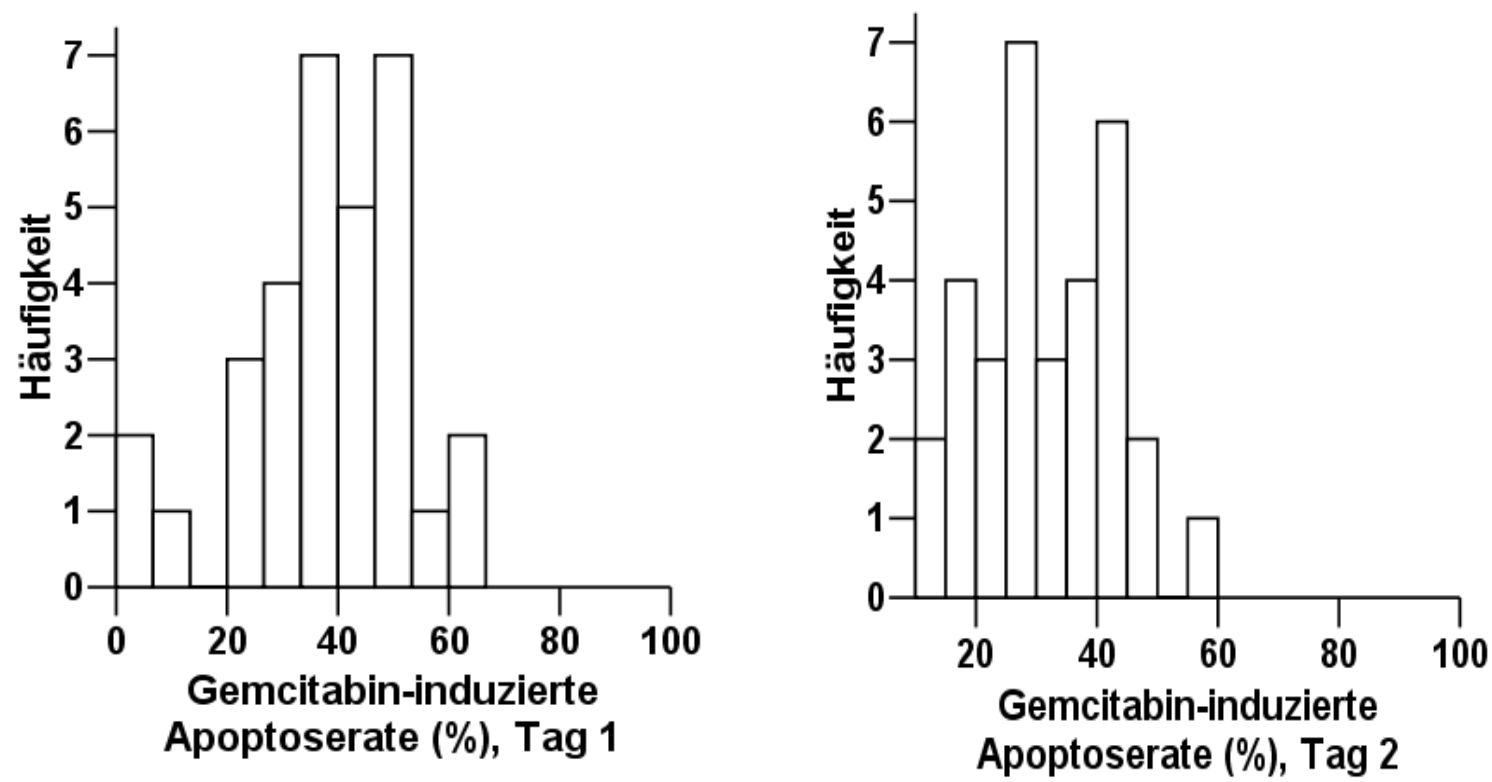

\section{Abbildung 17}

Häufigkeitsverteilung der induzierten LCL-Apoptose. Oben sind die Verteilungen für Cytarabin, unten für Gemcitabin, jeweils für die erste Messung (Tag 1, links) bzw. die Wiederholungsmessung (Tag 2, rechts) veranschaulicht. Die Zellen wurden mit beiden Substanzen in einer Konzentration von $10 \mu \mathrm{g} / \mathrm{ml}$ für $48 \mathrm{~h}$ bei $37^{\circ} \mathrm{C}$ behandelt.

Um später den Einfluss von Genvarianten (welche in diesem Versuchsansatz als unveränderlich betrachtet werden können) auf die induzierte Zellapoptose untersuchen zu können, musste sicher gestellt werden, dass die funktionellen Messungen innerhalb der einzelnen Zelllinien reproduzierbar waren. Dazu wurden die Messwerte für die Nukleosid induzierte Apoptose zwischen den beiden Messtagen korreliert. Bei Cytarabin fand sich eine mäßige Korrelation (Abbildung 18, 
links), bei Gemcitabin war diese nur sehr gering ausgeprägt (Abbildung 18, Abbildung 19, rechts).
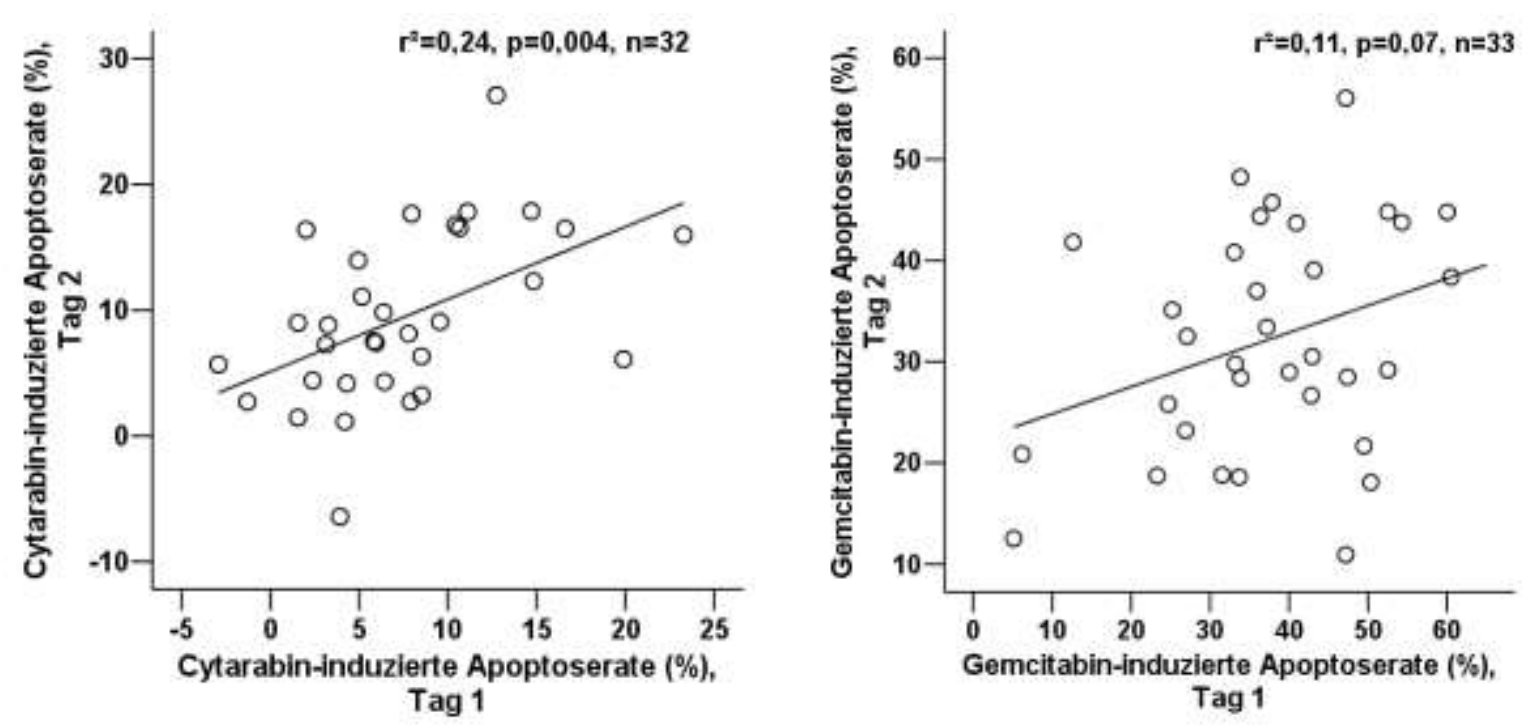

\section{Abbildung 18}

Korrelation der induzierten LCL-Apoptoserate zwischen den beiden Messtagen. Die Versuchsbedingungen sind in Abbildung 17 beschrieben.

Analog sollte die mit dem MTT-Assay ermittelte Zellvitalität zwischen den beiden Messtagen verglichen werden. Eine Korrelation fand sich dabei weder für Gemcitabin noch für Cytarabin (Abbildung 19). Weil bei den FACS-Analysen im Gegensatz zu den MTT-Messungen eine zumindest mäßige (und im Falle von Cytarabin auch deutlich statistisch signifikante) Inter-Messtag-Korrelation vorhanden war, wurden für die späteren Vergleiche mit den Genotypen nur die Daten aus den FACSMessungen verwendet. 

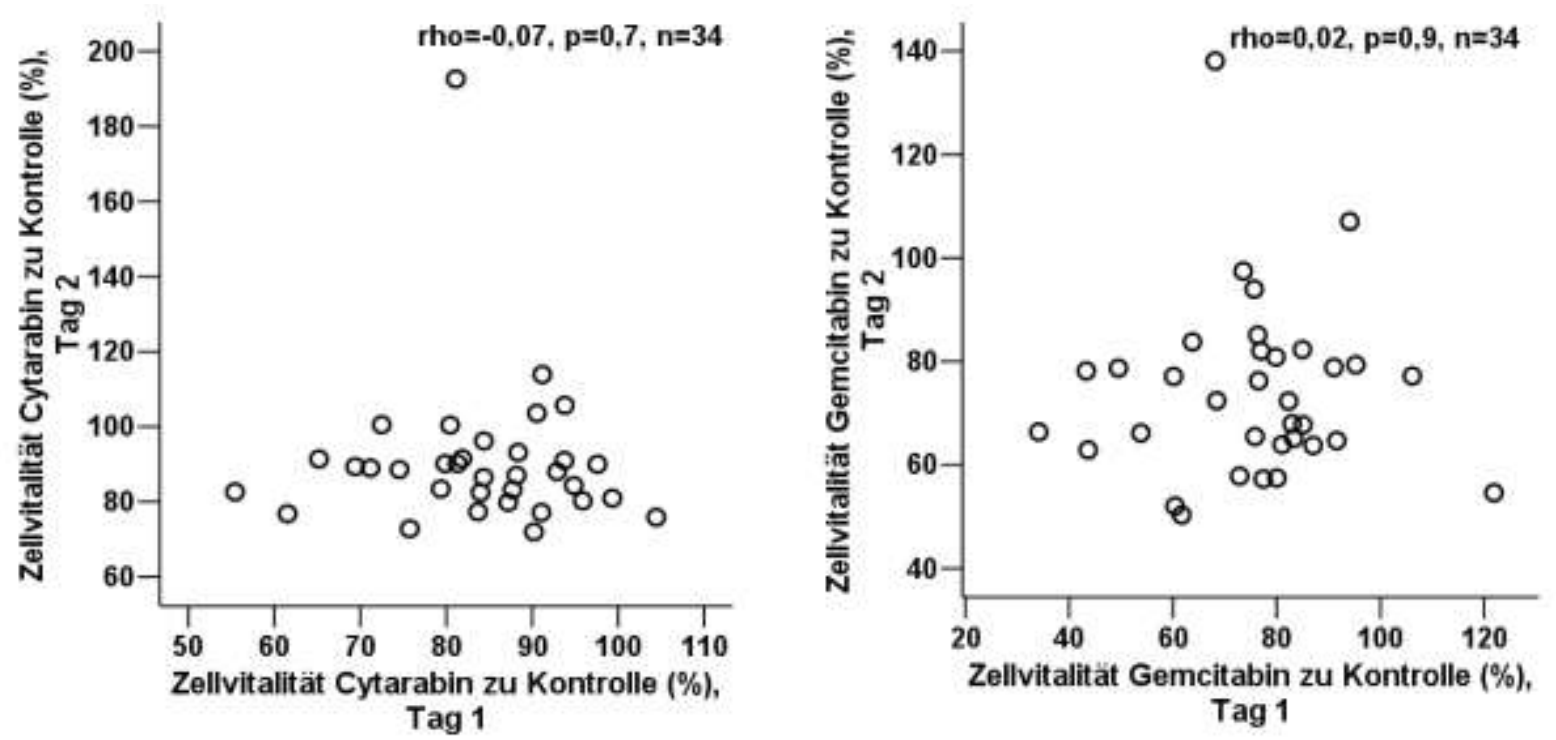

\section{Abbildung 19}

Inter-Messtag-Korrelation der Effekte von Cytarabin und Gemcitabin auf die Zellvitalität, gemessen mit dem MTT-Assay. Die Stärke der Korrelation wurde mit dem nicht-parametrischen Spearman-rhoKoeffizienten bestimmt. Zu den Inkubationsbedingungen siehe Abbildung 17

Wurde die mit FACS gemessene induzierte Apoptose mit der durch MTT-Assay ermittelten Veränderung der Zellvitalität verglichen, konnte bei Gemcitabin an beiden Messtagen eine signifikante, wenngleich nur mäßig ausgeprägte Korrelation festgestellt werden (Abbildung 20). Eine höhere Apoptoserate war dabei tendenziell mit einer verringerten Zellvitalität verbunden. Bei Cytarabin zeigte sich eine solche Korrelation zwischen FACS und MTT nicht $(p>0,1)$.
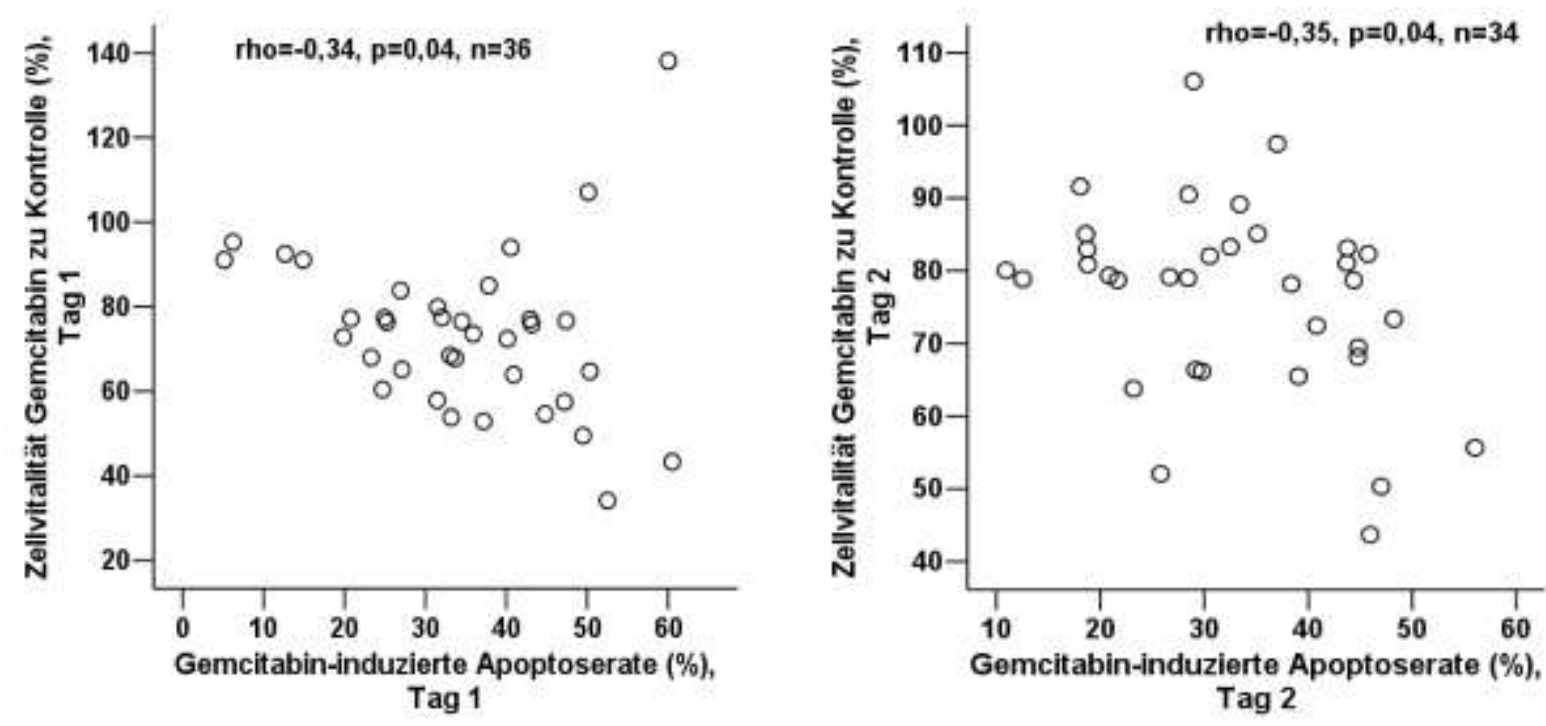

\section{Abbildung 20}

Vergleich der Effekte von Gemcitabin auf Apoptose und Zellvitalität. Die Daten sind für die Erstmessung (Tag1) und die Wiederholung (Tag2) getrennt dargestellt. Zu den Inkubationsbedingungen siehe Abbildung 17 Die Stärke der Korrelation wurde wegen signifikanter Abweichung von einer Normalverteilung mit dem Koeffizient nach Spearman rho ermittelt. 


\subsubsection{Einfluss von NBTI auf Nukleosid-induzierte Reduktion der Zellvitalität}

Bei den Zellen aus der Probandenstudie war eine starke Verminderung der Cytarabin-ausgelösten Apoptose-Induktion durch den ENT1-Inhibitor NBTI beobachtet worden (Abbildung 8). In ähnlicher Weise sollte nun bei den LCLs untersucht werden, ob sich NBTI auf die Gemitabin- und Cytarabin-vermittelte Reduktion der Zellvitalität auswirkt. Wie schon bei den PBMCs zeigte sich ein deutlich protektiver Effekt von NBTI in Bezug auf die durch Cytarabin reduzierte Zellvitalität (Abbildung 21). In markantem Gegensatz dazu war ein solcher Effekt bei Gemcitabin nicht vorhanden.

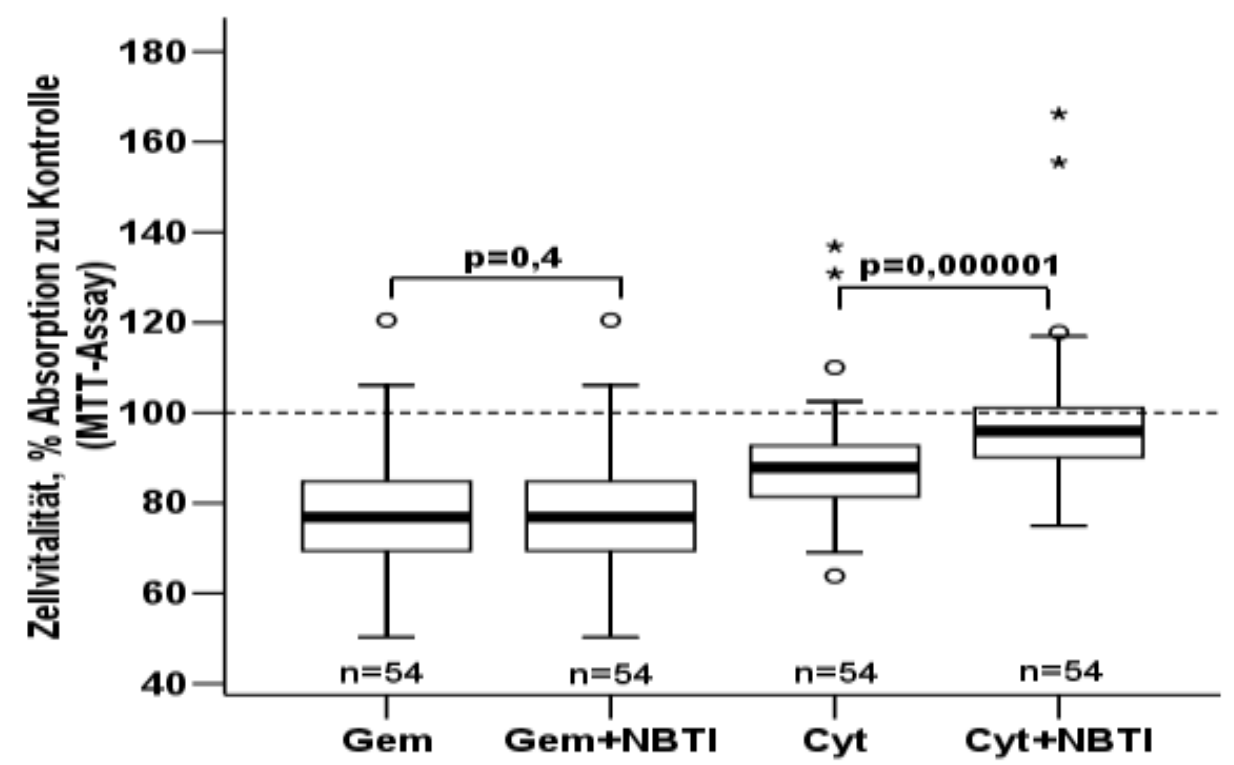

Abbildung 21

Effekte von Nitrobenzylthioinosin auf die Zytostatika-induzierte Vitalität von LCLs. Cytarabin und Gemcitabin wurden dabei in einer Konzentration von $10 \mu \mathrm{g} / \mathrm{ml}$, Nitrobenzylthioinosin (NBTI) von $100 \mathrm{nM}$ eingesetzt. Die Inkubationszeit war hier $24 \mathrm{~h}$ bei $37^{\circ} \mathrm{C}$.

\subsubsection{Einfluss von Genvarianten in Nukleosid-Kandidatengenen auf induzierte Apoptose}

Auf Grund der nur bei den FACS-Messungen zwischen den beiden Messtagen korrelierten Apoptoseraten wurden nur diese für die Genotyp-Analysen berücksichtigt. Dabei war man sich bewusst, dass diese Daten mittelgradig (bei Cytarabin, Korrelationskoeffizient $r \sim 0,5$ ) bzw. nur mäßig positiv (Gemcitabin, $r \sim 0,33)$ zwischen den beiden unabhängigen Messtagen korrelierten. Für die Apoptosedaten wurden die Mittelwerte aus den beiden Messtagen gebildet und zu den aus der HapMap-Datenbank extrahierten Genpolymorphismen in zwölf Genen 
für Transport und Metabolismus von Pyrimidin-Nukleosid-Analoga in Beziehung gesetzt. Bei der Auswahl dieser Gene wurde berücksichtigt, ob diese in nennenswertem Ausmaß in B-Lymphozyten bzw. Iymphoblastoiden B-Zellen wie den LCLs exprimiert werden. Für jedes dieser Gene (inklusive eines flankierenden Bereichs von je 10 kb im 5'- und 3'-Bereich) wurden alle in der HapMap-Datenbank verzeichneten Polymorphismen betrachtet. Positionen, bei denen nur ein Allel auftrat, wurden nicht weiter analysiert.

Nachfolgend sind die Assoziationsanalysen der Apoptosemessungen mit Genvarianten zunächst in Nukleosid-Transportern und dann in metabolisierenden Genen aufgeführt. Die Angaben über die genomische Lokalisation beziehen sich dabei jeweils auf die Version 36.3 der NCBI-Datenbank (Build 36.3). In den Grafiken sind die Assoziationen zwischen den einzelnen Genpolymorphismen einerseits und den Apoptosemessungen andererseits als negativer dekadischer Logarithmus des mit dem Jonckheere-Terpstra-Tests ermittelten $p$-Wertes dargestellt. Ein Wert auf der y-Achse von 1,3 entspricht dabei dem nominalen Signifikanzniveau von 0,05. In Anbetracht der großen Zahl der analysierten Genpolymorphismen sollte zur Reduktion der Zahl falsch positiver Befunde eine Assoziation jedoch deutlich unter 0,05 bzw. in der grafischen Darstellung deutlich über 1,3 liegen (Problem des multiplen Testens).

Beim ENT1 zeigte sich weder für Cytarabin noch für Gemcitabin ein relevanter Einfluss von Genpolymorphismen (Abbildung 22). Der Wert von 1,5 für lediglich eine Genvariante bedeutet nur ein geringfügiges Überschreiten des Grenzwertes für die nominale statistische Signifikanz und wird wegen der großen Zahl der betrachteten Varianten als nicht relevant angesehen. 


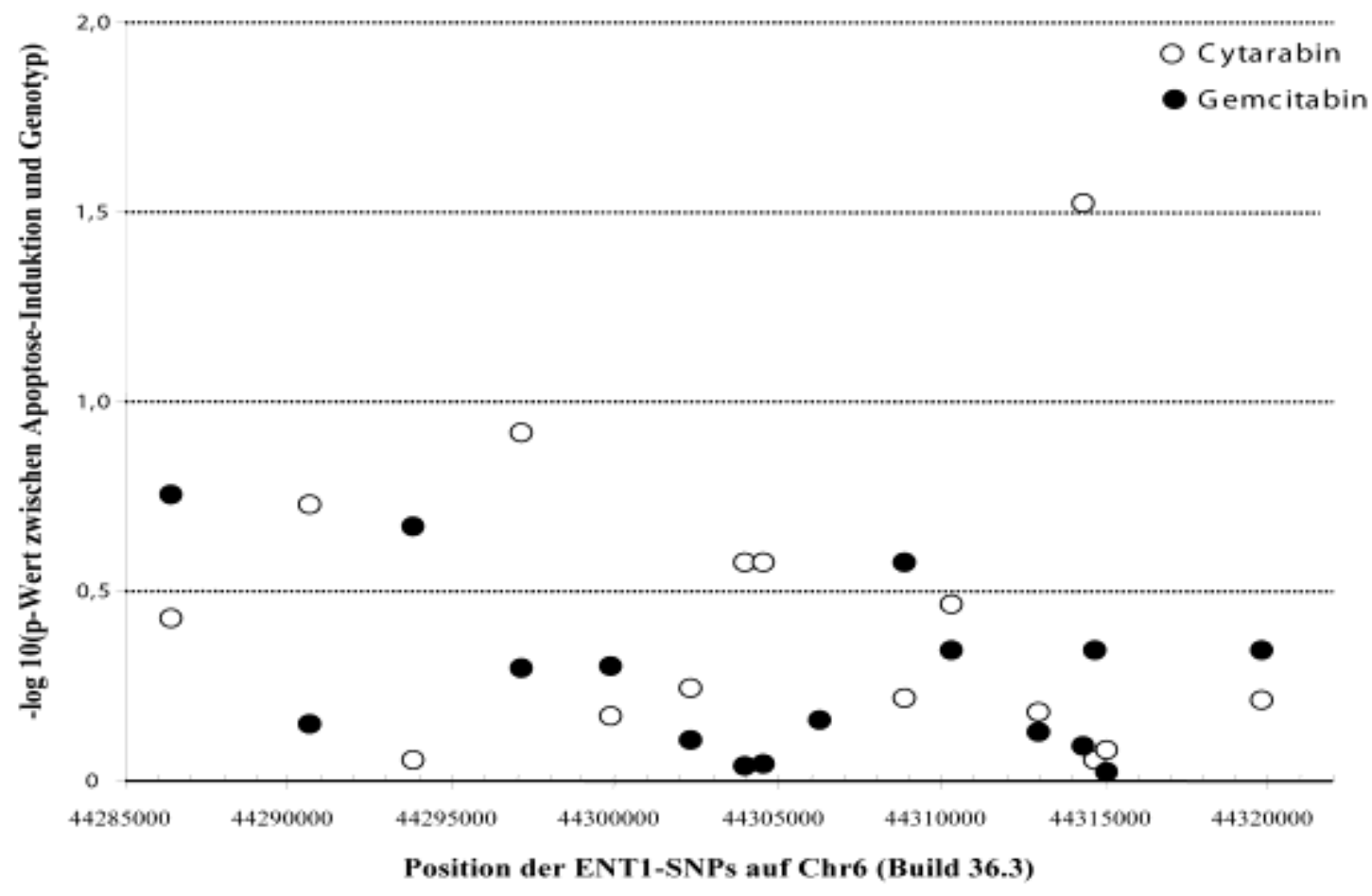

\section{5'}

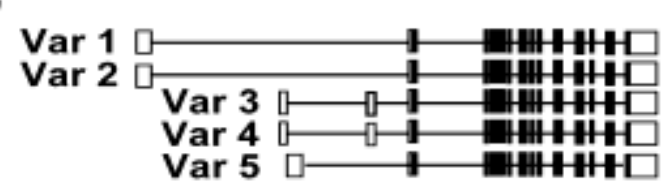

3'
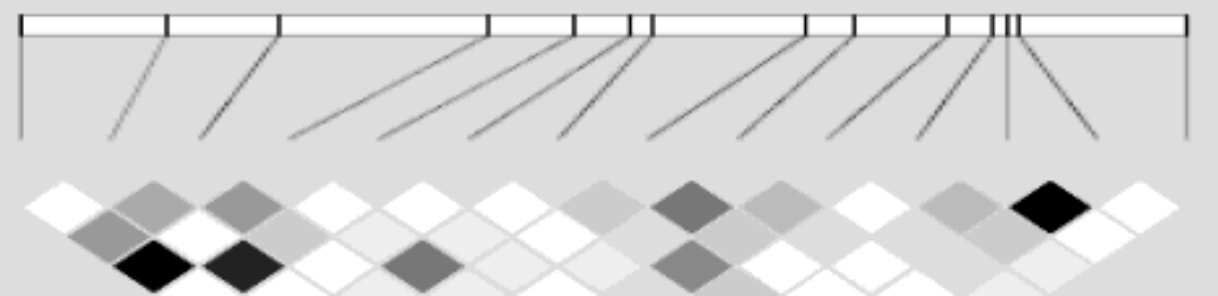

\section{Abbildung 22}

Induzierte LCL-Apoptose in Relation zu ENT1-Genpolymorphismen. Im oberen Teil es Bildes ist für jeden Polymorphismus der negative dekadische Logarithmus des p-Wertes der Assoziation mit der Apoptoseinduktion durch Cytarabin (weiße Kugeln) und Gemcitabin (schwarze Kugeln) aufgetragen. Apoptose der LCLs wurde durchflusszytometrisch nach $48 \mathrm{~h}$ Inkubation bei $37^{\circ} \mathrm{C}$ mit $10 \mu \mathrm{g} / \mathrm{ml}$ Cytarabin bzw. Gemcitabin ermittelt. Die statistische Testung auf Genotyp-Phänotyp-Assoziation erfolgte mit dem Jonckheere-Terpstra-Trend-Test. Ein Wert von 1,3 in der Grafik entspricht dabei einem Signifikanzniveau von 0.05. In der Mitte ist die genomische Struktur des Gens schematisch dargestellt, darunter die paarweise genetische Kopplung der Polymorphismen. Die Lokalisationsangaben auf der Abszisse des oberen Bildteils beziehen sich auch auf das Schema der Genstruktur und den Kopplungsplot (zu dessen näherer Erläuterung siehe Abbildung 9). 
Hinsichtlich des CNT1 zeigte sich für ein Cluster von Polymorohismen im mittleren Genbereich eine Beeinflussung der induzierten Apoptose von LCLs für Gemcitabin, jedoch nicht für Cytarabin (Abbildung 23). In diesem Cluster befindet sich der Aminosäureaustausch Asn521Asp in Exon 13 (dbSNP-Datenbank: rs2242046, $p=0,03$ für Induktion von Apoptose und $p=0,006$ von Nekrose, Abbildung 24). Bei Vorliegen der Aspartat-Variante war eine höhere Sensitivität gegenüber Gemcitabin zu verzeichnen. Bezüglich der Nekrose zeigte rs2242046 die stärkste Assoziation aller CNT1-SNPs. 

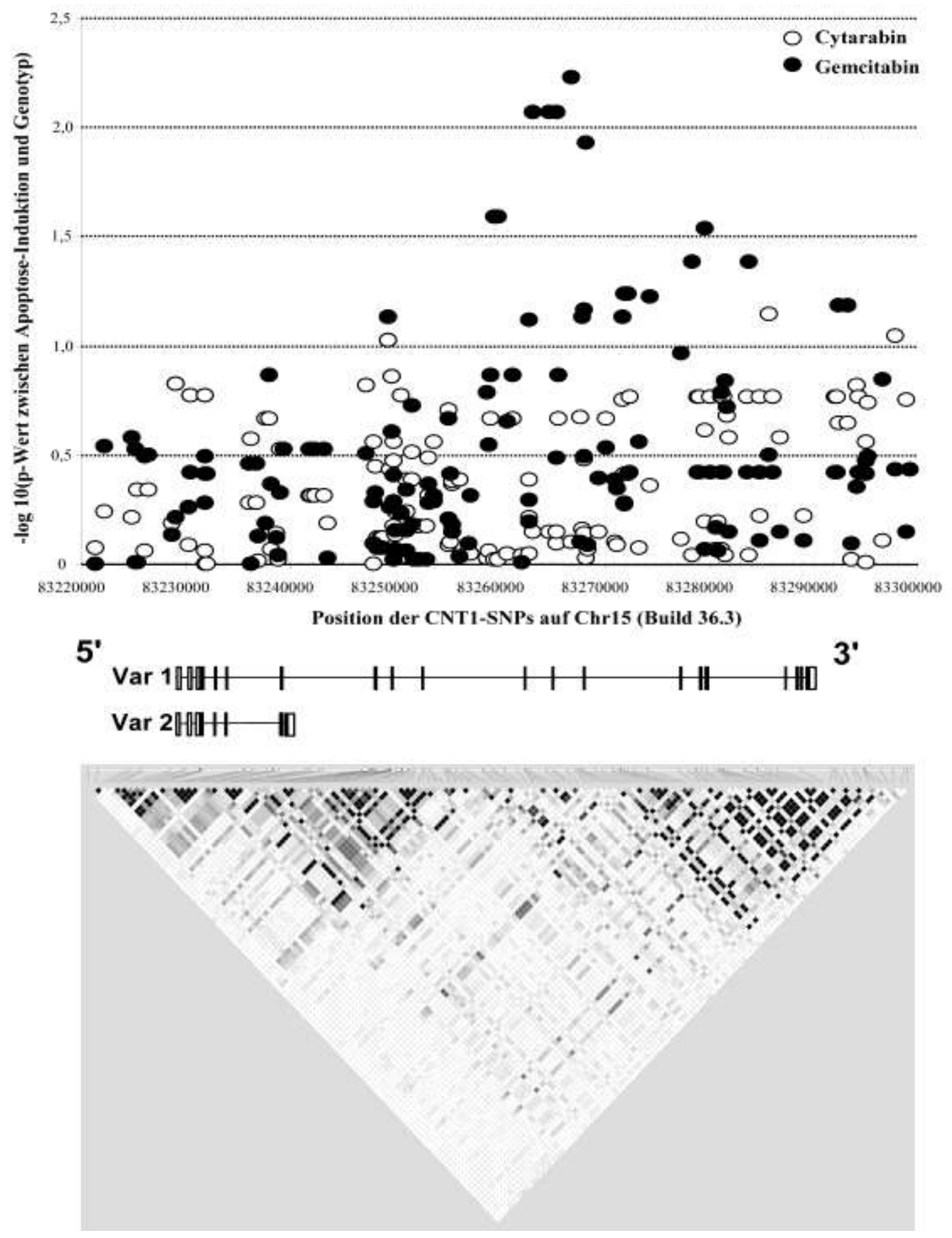

Abbildung 23

Induzierte LCL-Apoptose in Relation zu CNT1-Genpolymorphismen. Darstellungsweise analog zu Abbildung 22 


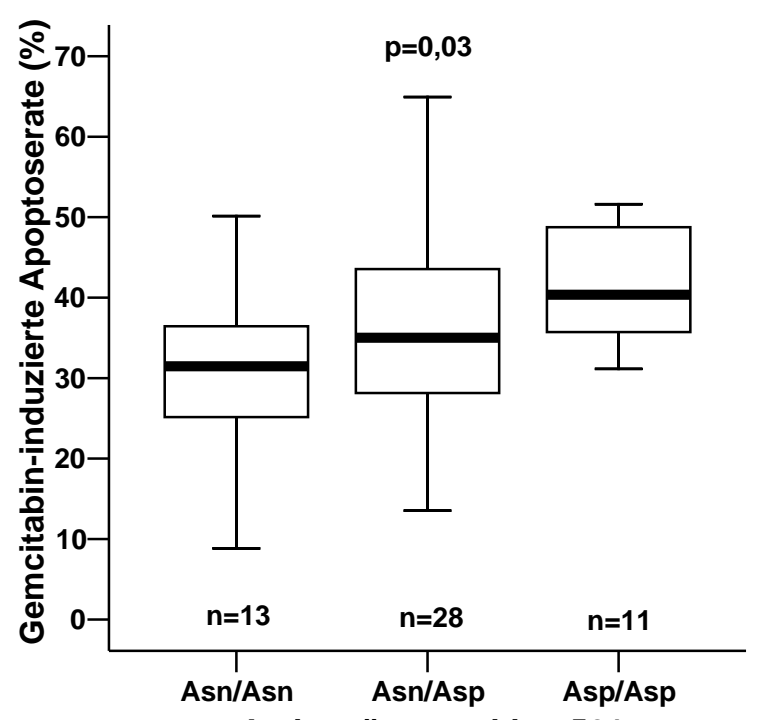

Aminosäureposition 521

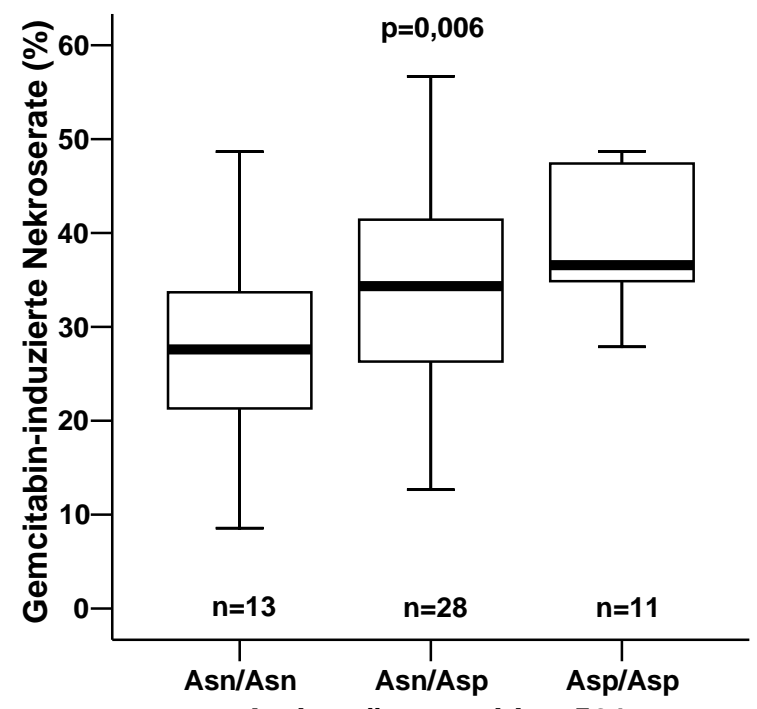

Aminosäureposition 521

\section{Abbildung 24}

Asn521Asp und Nukleosid-Analoga-induzierte Zytotoxizität. Die Versuchsbedingungen entsprechen denen von Abbildung 22 Die p-Werte wurden mit dem Trend-Test nach Jonckheere-Terpstra berechnet.

Ähnlich wie beim CNT1 waren für eine Gruppe von SNPs im CNT3 Assoziationen von $p<0,05$ mit der Gemcitabin-vermittelten Apoptose zu sehen. Das stärkste Signal zeigte dabei ein SNP in Intron 4, rs13288052, mit $p=0,002$ bzw. einem Wert von 2,7 auf der $y$-Achse in der nachstehenden Abbildung 25. Auch die übrigen 14 SNPs mit $p<0,05$ lagen entweder in intronischen Bereichen oder jenseits des 3'-Endes des transkribierten Gens. Auf die Cytarabin-induzierte Apoptose hatten diese Genvarianten keinen Einfluss. 

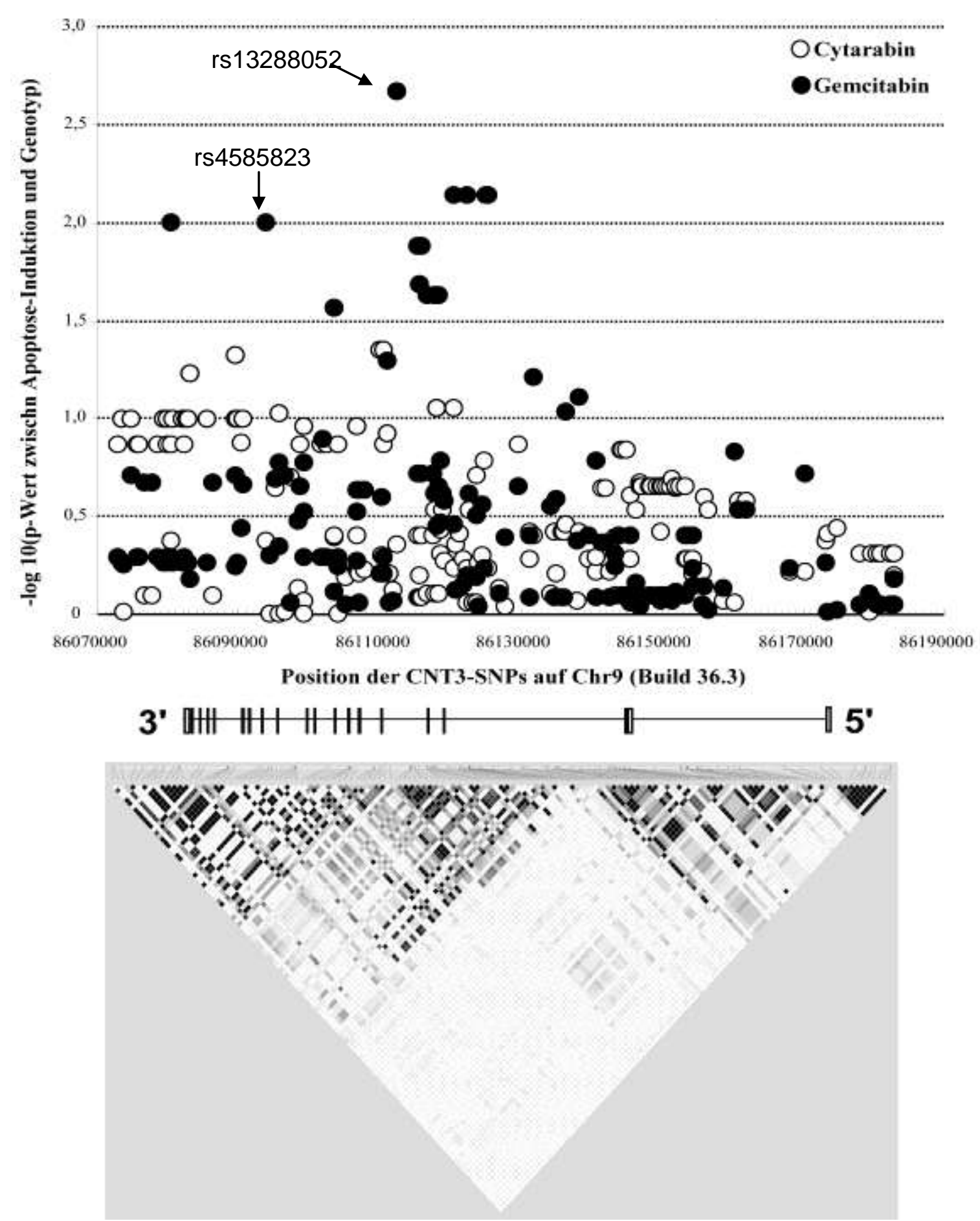

\section{Abbildung 25}

Induzierte LCL-Apoptose in Relation zu SLC28A3-Genpolymorphismen. Die Darstellungsweise entspricht der in Abbildung 22

Im gesamten Genbereich der DCK besteht ein starkes genetisches Kopplungsungleichgewicht (engl. linkage disequilibrium). Dies wird in Abbildung 26 durch einen großen Block dunkel gefärbter Rauten als Ausdruck des paarweisen Kopplungsgrades dargestellt. Lediglich zwei Polymorphismen, die ihrerseits eng miteinander gekoppelt sind, durchbrechen den großen Block. Eine Assoziation mit 
der Zytotoxizität von Cytarabin oder Gemcitabin lag für keinen dieser DCKPolymorphismen vor.

\section{DCK}
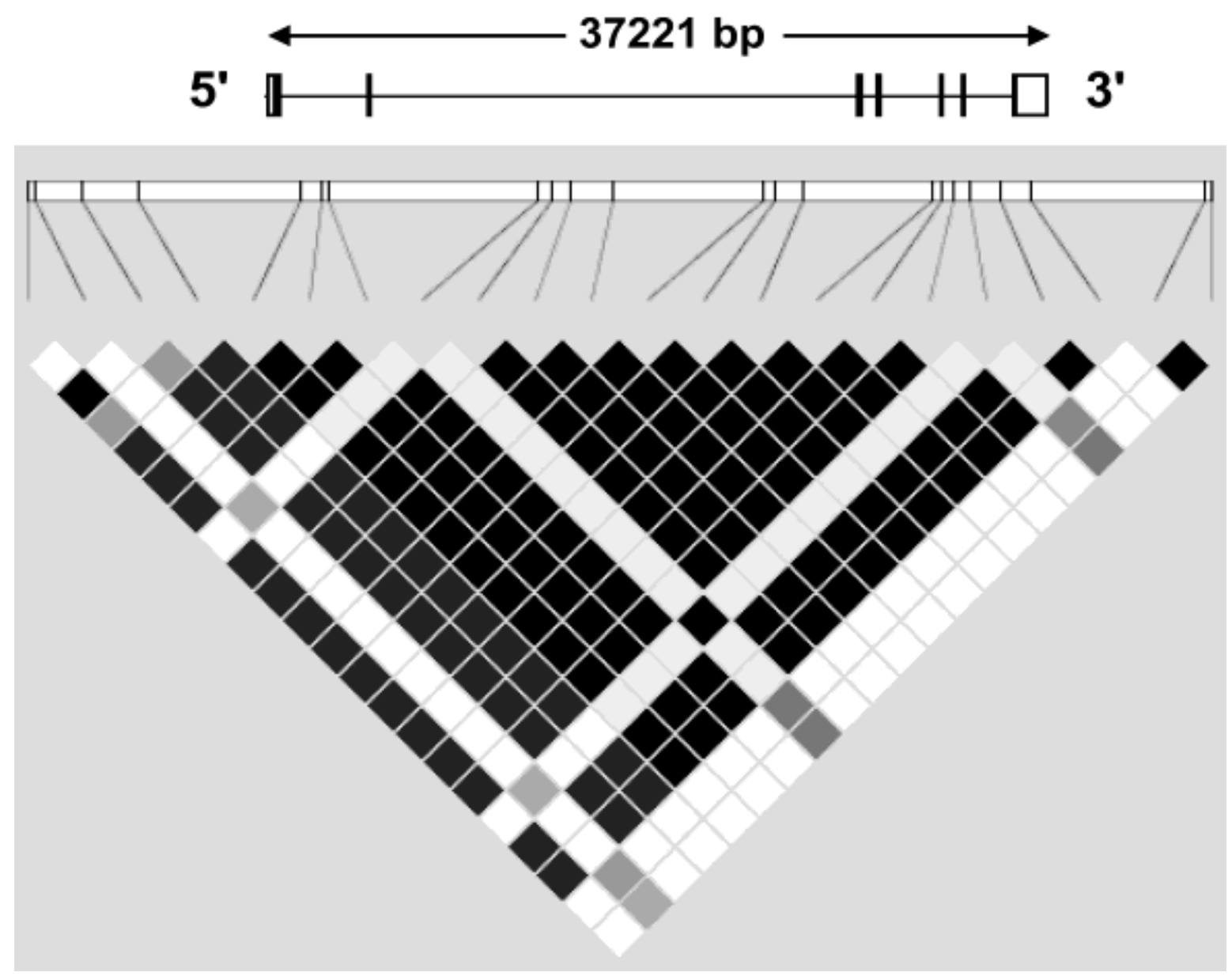

\section{Abbildung 26}

Induzierte LCL-Apoptose in Relation zu DCK-Genpolymorphismen. Die Darstellungsweise ist analog zu der in Abbildung 22

Im RRM2B-Gen waren zwei Polymorphismen nominal signifikant mit der GemcitabinToxizität assoziiert (Abbildung 27). Diese befinden sich in Intron 7 (rs17432015, $p=0,004)$ bzw. jenseits des 3'-Endes (rs16869246, $p=0,009$ ) des Gens. Zwei vollständig miteinander gekoppelte Genvarianten, rs3204695 und rs4102401, zeigten einen geringgradigen Einfluss auf die Cytarabin-induzierte Apoptose. Diese beiden Varianten sind in der untranslatierten, aber transkribierten 3'-Region von RRM2B lokalisiert. 

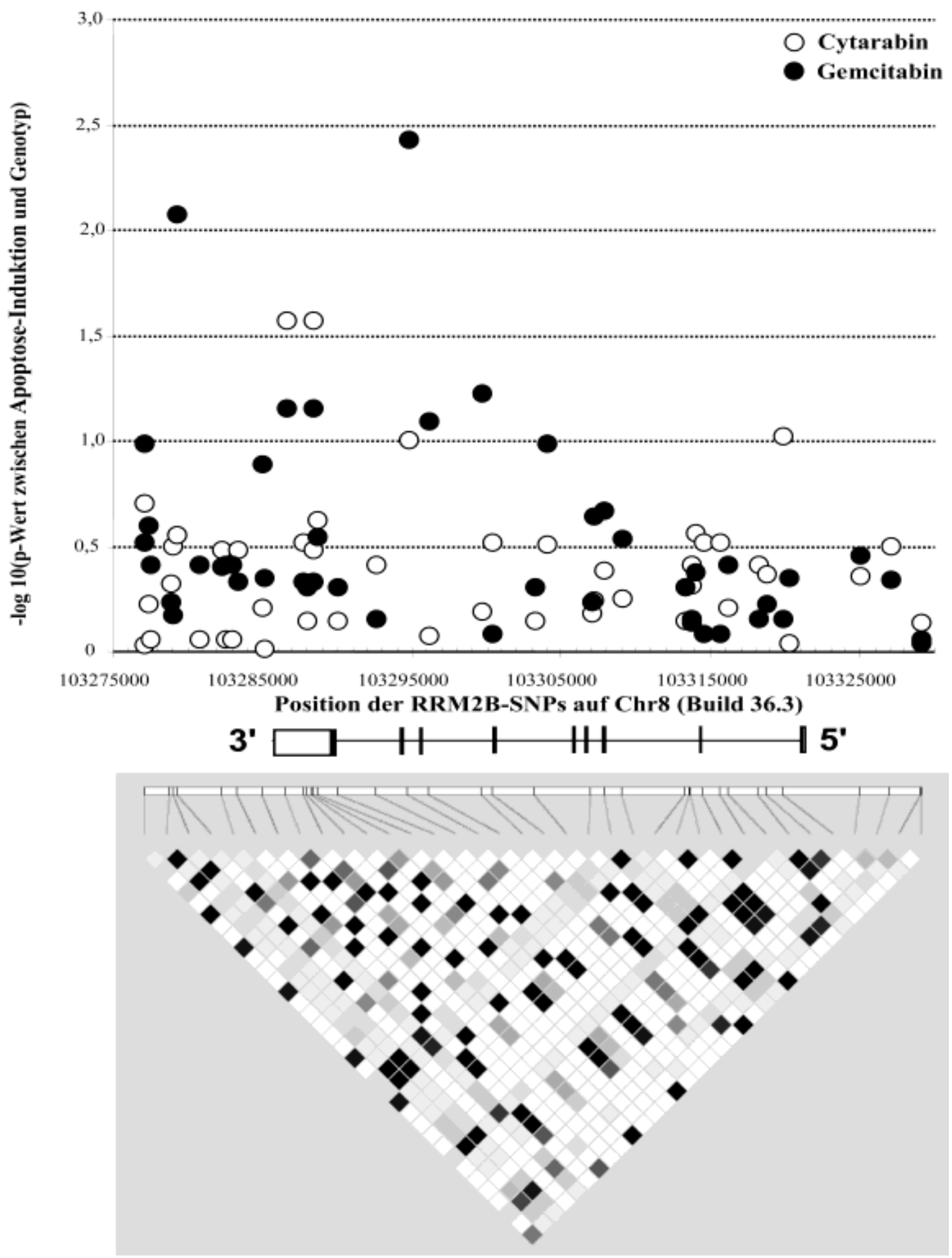

Abbildung 27

Induzierte LCL-Apoptose in Relation zu RRM2B-Genpolymorphismen. Zur Darstellungsweise siehe Abbildung 22

Das NT5C3-Gen liegt innerhalb eines großen Blockes von stark miteinander in einem Kopplungsungleichgewicht stehenden Varianten. Diese Blockstruktur als Ausdruck starker genetischer Konservierung wird nur durch einige wenige Varianten 
unterbrochen. Insgesamt zehn NT5C3-Genpolymorphismen hatten einen Einfluss auf die Cytarabin-Zytotoxizität mit $p<0,05$ (Abbildung 28). Diese zehn Polymorphismen repräsentieren Varianten, welche nicht Teil des großen Kopplungsblockes sind und stehen wechselseitig in einem unterschiedlich starken Kopplungsungleichgewicht. Zur Identifikation der mutmaßlich am stärksten beeinflussenden Genvariante oder zur Klärung möglicher additiver Effekte wurde eine lineare Regressionsanalyse mit der Cytarabin-induzierten Zytotoxizität als abhängiger und den zehn Genpolymorphismen als unabhängige Variablen durchgeführt. Dabei stellte sich die Variante rs6946062 als stärkster Prädiktor der zytotoxischen Wirkung von Cytarabin : allein dadurch waren $31,8 \%$ der beobachteten Variabilität erklärbar $(p=0,0001)$. Dabei konnte für die Zytotoxizität in allen drei Genotyp-Subgruppen eine Normalverteilung angenommen werden. Dieser Genvariante liegt in Intron 1, bezogen auf das längste Transkript bzw. im Promotorbereich bezüglich der beiden kürzeren Transkriptvarianten. 

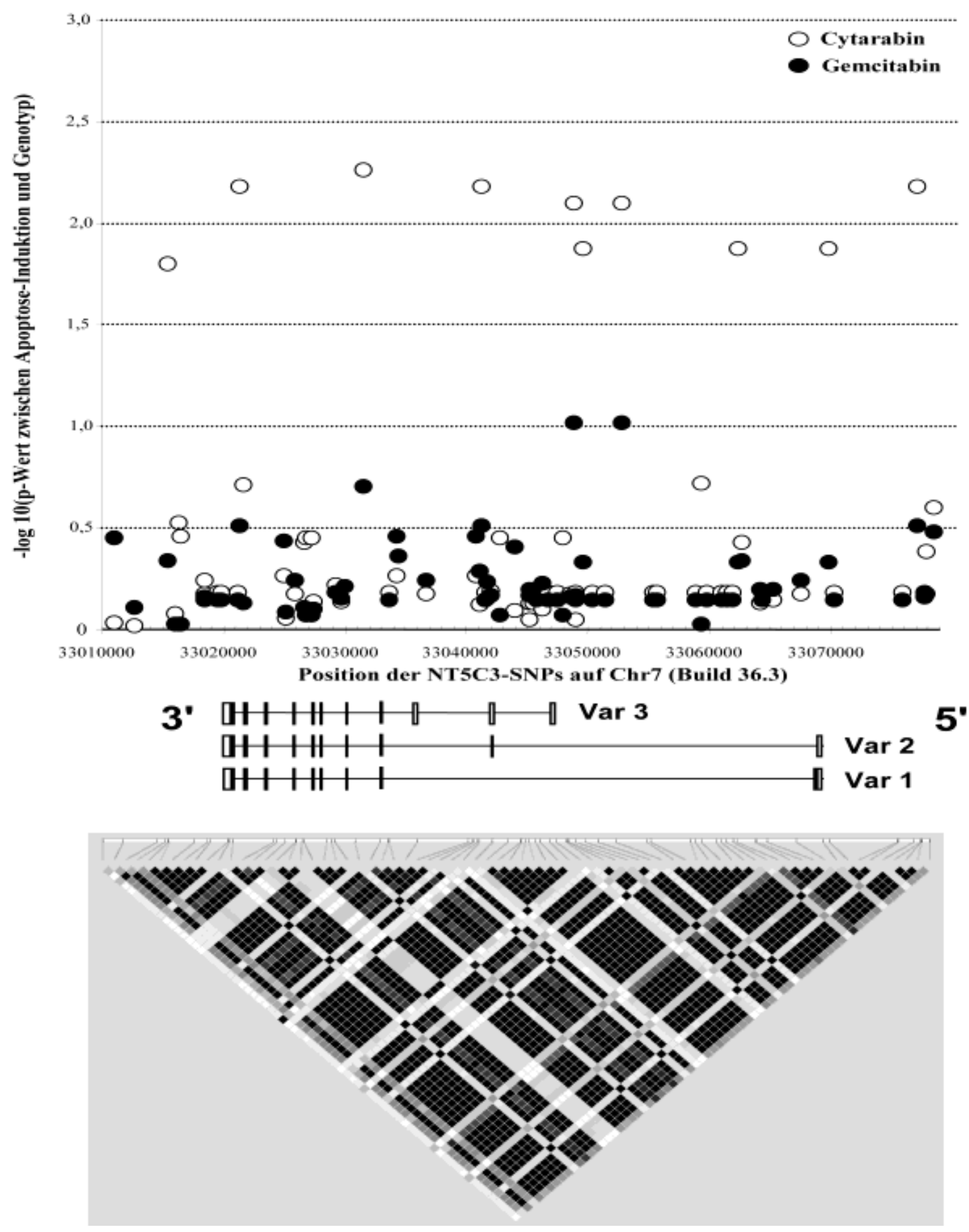

\section{Abbildung 28}

Induzierte LCL-Apoptose in Relation zu NT5C3-Genpolymorphismen. Darstellungsweise analog zu Abbildung 22

Die stärksten Genotyp-Phänotyp-Signale aller untersuchten Gene waren für Genpolymorphismen von DCTD zu sehen. Im 3'-Bereich dieses Gens waren 15 Varianten mit der Cytarabin-bedingten Zytotoxizität mit $p<0,001$ assoziiert (Abbildung 29), wobei das stärkste Signal zwischen Cytarabin-induzierter Apoptose 
und einer Variante unmittelbar hinter dem 3'-Transkriptionsende beobachtet wurde (rs7677967, $p=0,00005$ gemäß des Jonckheere-Terpstra-Trend-Tests). Die Assoziationen der anderen 14 Varianten sind entsprechend dem Ausmaß an genetischer Kopplung mit rs7677967 bedingt.
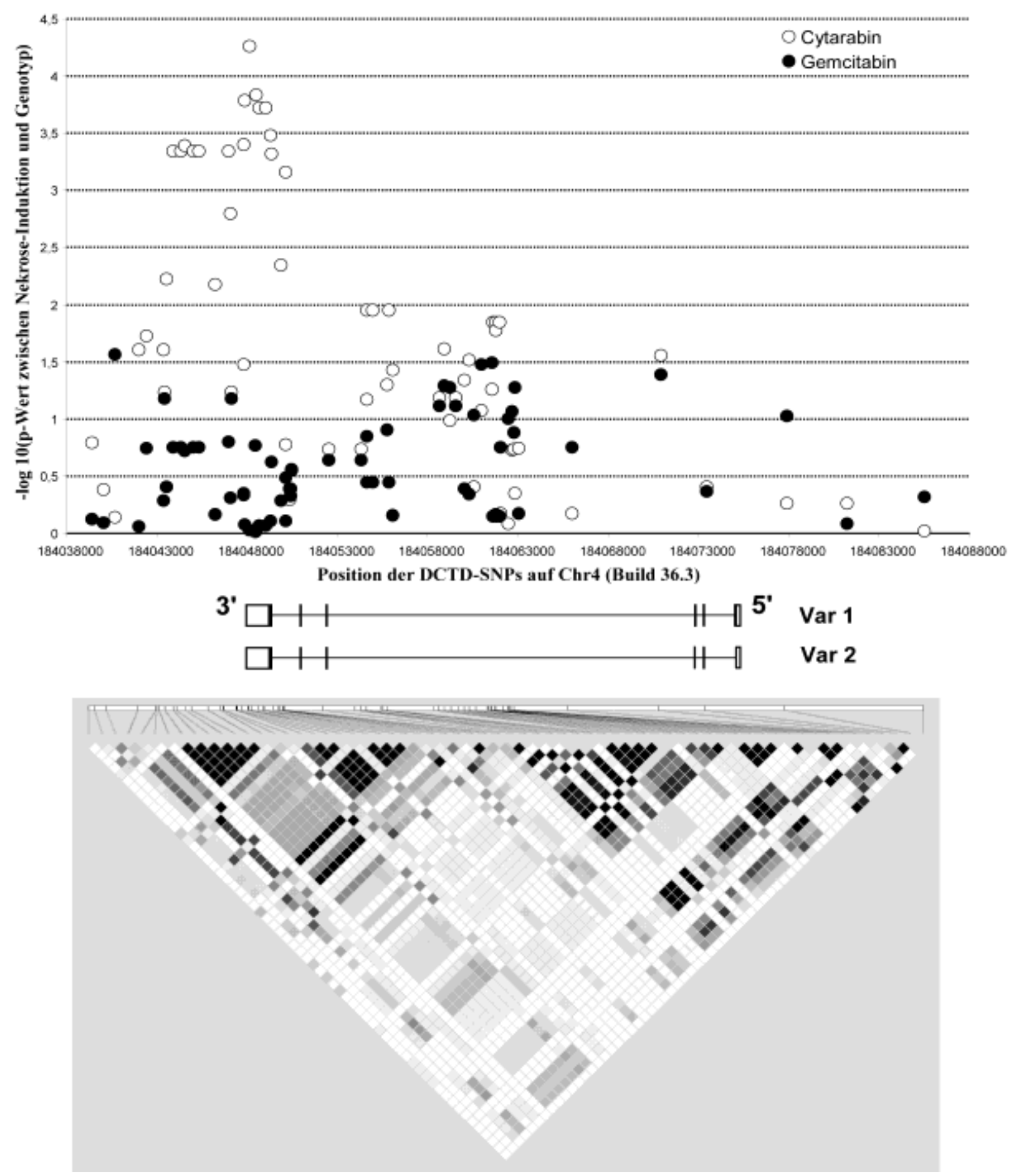

Abbildung 29

Induzierte LCL-Nekrose in Relation zu DCTD-Genpolymorphismen. Darstellungsweise analog zu Abbildung 22 
Im Genbereich von CDA zeigten sich nur schwache Assoziationen von 3 SNPs $(0,02<p<0,05) \quad$ mit Cytarabin-induzierter Apoptose, bei Gemcitabin keinerlei signifikante Assoziationen. Aus diesem Grund wurde hier auf eine bildliche Darstellung verzichtet. Dies gilt auch für CMPK1, NT5C, RRM1 und RRM2, wo sich für keine einzige Genvariante eine Assoziation mit $p<0,05$ fand. 


\section{Diskussion}

Nun sollen die wichtigsten Ergebnisse meiner Arbeit diskutiert und zur bestehenden Literatur in Beziehung gesetzt werden. Gemäß dem Ziel, genetische Determinanten für die Sensitivität gegenüber den Nukleosid-Analoga Gemcitabin und Cytarabin zu identifizieren, wurden zwei Strategien verfolgt: zunächst fokussiert auf den ENT1Transporter entsprechend seiner in der Literatur dokumentierten Bedeutung. In einem zweiten explorativen Ansatz die Prüfung weiterer mutmaßlich bedeutsamer Kandidatengene für die Wirksamkeit dieser Nukleosid-Analoga.

\subsection{ENT1-Transporter und die Zytotoxizität von Gemcitabin und Cytarabin}

Als wichtigste Ergebnisse im Hinblick auf die Bedeutung des ENT1-Transporters sind folgende drei Befunde zu nennen. Erstens, eine positive Korrelation zwischen der basalen ENT1-mRNA-Expression und der Zellapoptose unter Gemcitabin (Abbildung 7, Mitte), zweitens eine massive Hemmung der Cytarabin-Zytotoxizität durch NBTI (Abbildung 8) und drittens eine erheblich verminderte Empfindlichkeit gegenüber den Nukleosid-Analoga bei Vorliegen des Aminosäureaustauschs lle216Thr (Abbildung 11 und Abbildung 13). Diese drei Aspekte sollen nachfolgend eingehender beleuchtet werden.

\subsubsection{ENT1-Transkription und Apoptose unter Gemcitabin}

Die Stärke der Korrelation zwischen der basalen ENT1-Transkription und der Zellapoptose nach $48 \mathrm{~h}$ Gemcitabin-Behandlung war zwar eher geringgradig, jedoch statistisch signifikant (Abbildung 7, Mitte). Außerdem ist zu berücksichtigen, dass bereits auf dem Kontrollniveau ein gewisser Zusammenhang zwischen der ENT1Transkription und der Zellvitalität zu beobachten war (Abbildung 7, links). Die Bedeutung der ENT1-Transkription für die Sensitivität gegenüber Gemcitabin wird aber dadurch gestützt, dass meine Daten diejenigen einer früheren Studie (Preuß 2009) mit einem praktisch identischen Korrelationskoeffizienten bestätigen (Pearson $r=0,34$ bzw. 0,36, Abbildung 30)

Die Versuchsbedingungen waren identisch, Unterschiede bestanden nur in der Wahl der Referenzgene bei der Normierung der ENT1-Transkriptionsdaten. Ein artifizieller 
Einfluss dieser Referenzgene kann jedoch ausgeschlossen werden, da in beiden Studien auch ohne Normierung eine ähnliche Korrelation bestand.

Ein Gemcitabin vergleichbarer Effekt zeigte sich nicht für Cytarabin, zumindest nicht für die Inkubationszeit von $48 \mathrm{~h}$ (Abbildung 7 , rechts). Eine Erklärung dafür könnte sein, dass unter diesen Bedingungen der Anteil apoptotischer Zellen bereits so hoch war, dass ein Einfluss durch die Transkriptzahlen des ENT1 nicht mehr nachweisbar war. Dafür, dass ein solcher Effekt prinzipiell vorhanden ist, spricht ein Trend für eine Korrelation zwischen ENT1-Transkripten und Apoptose unter Cytarabin, wenn dieses nur $6 \mathrm{~h}$ lang auf die Zellen gegeben und anschließend ohne Zytostatikum für weitere $42 \mathrm{~h}$ inkubiert wurde $(r=0,23, p=0,06)$.
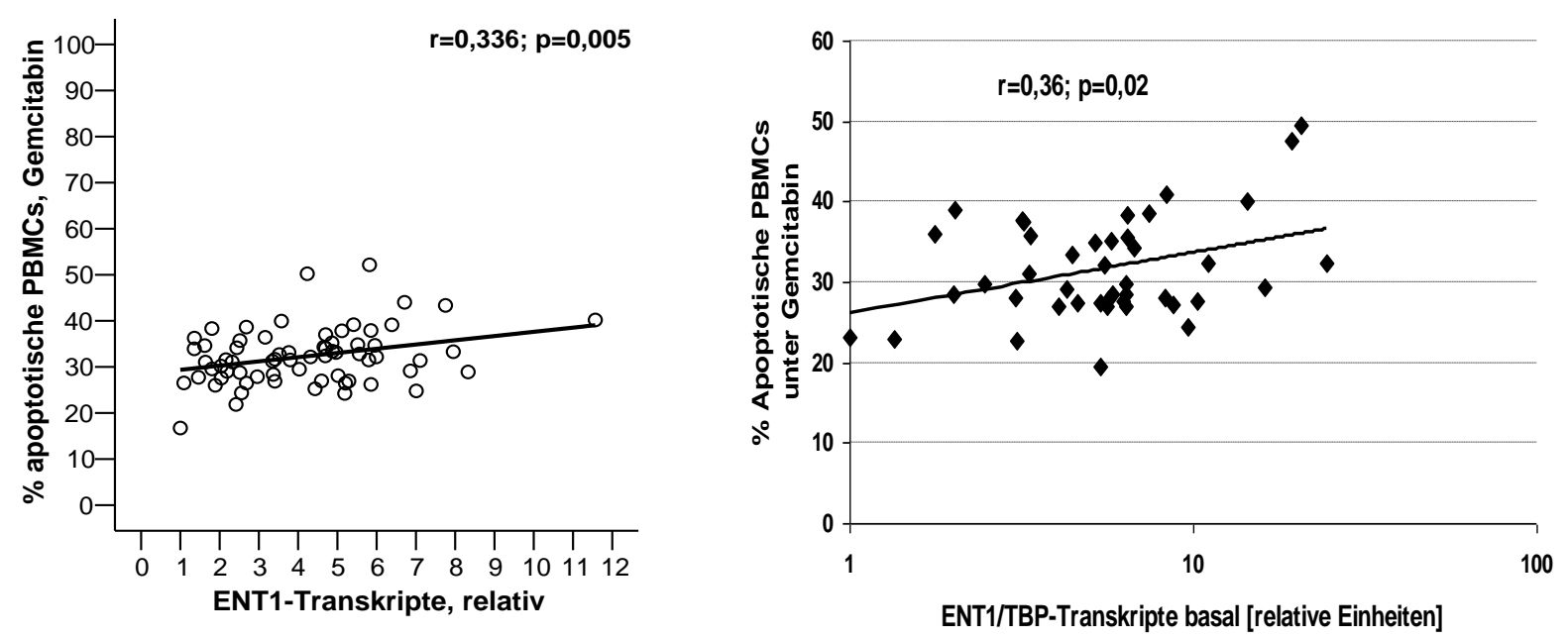

\section{Abbildung 30}

ENT1-Transkription und Toxizität unter Gemcitabin im Vergleich mit einer früheren Studie. Links sind die Daten meiner Studie dargestellt, rechts diejenigen aus der Dissertation von Preuß 2009. Die Versuchsbedingungen waren in beiden Studien identisch (isolierte PBMCs, $10 \mu \mathrm{g} / \mathrm{ml}$ Gemcitabin mit Inkubation für $48 \mathrm{~h}$ bei $37^{\circ} \mathrm{C}$ ).

Die klinische Relevanz der ENT1-Expression für die Wirksamkeit von Gemcitabin ist gut belegt. Spratlin et al. beschrieben erstmals einen Zusammenhang zwischen einer immunhistochemisch nachweisbaren ENT1-Expression bei Pankreaskarzinomen und der Überlebenszeit unter Gemcitabin-Therapie (Spratlin et al. 2004): mehr ENT1 bedeutete tendenziell besseres Überleben. Später konnte auch eine vergleichbare Beziehung mit der mRNA-Expression des ENT1 aufgezeigt werden (Giovannetti et al. 2006). Letzterer Befund wurde unabhängig von anderen Gruppen in Relation zum krankheitsfreien Überleben bestätigt (Farrell et al. 2009; Fujita et al. 2010; Michalski et al. 2008). Gänzlich unumstritten ist die Bedeutung der ENT1-Expression für die Effizienz einer Gemcitabin-Therapie bei Pankreas-Karzinom aber nicht (Ashida et al. 
2009). Stattdessen legt letztgenannte Publikation einen Einfluss der dCK-Expression nahe. Auch bei anderen Tumor-Entitäten wie dem nicht kleinzelligen Bronchialkarzinom scheint das Fehlen von ENT1 mit einem Nicht-Ansprechen auf Gemcitabin verbunden zu sein (Oguri et al. 2007). Umgekehrt sieht es so aus, dass eine Überexpression des ENT1 per se einen negativen Prädiktor für den Verlauf von Tumorerkrankungen darstellt (Santini et al. 2008; Santini et al. 2010), möglicherweise durch eine bessere Versorgung von Tumorzellen mit Nukleosid-Substraten.

In Zellkulturen als Modelle für adenomatöse Pankreas- und Gallengangskarzinome war die Sensitivität gegenüber Gemcitabin umso höher, je mehr ENT1 vorhanden war (Mori et al. 2007). Als proof of principle-Experiment konnte durch adenovirale Transfektion von ENT1 in humane Pankreaskarzinomzellen die Sensitivität gegenüber Gemcitabin gesteigert werden (Perez-Torras et al. 2008). Auch in lymphoiden Zellen wurde eine Abhängigkeit der Gemcitabin-Empfindlichkeit von der Expression des ENT1 und weiterer Kandidatengene beschrieben (Giovannetti et al. 2007). Bei der Behandlung myeloischer Leukämien mit Cytarabin scheint die ENT1Expression ebenfalls eine wichtige Determinante für den Therapieerfolg zu sein (Galmarini et al. 2002). Allerdings sprachen trotz Herunterregulation des ENT1 durch Imatinib die chronisch-myeloischen Tumorzellen auf Gemcitabin weiterhin an (Leisewitz et al. 2008).

Eine Domäne für die Anwendung von Cytarabin sind akute Leukämien. In blastoiden Zellen war die Empfindlichkeit gegenüber Cytarabin umso höher, je mehr ENT1 auf mRNA-Ebene exprimiert war (Hubeek et al. 2005). Die Effektiviät von Cytarabin scheint somit - ähnlich wie bei Gemcitabin - von der ENT1-Expression abhängig zu sein. Ob dies spezifisch von der Art der malignen Erkrankung abhängt oder ein allgemeines Phänomen darstellt, müsste noch weiter untersucht werden. Meine Daten mit isolierten PBMCs und T-Lymphozyten unterstreichen die Bedeutung der ENT1-Expression für die zytotoxische Wirkung von Gemcitabin und Cytarabin, wenngleich der Effekt eher gering ist und somit weitere Kandidatengene eine wichtige Rolle spielen dürften.

\subsubsection{Zytotoxizität bei Hemmung des ENT1}

Die zytotoxische Wirkung von Cytarabin wurde bei gleichzeitiger Inkubation mit dem ENT1-Inhibitor NBTI stark (>50\%) reduziert, sowohl in PBMCs als auch in der Subpopulation der T-Lymphozyten (Abbildung 8). Es ist bekannt, dass der ENT1 - im 
Unterschied zum ENT2 - sehr sensitiv gegenüber einer Hemmung durch NBTI ist (Baldwin et al. 2004). Aus der Literatur ist nicht bekannt, inwiefern die ENTs 3 und 4 durch NBTI hemmbar sind. Grundsätzlich ist auch denkbar, dass andere Transportsysteme als die ENTs durch NBTI beeinflusst werden und zu dem beobachteten Effekt in Abbildung 8 beigetragen haben. Wegen der starken Inhibition des ENT1 durch NBTI (Inhibitionskonstante $~ 5 \mathrm{nM}$, Yao et al. 1997) kann jedoch angenommen werden, dass ein erheblicher Anteil der NBTI-vermittelter Reduktion der Cytarabin-Toxizität auf einer Hemmung des ENT1 beruht. In der Literatur wird NBTI - auch als NBMPR bezeichnet - als ein ENT1-spezifischer Inhibitor betrachtet (Zimmerman et al. 2009). In human Pankreaskarzinom-Zellinien war die Aufnahme von Gemcitabin durch NBTI vermindert (Tsujie et al. 2007).

Systematische Messreihen zur Darstellung der Zytotoxizitäts-Reduktion von Gemcitabin und Cytarabin durch NBTI an einer größeren Anzahl von Zellen gibt es meines Wissens bislang noch nicht. Analoge Messungen mit Gemcitabin und NBTI wurden bei den nativen Blutzellen nicht angestellt, da die zytotoxische Wirkung von Gemcitabin verglichen mit Cytarabin relativ gering war (Abbildung 4) und dadurch keine starken Effekte durch NBTI zu erwarten waren. Bei den LCLs, die -anders als die PBMCs- auf Gemcitabin stärker reagierten als Cytarabin, konnte durch NBTI keinerlei Reduktion der Gemcitabin-Toxizität erreicht werden (Abbildung 21). Im Unterschied dazu konnte die Cytarabin-Toxizität durch NBTI bei den LCLs nahezu komplett aufgehoben werden. Zwischen den beiden untersuchten Zelltypen, isolierten Leukozyten einerseits und LCLs andererseits, scheinen hinsichtlich der Nukleosid-Empfindlichkeit erhebliche Unterschiede $\mathrm{zu}$ bestehen, die die Übertragbarkeit der Ergebnisse zwischen den Zellarten nicht ohne weiteres zulassen.

\subsubsection{Funktionelle Genvarianten im ENT1}

Von den insgesamt 18 untersuchten Varianten, die ziemlich umfassend die genetische Variabilität im ENT1 beschreiben, konnte ein reproduzierbarer Zusammenhang mit funktionellen Messparametern nur für den in Exon 9 lokalisierten Aminosäureaustausch lle216Thr festgestellt werden. Zwei andere Polymorphismen, rs1886884 und rs9394992, die in meinen Daten nominal signifikante Assoziationen zeigten, wurden nachträglich auch an den Proben der früheren Studie (Preuß 2009) bestimmt und waren dort entweder nicht signifikant oder hatten sogar einen gegenläufigen Effekt. 
Das 216Thr-Allel hatte in meiner Studienpopulation nur eine Häufigkeit von 2\% (Tabelle 13). Auf Grund der geringen Zahl von nur drei Variantenträgern muss der Befund einer reduzierten Cytarabin-Sensitivität (Abbildung 11, links) zurückhaltend bewertet werden. Allerdings stimmt dieses Ergebnis gut mit den Daten der früheren Studie überein und auch in Zusammenfassung beider Studienteile zeigte sich eine nominale statistische Signifikanz mit $\mathrm{p}<0,05$ (Abbildung 11, rechts). Einzuwenden wäre hier, dass eine Signifikanz auch unter der Berücksichtigung multiplen Testens nicht erreicht wurde. Für eine biochemische Bedeutung spricht jedoch, dass diese auch die Wirkung von NBTI beeinflusste und somit ein ENT1-spezifischer Effekt vorzuliegen scheint (Abbildung 12, rechts), wenngleich hier die Gruppe der Variantenträger nur zwei Personen umfasste. Die Hypothese einer möglichen funktionellen Relevanz dieser Aminosäurevariante wird auch dadurch unterstützt, dass auch die Gemcitabin-Zytotoxizität bei Vorliegen des Variantenallels vermindert wurde (Abbildung 13).

Aus der Literatur ist bekannt, dass Mutationen im ENT1 Resistenzen gegenüber Zytostatika vermitteln, welche über diesen Transporter in die Zellen aufgenommen werden (Zimmerman et al. 2009). In Bezug auf Genpolymorphismen ( $\geq 1 \%$ Allelhäufigkeit) gibt es im kodierenden Bereich des ENT1 nur wenig genetische Variation (Osato et al. 2003). Die einzige Variante, die bei Kaukasiern als nichtsynonymer Aminosäureaustausch mit einer Häufigkeit von $\geq 1 \%$ vorkommt, ist lle216Thr. Für diese wurden eingehendere Transportmessungen, welche auch Cytarabin und Gemcitabin beinhalteten, durchgeführt: Der Transport der untersuchten Substanzen wurde jedoch nicht beeinflusst (Osato et al. 2003). Hier sollte aber bedacht werden, dass die Inkubationszeit nur 20 min betrug und zytotoxische Effekte - wie sie meine Daten nahelegen - erst deutlich später auftraten. Es ist durchaus denkbar, dass diese Variante andere Auswirkungen hat, als bei den initialen Transportmessungen erfassbar sind. Auf Grund der offenbar fehlenden Assoziation mit initialen Transportvorgängen sind zur Prüfung anderer Hypothesen umfassendere weitere Experimente nötig, um eine tatsächliche biochemische Bedeutung dieser Variante postulieren zu können.

In den mit LCLs durchgeführten Messungen zeigte sich für keine Variante ein nennenswerter Zusammenhang mit der zytotoxischen Wirkung von Gemcitabin oder Cytarabin (Abbildung 22). Die zuvor beschriebene Aminosäurevariante lle216Thr war in diesem Datensatz nicht enthalten. 


\subsection{Weitere Nukleosidtransporter}

Als weitere Kandidatengene für die Zytotoxizität der beiden Pyrimidin-NukleosidAnaloga wurden die konzentrativen Nukleosidtransporter CNT1 und CNT3 betrachtet. Hierfür wurden die Genotypdaten aus der HapMap-Datenbank (http://hapmap.org/index.html.en) für die entsprechenden LCLs verwendet und zu den Zytotoxizitätsmessungen in Beziehung gesetzt. Der CNT2 wurde hier nicht analysiert, da dieser praktisch nur für Purin-Nukleoside relevant ist.

\subsubsection{CNT1}

Im CNT1 war bei den LCLs für eine Gruppe von Genpolymorphismen eine Assoziation mit der Gemcitabin-induzierten Zytotoxizität festzustellen (Abbildung 23). $\mathrm{Zu}$ dieser Gruppe von Genvarianten gehört der Austausch der basischen Aminosäure Asparagin zur sauren Asparaginsäure an Position 521. Beide Allele sind mit 52\% bzw. 48\% praktisch gleich häufig. Bei den Assoziationen mit der Zytotoxizität von Gemcitabin ist allerdings zu berücksichtigen, dass die Korrelation an zwei unabhängigen Messtagen eher gering war (siehe Abbildung 18, rechts).

In der Literatur ist die Asn521Asp-Variante bislang nicht als funktionell oder klinisch assoziiert beschrieben. Lediglich in einer Publikation wurde die Hemmbarkeit der Aufnahme von Tritium-markiertem Thymidin durch Gemcitabin in Relation zu Genpolymorphismen des CNT1 untersucht (Gray et al. 2004a). Die Asn521AspVariante zeigte dabei keinen Effekt, jedoch der Aminosäureaustausch Val189lle. Dieser hatte jedoch in meinen Messungen keinen Einfluss. Die grundsätzliche Bedeutung des CNT1 für die Sensitivität gegenüber Gemcitabin ist dadurch belegt, dass bei einem Knockdown dieses Transporters Zellen weniger empfindlich auf dieses Zytostatikum sind (Hartford et al. 2009).

\subsubsection{CNT3}

Ähnlich wie bei CNT1 wurden auch bei CNT3 Assoziationen mit der Gemcitabininduzierten Zytotoxizität beobachtet (Abbildung 25), am stärksten ausgeprägt für einen in Intron 4 lokalsierten SNP (rs13288052). Für diesen gibt es in der Literatur noch keine Daten. Der bei mir etwas schwächer assoziierte SNP rs4585823 ist parziell mit rs13288052 gekoppelt. Genauer gesagt stellt das seltene Allel von 
rs13288052 (Allelfrequenz 7,6\%) eine Untergruppe des seltenen Allels von rs4585823 (13,3\%) dar. Rs4585823 war in einem Datensatz enthalten, in dem Genom-weit Assoziationen mit IC50-Werten für die Toxizität von Gemcitabin geprüft wurden (Li et al. 2009). Dort hatte diese Variante keinen Effekt. Jedoch wurde in der zitierten Arbeit ein einfacher Zellvitalitätsassay mit $96 \mathrm{~h}$ Zytostatika-Inkubation gewählt. Auf Grund der sehr heterogenen Proliferationsrate der LCLs ist diese Methode jedoch sehr zweifelhaft. Diese Annahme wird bekräftigt durch von mir durchgeführte parallele Messungen der Zytotoxizität mittels MTT-Assay und Durchflusszytometrie. Nur bei der letzteren Methode konnte bei Wiederholungsmessungen zu späteren Zeitpunkten eine gewisse Korrelation festgestellt werden (vergleiche Abbildung 18 und Abbildung 19). Es scheint daher sehr fraglich, ob über einfache Zellvitalitätsassays erhobene Funktionsdaten bei LCLs zur Assoziationsanalyse mit Genotypen geeignet sind.

Von den beiden bei Kaukasieren häufigen nicht-synonymen Aminosäureaustauschen war in dem von mir verwendeten HapMap-Datensatz Tyr113Cys repräsentiert, Tyr513Phe dagegen nicht. Die Variante an Position 113 zeigte jedoch keinerlei Modulation der Empfindlichkeit gegenüber Gemcitabin oder Cytarabin.

\subsection{Enzyme zur Aktivierung von Nukleosid-Analoga}

Weitere Kandidatengene für die Effektivität von Gemcitabin und Cytarabin stellen Enzyme dar, welche diese Nukleosid-Analoga zu biologisch aktiven Verbindungen aktivieren. Dazu zählen insbesondere DCK und CMPK1. Für beide Gene konnten jedoch keine nennenswerten Assoziationen mit den Ergebnissen der Zytotoxizitätsmessungen aufgezeigt werden. Dies war auch in der bereits zuvor zitierten Genom-weiten Studie zur Identifizierung genetischer Prädiktoren der Gemcitabin- bzw. Cytarabin-Empfindlichkeit bei LCLs Fall (Li et al. 2009).

\subsection{Enzyme zur Degradierung von Nukleosid-Analoga}

Zu den Enzymen, die Nukleosid-Analoga bzw. phosphorylierte Metabolite deaktivieren, zählen vor allem CDA, DCTD, NT5C und NT5C3. Für Cytarabin, nicht jedoch für Gemcitabin, stellten sich für Genpolymorphismen in zweien dieser Gene deutliche Assoziationen heraus. Am deutlichsten war dies für ein Cluster von SNPs im Genbereich von DCTD zu sehen (Abbildung 29). Die Variante mit dem stärksten 
Signal (rs7677967) lag hinsichtlich ihres statistischen p-Wertes um etwa den Faktor 1000 unter dem Signifikanzniveau von 0,05. Somit kann dieser Befund auch bei konservativer Adjustierung auf multiples Testen (insgesamt 724 Varianten analysiert) als statistisch signifikant betrachtet werden. Dies ist umso mehr der Fall, da die Zahl von 724 deutlich niedriger liegt, wenn die zum Teil starke genetische Kopplung berücksichtigt wird. Je stärker der Grad dieser Kopplung ist, desto weniger kann von unabhängigen Tests gesprochen werden. Rs7677967 befindet sich unmittelbar jenseits des 3'-Transkriptionsendes. Es gibt bislang nur eine Publikation über eine mögliche funktionelle Bedeutung dieser Variante (Zhang et al. 2009). Darin wird ein Effekt auf die Transkription der DCTD-Isoformen postuliert. Interessant ist in diesem Zusammenhang, dass die SNPs, welche mit der Transkription der Isoformen verbunden waren, mit denen übereinstimmen, die bei mir mit der Zytotoxizität von Cytarabin assoziiert waren. Daraus kann die Hypothese abgeleitet werden, dass die Transkriptionsisoformen in Relation zur Aktivierung der Nukleosid-Analoga und folglich zu deren zytotoxischer Wirkung stehen. Dies müsste in weiteren Untersuchungen geprüft werden. Obwohl Gemcitabin und Cytarabin in ihrer chemischen Struktur einander sehr ähnlich sind, fällt auf, dass kaum eine Überlappung bei den Genotyp-Assoziationen bestand und die starken Befunde bei DCTD-Polymorphismen Cytarabin-spezifisch waren. Dies stimmt jedoch gut mit der Literaturdatanlage zu diesem Sachverhalt überein (Li et al. 2009).

Weiterhin war eine Gruppe von zehn Genpolymorphismen im Genbereich von NT5C3 mit der Cytarabin-Toxizität verknüpft (Abbildung 28). In einer multiplen linearen Regressionsanalyse wurde rs6946062 als stärkster Einflussfaktor identifiziert. Für diese Variante gibt es in der Literatur noch keine Daten hinsichtlich ihrer möglichen Funktionalität. Einer der anderen neun SNPs, die ähnlich stark mit der Variabilität der Cytarabin-Wirkung verbundenen waren, ist rs6976843, welcher sich in der Promotorregion dieses Gens befindet. Dieser SNP war in einer Studie enthalten, in der Expression und Enzymaktivität von NT5C3 in Bezug auf Polymorphismen dieses Gens untersucht wurden (Aksoy et al. 2009). Für rs6976843 war dabei kein Effekt erkennbar. Zwei weitere in der zitierten Arbeit mit Proteinexpression von NT5C3 verbundene Varianten (Asp283His und rs11974256) waren in meinem Datensatz nicht enthalten. Daher kann keine Aussage über eine Relevanz für zytotoxische Wirkung der Nukleosid-Analoga getroffen werden. 
Generell scheint sich eine Änderung der Expression von NT5C3 erheblich auf die Sensitiviät der beiden untersuchten Nukleosid-Analoga auszuwirken (Li et al. 2008).

Ein NT5C3-Isoenzym von NT5C wurde ebenfalls im Hinblick auf mögliche funktionelle Genvarianten analysiert. Hierbei wurde jedoch keine Assoziation mit der Toxizität von Cytarabin bzw. Gemcitabin gefunden.

Im für die CDA kodierenden Gen waren nur sehr schwache Assoziationen mit der Cytarabin-induzierten Apoptose zu sehen, so dass diesen Genvarianten hier keine größere Bedeutung beigemessen wird. Der in der Literatur am meisten untersuchte Genpolymorphismus im CDA-Gen, der Aminosäureaustausch Lys27GIn (Gilbert et al. 2006), hatte in meinen Messungen keinen Effekt gezeigt.

\subsection{Indirekt mit der Aktivität von Nukleosid-Analoga verbundene Enzyme}

Nukleosid-Analoga können indirekt Auswirkungen auf andere Enzyme haben. Im Rahmen meiner Arbeit wurden in diesem Zusammenhang drei Komponenten der Ribonukleotid-Reduktase betrachtet, welche besonders wichtig für die selbstpotenzierende Wirkung von Gemcitabin sind (Heinemann et al. 1990): RRM1, RRM2 und RRM2B. Die Expression von RRM1 beispielsweise wird als ein Marker für Resistenz gegenüber der Gemcitabin-Therapie angesehen (Nakamura et al. 2010). Keine der Polymorphismen im Genbereich von RRM1 und RRM2 wirkte sich auf die Wirkung von Gemcitabin oder Cytarabin aus. In Bezug auf RRM2B fanden sich für zwei Polymorphismen mittelgradige Assoziationen bei Gemcitabin (Abbildung 27). Da noch keine diesbezüglichen Literaturbefunde existieren, kann gegenwärtig eine Einordnung dieses Ergebnisses noch nicht erfolgen, zumal nach Adjustierung auf multiples Testen hier nicht von einer statistischen Signifikanz gesprochen werden kann.

\subsection{Kritische Auseinandersetzung}

Als wesentliches Ergebnis meiner Arbeit sollten früher erhobene Daten in Bezug auf die Bedeutung des ENT1 für die zytotoxische Wirkung der beiden Nukleosid-Analoga Gemcitabin und Cytarabin (siehe Preuß 2009) zum einen bestätigt und zum anderen durch zusätzliche Messungen (spezifische Betrachtung der T-Lymphozyten als Subpopulationd der PBMCs, Spezifizierung der ENT1-Effekte durch den Inhibitor 
NBTI) ergänzt werden. Dabei konnte der Zusammenhang zwischen basaler ENT1Expression und dem Anteil apoptotischer Zellen unter Nukleosid-Analoga sowie zwischen der ENT1-Aminosäurevariante lle216Thr und reduzierter NukleosidAnaloga-Sensitivität reproduziert werden. Darüber hinaus wurde durch den ENT1spezifischen Inhibitor NBTI dessen Bedeutung für die Nukleosid-Zytotoxizität im Allgemeinen und für die lle216Thr-Variante im Besonderen bekräftigt.

Als zweiten wesentlichen Gewinn meiner Arbeit sehe ich die Identifizierung der Toxizität von Cytarabin und Gemcitabin relevanter Genpolymorphismen in weiteren Kandidatengenen. Für diese explorative Analyse wurden LCLs verwendet, welche zur Zeit der Durchführung meiner Experimente die genetisch am umfassendsten charakterisierten humanen Zelllinien weltweit darstellten. Im Unterschied zu einer Vergleichspublikation ( $\mathrm{Li}$ et al. 2009) habe ich zwei Methoden zur Erfassung der Zellvitalität und Wiederholungsmessungen von 32 Zelllinien zur Prüfung einer IntraZelllinien-Korrelation eingesetzt. Dabei erwies sich die durchflusszytometrische Methode gegenüber den zumeist verwendeten einfacheren Zellvitalitätsassays als deutlich überlegen. Auch wenn hier die Inter-Tag-Korrelation nicht besonders stark ausgeprägt war, so war sie doch statistisch signifikant, wohingegen bei dem MTTZellvitalitätsassay keinerlei Korrelation zwischen den Ergebnissen der beiden Messtage zu sehen war.

Als wesentliche Schwäche meiner Arbeit ist insbesondere zu nennen, dass einige Ergebnisse auf Grund einer kritisch niedrigen Fallzahl in einzelnen Untergruppen gegenwärtig noch zurückhaltend bewertet werden müssen. Dies gilt vor allem für die gefundene Reduktion der Sensitivität gegenüber Nukleosid-Analoga bei Vorliegen der Thr216-Variante im ENT1. Hinzu kommt, dass weitere biochemische und molekulare Experimente erforderlich wären, um eine Funktionalität dieser Variante plausibel darstellen zu können, umso mehr, als eine solche in der Literatur auf der Basis von Transportmessungen verneint wurde (Osato et al. 2003).

Für das Ziel, umfassende genetische Analysen durchführen zu können, war auch die Zahl der zur Verfügung stehenden LCLs recht klein. Daher wurde darauf verzichtet, die Funktionsmessungen Genom-weit mit Polymorphismen auf Assoziation zu prüfen. Stattdessen wurden hierfür Kandidatengene ausgewählt, deren Bedeutung für Transport und Metabolismus von Gemcitabin und Cytarabin gut dokumentiert ist. In Anbetracht der auf diese Weise insgesamt über 700 getesteten Genvarianten müssen viele der Assoziationen mit einem Signifikanzniveau < 0,05 sehr kritisch 
bewertet werden. Allerdings bleibt das stärkste Signal in DCTD in Bezug auf die Cytarabin-Toxizität auch dann statistisch signifikant, wenn man die Adjustierung auf multiples Testen nach Bonferroni anwendet. Diese muss jedoch wegen der starken genetischen Kopplung vieler der getesteten Genvarianten als zu konservativ angesehen werden. Setzt man eine Grenze von $r^{2}=0,5$ für die Unabhängigkeit zweier Genpolymorphismen, so müsste tatsächlich nur eine Adjustierung auf etwa 153 Varianten erfolgen. Das sich daraus ergebende Signifikanzniveau in Höhe von $\mathrm{p}=0,0003$ (bzw. einem Wert von 3,5 als negativem dekadischen Logarithmus wie auf den y-Achsen der Grafiken illustriert) wird jedoch auch nur für die Assoziation einiger Varianten im Genbereich von DCTD erreicht.

\subsection{Ausblick}

Den Darlegungen im Kapitel 4.6 „Kritische Auseinandersetzung“ folgend, ergeben sich als Stimulation und Hypothese für weiterführende Analysen insbesondere zwei Aspekte:

1. Meine Daten legen die Vermutung nahe, dass der lle216ThrAminosäureaustausch im ENT1 doch funktionell bedeutsam sein kann. Da offenbar kein Effekt auf die initiale Transportkinetik (über $20 \mathrm{~min}$ ) zu bestehen scheint (Osato et al. 2003), sollten andere Überlegungen geprüft werden. Denkbar wäre, dass sich diese Variante nicht auf die initiale Kinetik des Nukleosid-Transports, wohl aber im weiteren Verlauf bei längerer Exposition (bei meinen Experimenten $48 \mathrm{~h}$ ) auswirkt. Dieser Gedanke ist nicht abwegig, da es sich beim ENT1 um einen äquilibrierenden Transporter handelt, der ständig entsprechend dem Konzentrationsgradienten arbeitet -und dies bidirektional. Auf Grund der Lokalisation von lle216Thr in einer transmembranären Domäne ist auch denkbar, dass diese Variante weniger den Substrattransport als vielmehr die (längerfristige) Verankerung des ENT1 in der Zellmembran moduliert. Diese Ideen wären durch geeignete molekularbiologische Experimente zu überprüfen.

2. Die explorativ gefundene Assoziation von DCTD-Polymorphismen mit der Zytotoxizität von Cytarabin kann wegen des statistisch deutlich erkennbaren Zusammenhangs als lohnend für weitere Untersuchungen betrachtet werden. 
Diese sollten sowohl eine funktionelle Bestätigung als auch detaillierte Analysen zu einer mechanistischen Klärung beinhalten. Die Lokalisation direkt hinter dem Transkriptionsende sowie bereits durchgeführte Transkriptomanalysen deuten auf eine mögliche Regulation der Genexpression hin (Zhang et al. 2009).

Meine Ergebnisse geben den Anlass zu dem Optimismus, dem Ziel näher gekommen zu sein, genetische Prädiktoren für die Wirksamkeit der klinisch wichtigen Nukleosid-Analoga Gemcitabin und Cytarabin zu identifizieren. Weitere funktionelle Untersuchungen sind jedoch erforderlich, um den Wert dieser Befunde zu erhärten und als Basis für eine zukünftige Testung in klinischen Studienkollektiven. Positiven Falls wäre damit ein wichtiger Beitrag zu einer individualisierten und effizienteren Chemotherapie geleistet. Dies wäre insbesondere für die Tumorarten wünschenswert, deren Heilungsrate bislang noch sehr niedrig ist (z.B. PankreasKarzinom) bzw. wo bei guten Heilungsaussichten durch hohe Chemotherapiedosen aber eine erhebliche Gefährdung der Patienten besteht (z.B. CytarabinHochdosisgabe bei akuten Leukämien). 


\section{Zusammenfassung}

Nukleosid-Analoga sind wichtige Substanzen bei der Chemotherapie maligner Erkrankungen. Als Pyrimidinnukleoside werden insbesondere Cytarabin (v.a. bei akuten Leukämien) und Gemcitabin (bei soliden Tumoren wie Pankreaskarzinomen) verwendet. Die zelluläre Aufnahme dieser Medikamente erfolgt über spezifische Nukleosid-Transporter. Insbesondere die Expression des ENT1 (equilibrative nucleoside transporter 1) gilt Literaturberichten zufolge als wichtiger Parameter für die Wirksamkeit dieser Nukleosid-Analoga, sowohl in klinischen Studien als auch in der Zellkultur. Es wird vermutet, dass die Effektivität der Nukleosid-Analoga durch Genpolymorphismen beeinflusst wird.

Als Ziele meiner Arbeit sollte geprüft werden, ob eine Beziehung zwischen ENT1Expression und Zytotoxizität der beiden untersuchten Nukleosid-Analoga besteht, wie stark diese Zytotoxizität durch den ENT1-spezifischen Inhibitor NBTI reduziert wird und inwieweit diese funktionellen Parameter durch Polymorphismen in diesem Gen moduliert werden. Darüber hinaus sollten in einer explorativen Analyse in Bezug auf die Zytotoxizität relevante Genvarianten in weiteren Kandidatengenen für Transport und Metabolismus der Nukleosid-Analoga identifiziert werden.

Die Fragestellungen zum ENT1 wurden an isolierten Leukozyten von 72 gesunden Spendern kaukasischer Abstammung sowie an 54 lymphoblastoiden Zelllinien (LCLs) untersucht. Letztere wurden darüber hinaus zur Identifizierung möglicher funktioneller Genvarianten in weiteren Kandidatengenen verwendet. Die Leukozyten wurden 6 bzw. $48 \mathrm{~h}$ bei $37^{\circ} \mathrm{C}$ mit $10 \mu \mathrm{g} / \mathrm{ml}$ Gemcitabin bzw. Cytarabin inkubiert. Anschließend wurde der zytotoxische Effekt durchflusszytometrisch anhand des Anteils apoptotischer und nekrotischer Zellen erfasst. Diese Messwerte wurden zu der durch quantitative Real time-PCR bestimmten ENT1-Expression in der unbehandelten Kontrolle sowie zu 18 Polymorphismen im Genbereich von ENT1 in Beziehung gesetzt. Die LCLs wurden in analoger Weise über $48 \mathrm{~h}$ behandelt und die Zytotoxizität wurde über zwei unterschiedliche Verfahren, Durchflusszytometrie und MTT-Zellvitalitätsassay, gemessen. Dabei wurde das Experiment für 32 Zelllinien zur Bestimmung der Inter-Tag-Korrelation wiederholt. Die an LCLs erhobenen Zytotoxizitätsdaten wurden mit 724 Varianten in Kandidatengenen auf Assoziation geprüft. Die Genotypdaten dieser LCLs wurden von der HapMap-Datenbank heruntergeladen. 
Als wesentliche Ergebnisse dieser Arbeit stehen folgende vier Aspekte im Mittelpunkt: Zum einen konnte die Bedeutung des ENT1 für Zytotoxizität von Gemcitabin und Cytarabin bestätigt werden. Dies wurde deutlich durch eine Korrelation der basalen ENT1-Expression und der induzierten Apoptoserate sowie durch eine starke Reduktion der Zytotoxizität bei simultaner Behandlung mit dem ENT1-spezifischen Inhibitor NBTI. Der zweite wichtige Befund war eine starke Verminderung der Sensitivität der Probanden-Leukozyten gegenüber den beiden Nukleosid-Analoga bei Vorliegen des Aminosäureaustausches Ile->Thr an Position 216 des ENT1. Dem Ziel folgend, weitere Kandidatenloci für die Empfindlichkeit gegenüber diesen Nukleosid-Analoga zu identifizieren, wurde ein Cluster von Genpolymorphismen in der 3'-Region der DCTD gefunden. Dabei zeigte sich eine Assoziation mit der Zytotoxizität von Cytarabin mit $p=0,00005$. Dies war auch unter Berücksichtigung multiplen Testens statistisch signifikant. Die vierte wichtige Erkenntnis war, dass bei den LCLs mit einfachen Zellvitalitätsassays im Unterschied zur Durchflusszytometrie keinerlei Inter-Tag-Korrelation nachzuweisen war.

Als eine Konsequenz meiner Arbeit kann genannt werden, dass einfache Zellvitalitätsassays bei LCLs - wie sie in der Literatur typischerweise durchgeführt wurden - im Hinblick auf Assoziationsstudien mit Genotypen wegen der fehlenden Korrelation zwischen zwei Messtagen sehr kritisch bewertet werden sollten. Dies ist in Anbetracht der äußerst heterogenen Proliferationsrate der LCLs verständlich. Eine solche Inter-Tag-Korrelation war zwar auch bei meinen durchflusszytometrischen Messungen nur mäßiggradig, aber dennoch nennenswert vorhanden, vor allem bei Cytarabin. Daher erscheint auch die sehr starke Assoziation von DCTDPolymorphismen mit der durchflusszytometrisch bestimmten Cytarabin-induzierten Zytotoxizität plausibel und stellt einen interessanten Befund für weitere Untersuchungen dar. Die massive Empfindlichkeitsreduktion gegenüber den beiden Nukleosid-Analoga in Gegenwart des Thr216-Allels im ENT1 ist ebenfalls interessant, muss aber wegen der Seltenheit dieses Allels und eines negativen Literaturberichts hinsichtlich einer Beeinflussung des Nukleosid-Transports gegenwärtig noch zurückhaltend bewertet werden. Klar bestätigt werden konnte jedoch die Bedeutung des ENT1 für die Effektivität von Gemcitabin und Cytarabin. Insgesamt sollten die wesentlichen Ergebnisse meiner Arbeit weitere Forschungsvorhaben stimulieren und dem Ziel hilfreich sein, der Individualisierung 
und Optimierung der Chemotherapie mit diesen klinisch wichtigen Zytostatika näher zu kommen. 


\section{Tabellen- und Abbildungsverzeichnis}

\section{Tabellenverzeichnis}

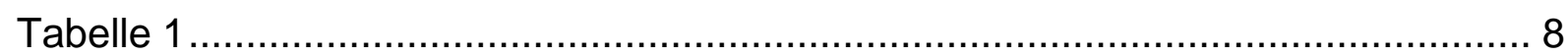

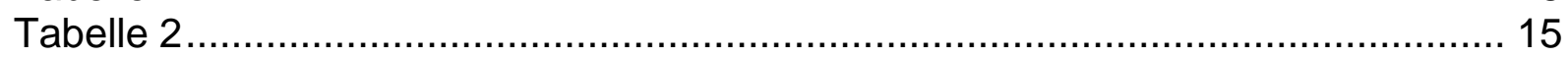

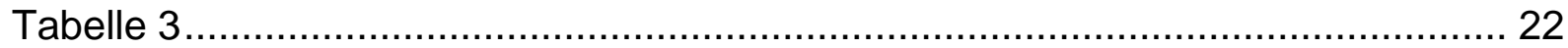

Tabelle 4

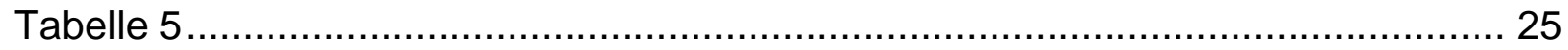

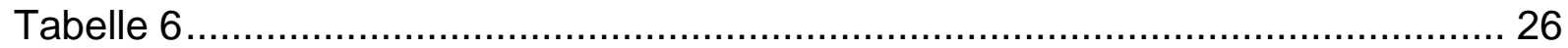

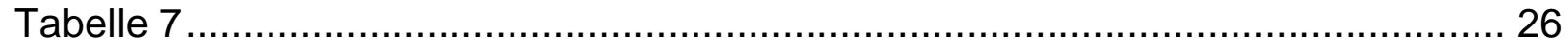

Tabelle 8

Tabelle 9

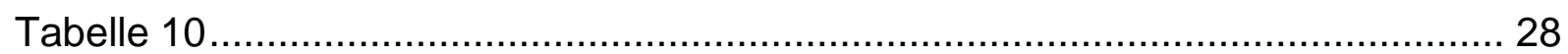

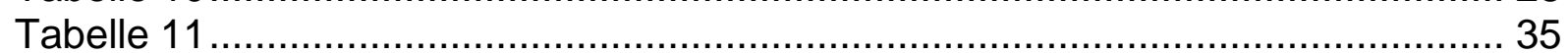

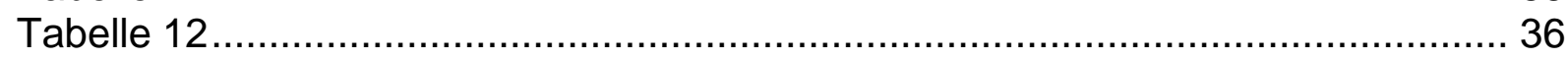

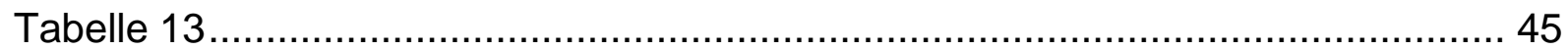

\section{Abbildungsverzeichnis}

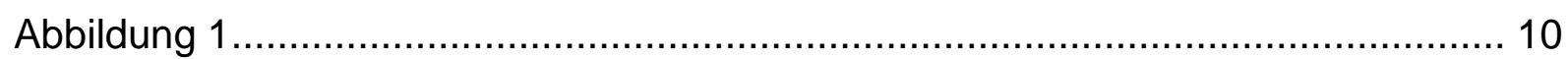

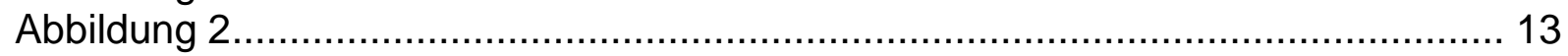

Abbildung 3

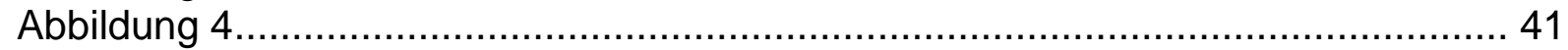

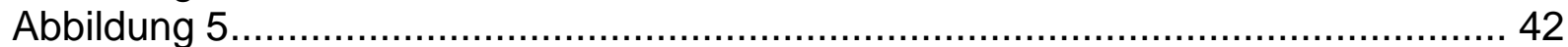

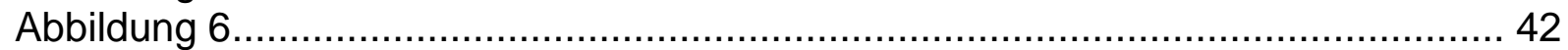

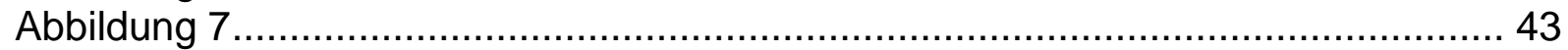

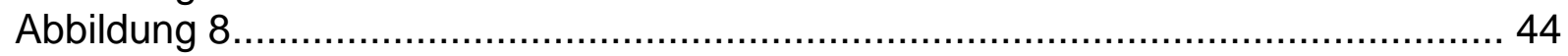

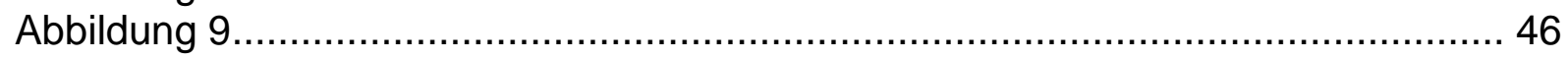

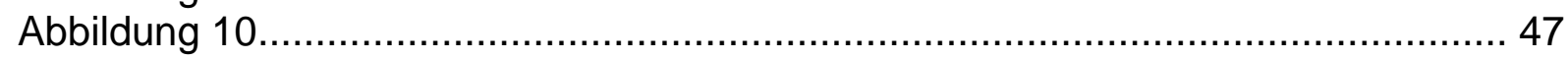

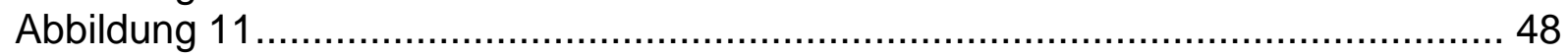

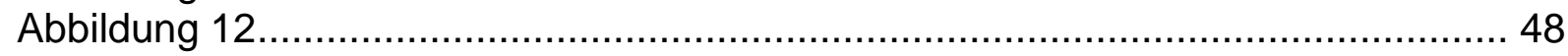

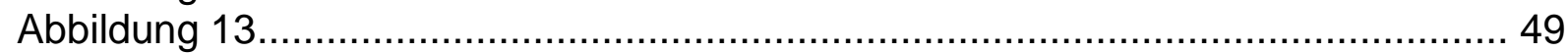

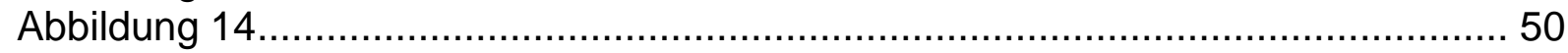

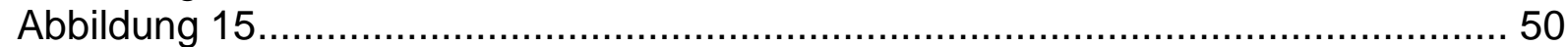

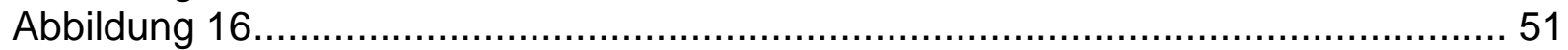

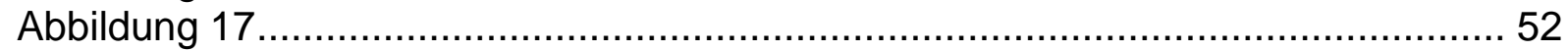

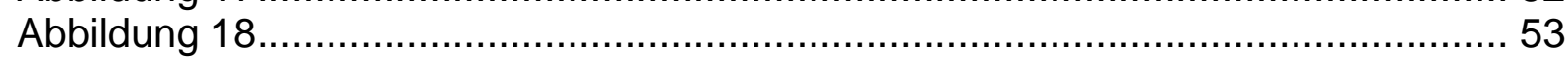

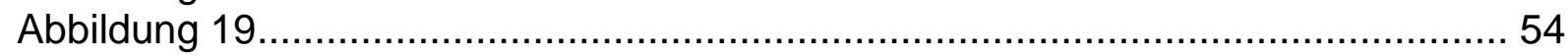

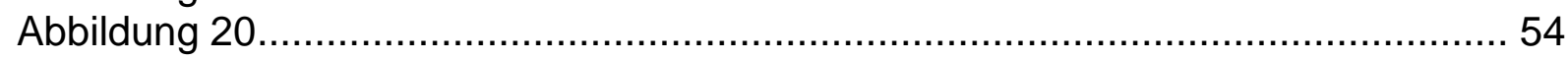

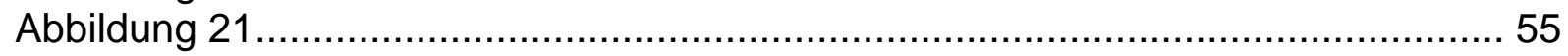

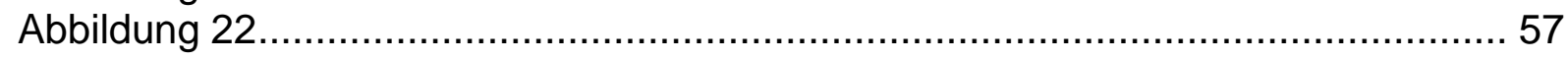

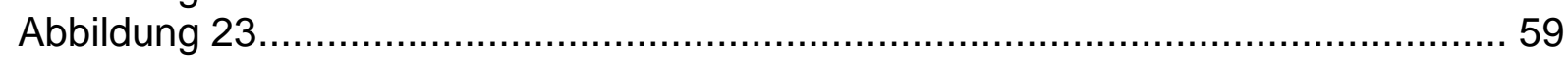

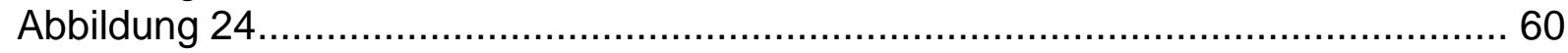

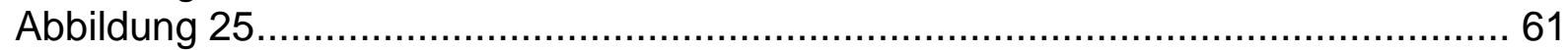

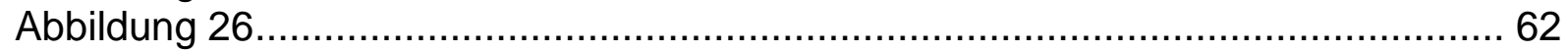

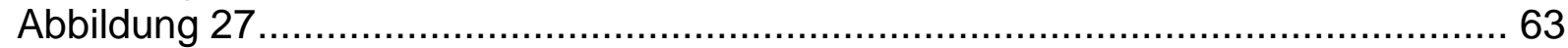

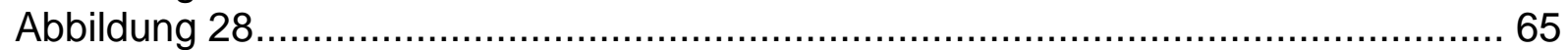

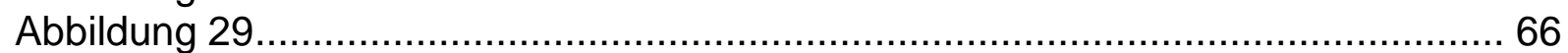

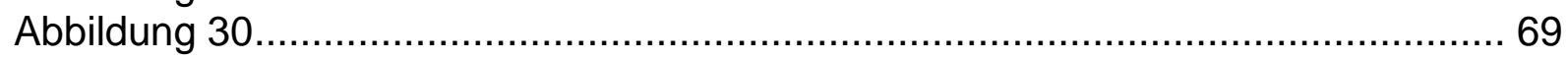




\section{Literaturverzeichnis}

Abbruzzese JL, Grunewald R, Weeks EA, Gravel D, Adams T, Nowak B, Mineishi S, Tarassoff P, Satterlee W, Raber MN et al. (1991): A phase I clinical, plasma, and

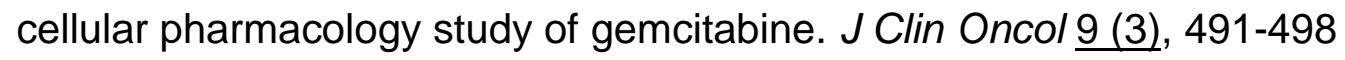

Aksoy P, Zhu MJ, Kalari KR, Moon I, Pelleymounter LL, Eckloff BW, Wieben ED, Yee VC, Weinshilboum RM, Wang L (2009): Cytosolic 5'-nucleotidase III (NT5C3): gene sequence variation and functional genomics. Pharmacogenet Genomics 19 (8), 567-576

Amici A, Emanuelli M, Magni G, Raffaelli N, Ruggieri S (1997): Pyrimidine nucleotidases from human erythrocyte possess phosphotransferase activities specific for pyrimidine nucleotides. FEBS Lett 419 (2-3), 263-267

Ashida R, Nakata B, Shigekawa M, Mizuno N, Sawaki A, Hirakawa K, Arakawa T, Yamao K (2009): Gemcitabine sensitivity-related mRNA expression in endoscopic ultrasound-guided fine-needle aspiration biopsy of unresectable pancreatic cancer. $J$ Exp Clin Cancer Res $\underline{28} 83$

Baldwin SA, Beal PR, Yao SY, King AE, Cass CE, Young JD (2004): The equilibrative nucleoside transporter family, SLC29. Pflugers Arch 447 (5), 735-743

Belt JA, Marina NM, Phelps DA, Crawford CR (1993): Nucleoside transport in normal and neoplastic cells. Adv Enzyme Regul 33 235-252

Braakhuis BJ, van Dongen GA, Vermorken JB, Snow GB (1991): Preclinical in vivo activity of 2',2'-difluorodeoxycytidine (Gemcitabine) against human head and neck cancer. Cancer Res $\underline{51 \text { (1) }}$, 211-214

Burris HA, 3rd, Moore MJ, Andersen J, Green MR, Rothenberg ML, Modiano MR, Cripps MC, Portenoy RK, Storniolo AM, Tarassoff P et al. (1997): Improvements in survival and clinical benefit with gemcitabine as first-line therapy for patients with advanced pancreas cancer: a randomized trial. J Clin Oncol 15 (6), 2403-2413 
Camiener GW, Smith CG (1965): Studies of the enzymatic deamination of cytosine arabinoside. I. Enzyme distribution and species specificity. Biochem Pharmacol 14 (10), 1405-1416

Cass CE, Young JD, Baldwin SA (1998): Recent advances in the molecular biology of nucleoside transporters of mammalian cells. Biochem Cell Biol 76 (5), 761-770

Chandrasena G, Giltay R, Patil SD, Bakken A, Unadkat JD (1997): Functional expression of human intestinal $\mathrm{Na}$--dependent and $\mathrm{Na}+$-independent nucleoside transporters in Xenopus laevis oocytes. Biochem Pharmacol 53 (12), 1909-1918

Clarke ML, Damaraju VL, Zhang J, Mowles D, Tackaberry T, Lang T, Smith KM, Young JD, Tomkinson B, Cass CE (2006): The role of human nucleoside transporters in cellular uptake of 4'-thio-beta-D-arabinofuranosylcytosine and beta-Darabinosylcytosine. Mol Pharmacol 70 (1), 303-310

Crawford CR, Ng CY, Noel LD, Belt JA (1990): Nucleoside transport in L1210 murine leukemia cells. Evidence for three transporters. J Biol Chem 265 (17), 9732-9736

Creutzig U, Ritter J, Zimmermann M, Reinhardt D, Hermann J, Berthold F, Henze G, Jurgens $\mathrm{H}$, Kabisch H, Havers $W$ et al. (2001): Improved treatment results in high-risk pediatric acute myeloid leukemia patients after intensification with high-dose cytarabine and mitoxantrone: results of Study Acute Myeloid Leukemia-Berlin-Frankfurt-Munster 93. J Clin Oncol 19 (10), 2705-2713

Damaraju VL, Damaraju S, Young JD, Baldwin SA, Mackey J, Sawyer MB, Cass CE (2003): Nucleoside anticancer drugs: the role of nucleoside transporters in resistance to

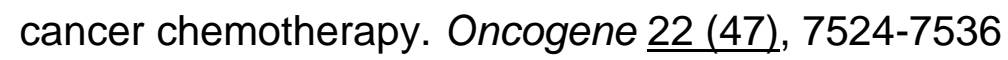

Ellison RR, Holland JF, Weil M, Jacquillat C, Boiron M, Bernard J, Sawitsky A, Rosner F, Gussoff B, Silver RT et al. (1968): Arabinosyl cytosine: a useful agent in the treatment of acute leukemia in adults. Blood $\underline{32}(4), 507-523$ 
Fachinformation zum Handelspräparat Gemzar®: Firma Lilly Deutschland GmbH, Gießen (2007)

Farrell JJ, Elsaleh H, Garcia M, Lai R, Ammar A, Regine WF, Abrams R, Benson AB, Macdonald J, Cass CE et al. (2009): Human equilibrative nucleoside transporter 1 levels predict response to gemcitabine in patients with pancreatic cancer. Gastroenterology $136(1), 187-195$

Fujita H, Ohuchida K, Mizumoto K, Itaba S, Ito T, Nakata K, Yu J, Kayashima T, Souzaki R, Tajiri T et al. (2010): Gene expression levels as predictive markers of outcome in pancreatic cancer after gemcitabine-based adjuvant chemotherapy. Neoplasia 12 (10), 807-817

Fukunaga AK, Marsh S, Murry DJ, Hurley TD, McLeod HL (2004): Identification and analysis of single-nucleotide polymorphisms in the gemcitabine pharmacologic pathway. Pharmacogenomics J $\underline{4(5)}$, 307-314

Galmarini CM, Thomas X, Calvo F, Rousselot P, Rabilloud M, El Jaffari A, Cros E, Dumontet C (2002): In vivo mechanisms of resistance to cytarabine in acute myeloid leukaemia. Br J Haematol 117 (4), 860-868

Garcia-Manteiga J, Molina-Arcas M, Casado FJ, Mazo A, Pastor-Anglada M (2003): Nucleoside transporter profiles in human pancreatic cancer cells: role of hCNT1 in 2',2'-

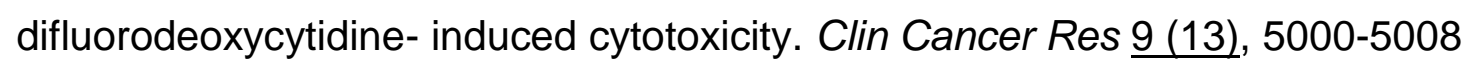

Gilbert JA, Salavaggione OE, Ji Y, Pelleymounter LL, Eckloff BW, Wieben ED, Ames MM, Weinshilboum RM (2006): Gemcitabine pharmacogenomics: cytidine deaminase and deoxycytidylate deaminase gene resequencing and functional genomics. Clin Cancer Res 12 (6), 1794-1803

Giovannetti E, Del Tacca M, Mey V, Funel N, Nannizzi S, Ricci S, Orlandini C, Boggi U, Campani D, Del Chiaro M et al. (2006): Transcription analysis of human equilibrative nucleoside transporter-1 predicts survival in pancreas cancer patients treated with gemcitabine. Cancer Res $\underline{66}$ (7), 3928-3935 
Giovannetti E, Mey V, Loni L, Nannizzi S, Barsanti G, Savarino G, Ricciardi S, Del Tacca M, Danesi R (2007): Cytotoxic activity of gemcitabine and correlation with expression profile of drug-related genes in human lymphoid cells. Pharmacol Res $\underline{55}$ (4), 343-349

Gray JH, Mangravite LM, Owen RP, Urban TJ, Chan W, Carlson EJ, Huang CC, Kawamoto M, Johns SJ, Stryke D et al. (2004a): Functional and genetic diversity in the concentrative nucleoside transporter, CNT1, in human populations. Mol Pharmacol $\underline{65}$ (3), 512-519

Gray JH, Owen RP, Giacomini KM (2004b): The concentrative nucleoside transporter family, SLC28. Pflugers Arch 447 (5), 728-734

Griffiths M, Beaumont N, Yao SY, Sundaram M, Boumah CE, Davies A, Kwong FY, Coe I, Cass CE, Young JD et al. (1997): Cloning of a human nucleoside transporter implicated in the cellular uptake of adenosine and chemotherapeutic drugs. Nat Med $\underline{3}$ (1), 89-93

Hartford CM, Duan S, Delaney SM, Mi S, Kistner EO, Lamba JK, Huang RS, Dolan ME (2009): Population-specific genetic variants important in susceptibility to cytarabine arabinoside cytotoxicity. Blood 113 (10), 2145-2153

Heinemann V (2003): Role of gemcitabine in the treatment of advanced and metastatic breast cancer. Oncology $\underline{64(3)}, 191-206$

Heinemann V, Xu YZ, Chubb S, Sen A, Hertel LW, Grindey GB, Plunkett W (1990): Inhibition of ribonucleotide reduction in CCRF-CEM cells by 2',2'-difluorodeoxycytidine. Mol Pharmacol $\underline{38(4)}, 567-572$

Heinemann V, Xu YZ, Chubb S, Sen A, Hertel LW, Grindey GB, Plunkett W (1992): Cellular elimination of 2',2'-difluorodeoxycytidine 5'-triphosphate: a mechanism of selfpotentiation. Cancer Res $\underline{52(3)}, 533-539$ 
Hertel LW, Boder GB, Kroin JS, Rinzel SM, Poore GA, Todd GC, Grindey GB (1990): Evaluation of the antitumor activity of gemcitabine (2',2'-difluoro-2'-deoxycytidine). Cancer Res $\underline{50(14)}$, 4417-4422

Huang P, Chubb S, Hertel LW, Grindey GB, Plunkett W (1991): Action of 2',2'-

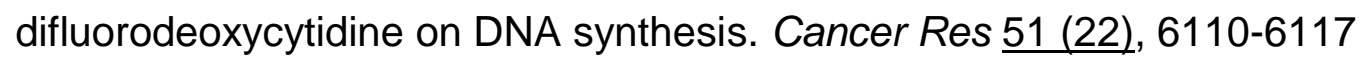

Hubeek I, Stam RW, Peters GJ, Broekhuizen R, Meijerink JP, van Wering ER, Gibson BE, Creutzig U, Zwaan CM, Cloos J et al. (2005): The human equilibrative nucleoside transporter 1 mediates in vitro cytarabine sensitivity in childhood acute myeloid leukaemia. Br J Cancer 93 (12), 1388-1394

Leabman MK, Huang CC, DeYoung J, Carlson EJ, Taylor TR, de la Cruz M, Johns SJ, Stryke D, Kawamoto M, Urban TJ et al. (2003): Natural variation in human membrane transporter genes reveals evolutionary and functional constraints. Proc Natl Acad Sci U $S A \underline{100(10)}, 5896-5901$

Leisewitz AV, Zimmerman El, Jones SZ, Yang J, Graves LM (2008): Imatinib-resistant CML cells have low ENT activity but maintain sensitivity to gemcitabine. Nucleosides Nucleotides Nucleic Acids 2 77 (6), 779-786

Li L, Fridley B, Kalari K, Jenkins G, Batzler A, Safgren S, Hildebrandt M, Ames M, Schaid D, Wang L (2008): Gemcitabine and cytosine arabinoside cytotoxicity:

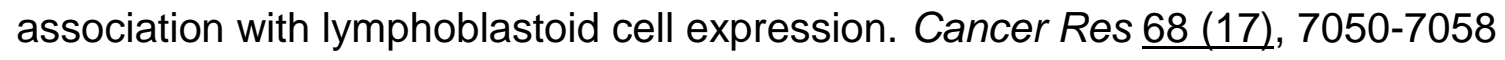

Li L, Fridley BL, Kalari K, Jenkins G, Batzler A, Weinshilboum RM, Wang L (2009): Gemcitabine and arabinosylcytosin pharmacogenomics: genome-wide association and drug response biomarkers. PLoS One 4 (11), e7765

Lopez C, Watanabe KA, Fox JJ (1980): 2'-fluoro-5-iodo-aracytosine, a potent and selective anti-herpesvirus agent. Antimicrob Agents Chemother 17 (5), 803-806 
Lund B, Hansen OP, Theilade K, Hansen M, Neijt JP (1994): Phase II study of gemcitabine (2',2'-difluorodeoxycytidine) in previously treated ovarian cancer patients. $J$ Natl Cancer Inst 86 (20), 1530-1533

Mackey JR, Mani RS, Selner M, Mowles D, Young JD, Belt JA, Crawford CR, Cass CE (1998): Functional nucleoside transporters are required for gemcitabine influx and

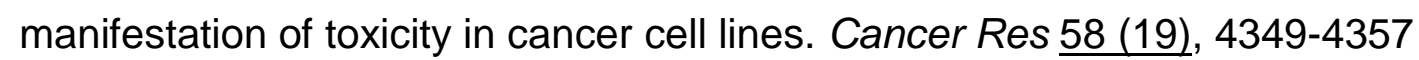

Mackey JR, Yao SY, Smith KM, Karpinski E, Baldwin SA, Cass CE, Young JD (1999): Gemcitabine transport in xenopus oocytes expressing recombinant plasma membrane

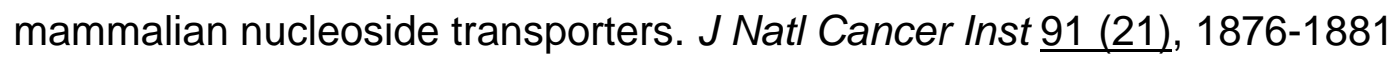

Mangravite LM, Lipschutz JH, Mostov KE, Giacomini KM (2001): Localization of GFPtagged concentrative nucleoside transporters in a renal polarized epithelial cell line. Am J Physiol Renal Physiol 280 (5), F879-885

Maring JG, Groen HJ, Wachters FM, Uges DR, de Vries EG (2005): Genetic factors

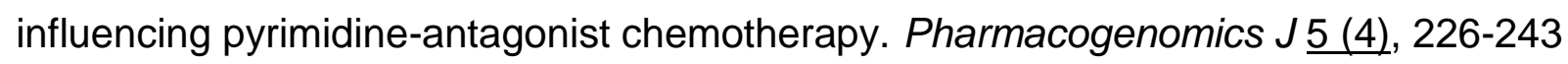

Matsuda A, Sasaki T (2004): Antitumor activity of sugar-modified cytosine nucleosides. Cancer Sci 95 (2), 105-111

Michalski CW, Erkan M, Sauliunaite D, Giese T, Stratmann R, Sartori C, Giese NA, Friess $\mathrm{H}$, Kleeff $\mathrm{J}$ (2008): Ex vivo chemosensitivity testing and gene expression profiling predict response towards adjuvant gemcitabine treatment in pancreatic cancer. $\mathrm{Br} \mathrm{J}$ Cancer $\underline{99(5)}, 760-767$

Mori R, Ishikawa T, Ichikawa Y, Taniguchi K, Matsuyama R, Ueda M, Fujii Y, Endo I, Togo S, Danenberg PV et al. (2007): Human equilibrative nucleoside transporter 1 is associated with the chemosensitivity of gemcitabine in human pancreatic adenocarcinoma and biliary tract carcinoma cells. Oncol Rep 17 (5), 1201-1205 
Myers SN, Goyal RK, Roy JD, Fairfull LD, Wilson JW, Ferrell RE (2006): Functional single nucleotide polymorphism haplotypes in the human equilibrative nucleoside transporter 1. Pharmacogenet Genomics 16 (5), 315-320

Nakamura J, Kohya N, Kai K, Ohtaka K, Hashiguchi K, Hiraki M, Kitajima Y, Tokunaga O, Noshiro H, Miyazaki K (2010): Ribonucleotide reductase subunit M1 assessed by quantitative double-fluorescence immunohistochemistry predicts the efficacy of gemcitabine in biliary tract carcinoma. Int J Oncol 37 (4), 845-852

Neff T, Blau CA (1996): Forced expression of cytidine deaminase confers resistance to cytosine arabinoside and gemcitabine. Exp Hematol 24 (11), 1340-1346

Oettle H, Post S, Neuhaus P, Gellert K, Langrehr J, Ridwelski K, Schramm H, Fahlke J, Zuelke C, Burkart C et al. (2007): Adjuvant chemotherapy with gemcitabine vs observation in patients undergoing curative-intent resection of pancreatic cancer: a randomized controlled trial. Jama $\underline{297}$ (3), 267-277

Oguri T, Achiwa H, Muramatsu H, Ozasa H, Sato S, Shimizu S, Yamazaki H, Eimoto T, Ueda R (2007): The absence of human equilibrative nucleoside transporter 1 expression predicts nonresponse to gemcitabine-containing chemotherapy in non-small cell lung cancer. Cancer Lett 256 (1), 112-119

Osato DH, Huang CC, Kawamoto M, Johns SJ, Stryke D, Wang J, Ferrin TE, Herskowitz I, Giacomini KM (2003): Functional characterization in yeast of genetic variants in the human equilibrative nucleoside transporter, ENT1. Pharmacogenetics $\underline{13}$ (5), 297-301

Pennycooke M, Chaudary N, Shuralyova I, Zhang Y, Coe IR (2001): Differential expression of human nucleoside transporters in normal and tumor tissue. Biochem Biophys Res Commun 280 (3), 951-959

Perez-Torras S, Garcia-Manteiga J, Mercade E, Casado FJ, Carbo N, Pastor-Anglada M, Mazo A (2008): Adenoviral-mediated overexpression of human equilibrative 
nucleoside transporter 1 (hENT1) enhances gemcitabine response in human pancreatic cancer. Biochem Pharmacol 76 (3), 322-329

Plunkett W, lacoboni S, Estey E, Danhauser L, Liliemark JO, Keating MJ (1985): Pharmacologically directed ara-C therapy for refractory leukemia. Semin Oncol 12 (2 Suppl 3), 20-30

Plunkett W, Gandhi V, Chubb S, Nowak B, Heinemann V, Mineishi S, Sen A, Herte LW, Grindey GB (1989): 2',2'-Difluorodeoxycytidine Metabolism and Mechanism of Action In Human Leukemia Cells. Nucleosides, Nucleotides and Nucleic Acids 8 (5\&6), 775-785

Plunkett W, Huang P, Searcy CE, Gandhi V (1996): Gemcitabine: preclinical pharmacology and mechanisms of action. Semin Oncol 23 (5 Suppl 10), 3-15

Preuß A: Funktionelle und genetische Variabilität in Nukleosidtransportern für die Wirksamkeit von Gemcitabin: Retrospektive und prospektive Patientenstudie bei Pankreaskarzinom sowie in-vitro-Untersuchungen an Blutzellen gesunder Spender. Medizinische Dissertation, Göttingen 2009.

Ritzel MW, Yao SY, Huang MY, Elliott JF, Cass CE, Young JD (1997): Molecular cloning and functional expression of cDNAs encoding a human $\mathrm{Na+-nucleoside}$ cotransporter (hCNT1). Am J Physiol 272 (2 Pt 1), C707-714

Ritzel MW, Yao SY, Ng AM, Mackey JR, Cass CE, Young JD (1998): Molecular cloning, functional expression and chromosomal localization of a cDNA encoding a human $\mathrm{Na}+$ /nucleoside cotransporter (hCNT2) selective for purine nucleosides and uridine. Mol Membr Biol 15 (4), 203-211

Ritzel MW, Ng AM, Yao SY, Graham K, Loewen SK, Smith KM, Hyde RJ, Karpinski E, Cass CE, Baldwin SA et al. (2001a): Recent molecular advances in studies of the concentrative $\mathrm{Na}$--dependent nucleoside transporter (CNT) family: identification and characterization of novel human and mouse proteins (hCNT3 and mCNT3) broadly selective for purine and pyrimidine nucleosides (system cib). Mol Membr Biol 18 (1), 6572 
Ritzel MW, Ng AM, Yao SY, Graham K, Loewen SK, Smith KM, Ritzel RG, Mowles DA, Carpenter P, Chen XZ et al. (2001b): Molecular identification and characterization of novel human and mouse concentrative $\mathrm{Na}$--nucleoside cotransporter proteins (hCNT3 and mCNT3) broadly selective for purine and pyrimidine nucleosides (system cib). J Biol Chem $\underline{276(4)}$, 2914-2927

Sandler AB, Nemunaitis J, Denham C, von Pawel J, Cormier Y, Gatzemeier U, Mattson K, Manegold C, Palmer MC, Gregor A et al. (2000): Phase III trial of gemcitabine plus cisplatin versus cisplatin alone in patients with locally advanced or metastatic non-smallcell lung cancer. J Clin Oncol 18 (1), 122-130

Santini D, Perrone G, Vincenzi B, Lai R, Cass C, Alloni R, Rabitti C, Antinori A, Vecchio F, Morini S et al. (2008): Human equilibrative nucleoside transporter 1 (hENT1) protein is associated with short survival in resected ampullary cancer. Ann Oncol 19 (4), 724728

Santini D, Vincenzi B, Fratto ME, Perrone G, Lai R, Catalano V, Cass C, Ruffini PA, Spoto C, Muretto P et al. (2010): Prognostic role of human equilibrative transporter 1 (hENT1) in patients with resected gastric cancer. J Cell Physiol 223 (2), 384-388

Schroder JK, Seidelmann M, Kirch HC, Seeber S, Schutte J (1998): Assessment of resistance induction to cytosine arabinoside following transfer and overexpression of the deoxycytidylate deaminase gene in vitro. Leuk Res 22 (7), 619-624

Shewach DS, Reynolds KK, Hertel L (1992): Nucleotide specificity of human deoxycytidine kinase. Mol Pharmacol $\underline{42(3)}, 518-524$

Shi JY, Shi ZZ, Zhang SJ, Zhu YM, Gu BW, Li G, Bai XT, Gao XD, Hu J, Jin W et al. (2004): Association between single nucleotide polymorphisms in deoxycytidine kinase and treatment response among acute myeloid leukaemia patients. Pharmacogenetics 14 (11), 759-768 
Slevin ML, Piall EM, Aherne GW, Johnston A, Lister TA (1982): The pharmacokinetics of cytosine arabinoside in the plasma and cerebrospinal fluid during conventional and high-dose therapy. Med Pediatr Oncol 10 Suppl 1 157-168

Smith KM, Ng AM, Yao SY, Labedz KA, Knaus EE, Wiebe LI, Cass CE, Baldwin SA, Chen XZ, Karpinski E et al. (2004): Electrophysiological characterization of a recombinant human Na+-coupled nucleoside transporter ( $\mathrm{hCNT1}$ ) produced in Xenopus oocytes. J Physiol 558 (Pt 3), 807-823

Spratlin J, Sangha R, Glubrecht D, Dabbagh L, Young JD, Dumontet C, Cass C, Lai R, Mackey JR (2004): The absence of human equilibrative nucleoside transporter 1 is associated with reduced survival in patients with gemcitabine-treated pancreas adenocarcinoma. Clin Cancer Res 10 (20), 6956-6961

Stam RW, den Boer ML, Meijerink JP, Ebus ME, Peters GJ, Noordhuis P, JankaSchaub GE, Armstrong SA, Korsmeyer SJ, Pieters R (2003): Differential mRNA expression of Ara-C-metabolizing enzymes explains Ara-C sensitivity in MLL generearranged infant acute lymphoblastic leukemia. Blood 101 (4), 1270-1276

Storniolo AM, Allerheiligen SR, Pearce HL (1997): Preclinical, pharmacologic, and phase I studies of gemcitabine. Semin Oncol 24 (2 Suppl 7), S7-2-S7-7

Sugiyama E, Kaniwa N, Kim SR, Kikura-Hanajiri R, Hasegawa R, Maekawa K, Saito Y, Ozawa S, Sawada J, Kamatani N et al. (2007): Pharmacokinetics of gemcitabine in Japanese cancer patients: the impact of a cytidine deaminase polymorphism. J Clin Oncol 25 (1), 32-42

Sundaram M, Yao SY, Ingram JC, Berry ZA, Abidi F, Cass CE, Baldwin SA, Young JD (2001a): Topology of a human equilibrative, nitrobenzylthioinosine (NBMPR)-sensitive nucleoside transporter (hENT1) implicated in the cellular uptake of adenosine and anticancer drugs. J Biol Chem $\underline{276}$ (48), 45270-45275

Sundaram M, Yao SY, Ng AM, Cass CE, Baldwin SA, Young JD (2001b): Equilibrative nucleoside transporters: mapping regions of interaction for the substrate analogue 
nitrobenzylthioinosine (NBMPR) using rat chimeric proteins. Biochemistry $\underline{40}$ (27), 81468151

Tempero M, Plunkett W, Ruiz Van Haperen V, Hainsworth J, Hochster H, Lenzi R, Abbruzzese J (2003): Randomized phase II comparison of dose-intense gemcitabine: thirty-minute infusion and fixed dose rate infusion in patients with pancreatic adenocarcinoma. J Clin Oncol 21 (18), 3402-3408

Tsujie M, Nakamori S, Nakahira S, Takahashi Y, Hayashi N, Okami J, Nagano H, Dono K, Umeshita K, Sakon M et al. (2007): Human equilibrative nucleoside transporter 1, as a predictor of 5 -fluorouracil resistance in human pancreatic cancer. Anticancer Res $\underline{27}$ (4B), 2241-2249

Velasquez WS, Cabanillas F, Salvador P, McLaughlin P, Fridrik M, Tucker S, Jagannath S, Hagemeister FB, Redman JR, Swan F et al. (1988): Effective salvage therapy for lymphoma with cisplatin in combination with high-dose Ara-C and dexamethasone (DHAP). Blood $71(1), 117-122$

von der Maase H, Hansen SW, Roberts JT, Dogliotti L, Oliver T, Moore MJ, Bodrogi I, Albers P, Knuth A, Lippert CM et al. (2000): Gemcitabine and cisplatin versus methotrexate, vinblastine, doxorubicin, and cisplatin in advanced or metastatic bladder cancer: results of a large, randomized, multinational, multicenter, phase III study. J Clin Oncol 18 (17), 3068-3077

White JC, Rathmell JP, Capizzi RL (1987): Membrane transport influences the rate of accumulation of cytosine arabinoside in human leukemia cells. J Clin Invest 79 (2), 380387

Yao SY, Ng AM, Muzyka WR, Griffiths M, Cass CE, Baldwin SA, Young JD (1997): Molecular cloning and functional characterization of nitrobenzylthioinosine (NBMPR)sensitive (es) and NBMPR-insensitive (ei) equilibrative nucleoside transporter proteins (rENT1 and rENT2) from rat tissues. J Biol Chem 272 (45), 28423-28430 
Yue L, Saikawa Y, Ota K, Tanaka M, Nishimura R, Uehara T, Maeba H, Ito T, Sasaki T, Koizumi S (2003): A functional single-nucleotide polymorphism in the human cytidine deaminase gene contributing to ara-C sensitivity. Pharmacogenetics 13 (1), 29-38

Zhang W, Duan S, Bleibel WK, Wisel SA, Huang RS, Wu X, He L, Clark TA, Chen TX, Schweitzer AC et al. (2009): Identification of common genetic variants that account for transcript isoform variation between human populations. Hum Genet 125 (1), 81-93

Zimmerman El, Huang M, Leisewitz AV, Wang Y, Yang J, Graves LM (2009): Identification of a novel point mutation in ENT1 that confers resistance to Ara-C in

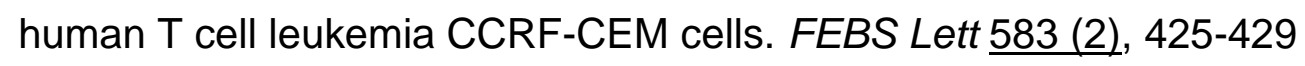




\section{Danksagung}

An dieser Stelle möchte ich mich bei allen Personen bedanken, die mir die Erstellung dieser Arbeit ermöglichten und mir immer zur Seite standen.

Mein besonderer Dank geht an Herrn Prof. Dr. J. Brockmöller für die Ermöglichung meiner Dissertation und das entgegengebrachte Vertrauen bei der Überlassung des interessanten Themas.

Ebenfalls möchte ich mich besonders bei meinem Betreuer Dr. M. Schirmer für die intensive und tatkräftige Unterstützung während der gesamten Arbeit bedanken. Vielen Dank auch für die äußerst hilfreiche und freundliche Zusammenarbeit bei der Erstellung meiner Dissertation.

Danke an Frau Dr. M. Hoffman für die Hilfestellung im experimentellen Teil dieser Arbeit.

An Frau Hohlborn ein Dankeschön, die immer dafür sorgte, dass die benötigten Materialien für die Experimente stets pünktlich bestellt wurden und ich den experimentellen Teil zügig durchführen konnte.

Vielen Dank an alle Mitarbeiter und Mitstreiter der Abteilung, für die Hilfestellung und Beratung während meiner Tätigkeit.

Danke an alle Probanden, ohne die diese Arbeit nicht möglich gewesen wäre.

Ich bedanke mich außerdem für die gute Teamarbeit mit Frau Dr. S. Becher und Herrn Dr. J. Janke, die ebenfalls in der Probandenrekrutierung beteiligt waren. 


\section{Lebenslauf}

Ich wurde am 08.12.1980 in Hildesheim geboren.

In Ottbergen besuchte ich von 1987 bis 1993 die Grundschule und anschließend die Orientierundsstufe. Im Anschluss daran folgte von 1993 bis 2001 die Schulausbildung auf dem Michelsen-Gymnasium in Hildesheim, wo ich 2001 das Abitur erfolgreich ablegte.

Anschließend absolvierte ich den Zivildienst beim Arbeiter-Samariter-Bund in Hildesheim.

Im Jahr 2003 begann ich mit dem Medizinstudium in Göttingen an der Medizinischen Fakultät der Georg-August-Universität. Meine Dissertation begann ich im August 2007 in der Abteilung für Klinische Pharmakologie der Universitätsmedizin Göttingen unter der Leitung von Herrn Prof. Dr. J.Brockmöller. Im Mai 2010 schloss ich mein Medizinstudium an der Georg-August-Universität Göttingen mit dem Staatsexamen erfolgreich ab.

Seit dem 01.01.2011 arbeite ich als Assistenzarzt in der Abteilung für Hals-NasenOhrenheilkunde im Städtischen Klinikum Braunschweig. 